University of Tennessee Health Science Center UTHSC Digital Commons

\title{
A Review of Temporomandibular Disorder and an Analysis of Mandibular Motion
}

Shawn Patrick Lehman-Grimes

University of Tennessee Health Science Center

Follow this and additional works at: https://dc.uthsc.edu/dissertations

Part of the Medicine and Health Sciences Commons

\section{Recommended Citation}

Lehman-Grimes, Shawn Patrick, "A Review of Temporomandibular Disorder and an Analysis of Mandibular Motion" (2005). Theses and Dissertations (ETD). Paper 144. http://dx.doi.org/10.21007/ etd.cghs.2005.0178.

This Thesis is brought to you for free and open access by the College of Graduate Health Sciences at UTHSC Digital Commons. It has been accepted for inclusion in Theses and Dissertations (ETD) by an authorized administrator of UTHSC Digital Commons. For more information, please contact jwelch30@uthsc.edu. 


\title{
A Review of Temporomandibular Disorder and an Analysis of Mandibular Motion
}

\begin{abstract}
This study quantified mandibular motion of asymptomatic subjects upon jaw opening and closing. Five males, mean age of 28 years, agreed to participate; they showed no sign or symptom of temporomandibular disorder (TMD) on clinical examination or by anamnestic history. Mandibular motion for each subject was measured with a tracking system and software utilizing the Screw Displacement Axis (SDA), which is a mathematical approach to analyzing and quantifying the movement of an object in three dimensions. Rotation and translation were calculated, as well as two- and three-dimensional charting of condylar path and sagittal condylar intercepts. Furthermore, analyses examined error propagation, change in error amplitude with varying test conditions, and a comparison between theoretical and experimental data. The mean maximum roation around the screw displacement axes was

$25.0^{\circ}\left(\mathrm{sd}=4.0^{\circ}\right)$. Mean translation along the screw displacement axes was $2.3 \mathrm{~mm}(\mathrm{sd}=0.68 \mathrm{~mm})$. The SDA intersection plots showed that the paths of motion for all subjects were posterior and inferior to the candyle. During opening, paths start nearer to the condyle and travel inferiorly and anteriorly. Jaw closing followed the reverse path (superior and posterior) with the final position approximating the area of the initial axis. Mean SDA intercepts with the sagittal plane of the condyle were positioned posterior and inferior of the selected center of the condyle. SDA position and orientation parameters were inversely related to the rotational increment. As rotational increments approached $5^{\circ}$, there was little change in the uncertainty values, indicating that data should be processed at increments of at least $4^{\circ}$ to $5^{\circ}$. Coordinate data obtained with the tracking systemn displayed an error that was not present when the targets were stationary, nor did its amplitude change with a change in velocity. These observations led to the idea that the error associated with the tracking system relied purely on target position. The only way to counter this system error was to raise the rotational increments in data processing and find an area in the sensor's viewing field that produces the least error. The closest the targets could be brought to the camera while maintaining a viewing area large enough to test jaw motion was in the range of $150-200 \mathrm{~mm}$ from the senor. The experimental data obtained from the SDA intercepts at $10^{\circ}$ iterations showed a path similar to theoretical expectations. The screw displacement axis method does have limitations. If only translational motion occurs, the SDA is undefinded. The SDA method is also very prone to measurement error. At low rotational increments, large error of the SDA parameters can be encourntered due to small measurement inaccuracies. However, small rotational increments are necessary to reliably approximate the continuous movement through a series of finite calculations. A balance is threfore required between these two opposing error sources.
\end{abstract}

\section{Document Type}

Thesis

\section{Degree Name}

Master of Dental Science (MDS)

Program

Orthodontics

\section{Research Advisor}

Denis D'angelo, Ph.D.

\section{Keywords}

TMJ, TMD (temporomandibular disorder), Joint Motion, Screw Displacement Axis (SDA) 


\section{Subject Categories}

Medicine and Health Sciences

This thesis is available at UTHSC Digital Commons: https://dc.uthsc.edu/dissertations/144 


\title{
A Review of Temporomandibular Disorder and an Analysis of Mandibular Motion
}

\author{
A Thesis \\ Presented for \\ The Graduate Studies Council \\ The University of Tennessee \\ Health Science Center
}

\author{
In Partial Fulfillment \\ Of the Requirements for the Degree \\ Master of Dental Science \\ From The University of Tennessee
}

By

Shawn Patrick Lehman-Grimes, D.D.S.

May 2005 
Copyright @ Shawn Patrick Lehman-Grimes 2005

All rights reserved 


\section{Dedication}

This thesis is dedicated to my wife

Mrs. Mayra Karina Lehman-Grimes

and

my parents

Dr. Frank Marlin Grimes

and

Mrs. Patricia Diane Grimes

who have given me invaluable support and encouragement throughout my educational endeavors. 


\section{Acknowledgments}

I would like to first thank John Judd for his dedication, help, and encouragement with this research project. This was truly a collaboration between the Orthodontic and Biomedical Engineering Departments. John was responsible for all tables and graphs, as well as all data and statistical analyses. Furthermore, John helped in writing this thesis, particularly concerning explanations of the screw displacement axis theory. Please refer to John's thesis for further explanation of the screw displacement axis:

Judd J. Assessment of asymptomatic mandibular motion using screw displacement axis theory. University of Tennessee Health Science Center, 2005. [Thesis]

Secondly, I would like to thank Dr. Denis DiAngelo for his guidance and mentorship. Dr. DiAngelo maintained great patience with my learning curve concerning three-dimensional animation and mandibular motion. Dr. DiAngelo also allowed other students to help with this project, particularly Charles S. Sullivan III. Charles was instrumental in development of all three-dimensional images.

Lastly, I would like to thank Dr. Edward Harris for his guidance with this project, and especially for his suggestion to embark on a joint thesis project with the Department of Biomedical Engineering. I hope that collaborative efforts with other departments become a regular occurrence. 


\begin{abstract}
This study quantified mandibular motion of asymptomatic subjects upon jaw opening and closing. Five males, mean age of 28 years, agreed to participate; they showed no sign or symptom of temporomandibular disorder (TMD) on clinical examination or by anamnestic history. Mandibular motion for each subject was measured with a tracking system and software utilizing the Screw Displacement Axis (SDA), which is a mathematical approach to analyzing and quantifying the movement of an object in three dimensions. Rotation and translation were calculated, as well as two- and three-dimensional charting of condylar path and sagittal condylar intercepts. Furthermore, analyses examined error propagation, change in error amplitude with varying test conditions, and a comparison between theoretical and experimental data. The mean maximum rotation around the screw displacement axes was $25.0^{\circ}\left(\mathrm{sd}=4.0^{\circ}\right)$. Mean translation along the screw displacement axes was $2.3 \mathrm{~mm}(\mathrm{sd}=0.68 \mathrm{~mm})$. The SDA intersection plots showed that the paths of motion for all subjects were posterior and inferior to the condyle. During opening, paths start nearer to the condyle and travel inferiorly and anteriorly. Jaw closing followed the reverse path (superior and posterior) with the final position approximating the area of the initial axis. Mean SDA intercepts with the sagittal plane of the condyle were positioned posterior and inferior of the selected center of the condyle. SDA
\end{abstract}


position and orientation parameters were inversely related to the rotational increment. As rotational increments approached $5^{\circ}$, there was little change in the uncertainty values, indicating that data should be processed at increments of at least $4^{\circ}$ to $5^{\circ}$. Coordinate data obtained with the tracking system displayed an error that was not present when the targets were stationary, nor did its amplitude change with a change in velocity. These observations led to the idea that the error associated with the tracking system relied purely on target position. The only way to counter this system error was to raise the rotational increments in data processing and find an area in the sensor's viewing field that produces the least error. The closest the targets could be brought to the camera while maintaining a viewing area large enough to test jaw motion was in the range of 150-200 mm from the sensor. The experimental data obtained from the SDA intercepts at $10^{\circ}$ iterations showed a path similar to theoretical expectations. The screw displacement axis method does have limitations. If only translational motion occurs, the SDA is undefined. The SDA method is also very prone to measurement error. At low rotational increments, large error of the SDA parameters can be encountered due to small measurement inaccuracies. However, small rotational increments are necessary to reliably approximate the continuous movement through a series of finite calculations. A balance is therefore required between these two opposing error sources. 


\section{Table of Contents}

Section I. Introduction 1

Section II. Review of the Literature 4

Anatomy of the Temporomandibular Joint 4

Temporomandibular Disorder $\quad 8$

Prevalence of Temporomandibular Disorder $r$

Etiology of Temporomandibular Disorder $\quad 10$

The Role of Malocclusion in Temporomandibular Disorder 12

The Role of Bruxism in Temporomandibular Disorder 13

Motion of the Mandible $\quad 14$

Three-Dimensional Analysis of Mandibular Motion $\quad 17$

$\begin{array}{ll}\text { Screw Axis Model } & 20\end{array}$

Computation of Screw Axis Parameters $\quad 22$

Previous Research Utilizing the Screw Axis Model 31

Section III. Materials and Methods 32

Accuracy and Error Assessment $\quad 32$

Error Propagation 33

Target Placement Area $\quad 35$

Theoretical and Experimental Data Comparison 36

In Vivo Testing $\quad 39$

Data Analysis $\quad 41$

Section IV. Results 46

Error Propagation and Uncertainty Values $\quad 46$

Target Area Placement $\quad 49$

Experimental Data Validation $\quad 51$

In Vivo Mandibular Motion $\quad 54$

Condylar Path $\quad 54$

SDA Translation and Rotation Motion of the Jaw 54

Two-Dimensional and Three-Dimensional Representation of SDA 59 
$\begin{array}{ll}\text { Section V. Discussion } & 66\end{array}$

$\begin{array}{ll}\text { Uncertainty } & 66\end{array}$

$\begin{array}{ll}\text { Target Placement } & 66\end{array}$

$\begin{array}{ll}\text { Data Validation } & 67\end{array}$

Condylar Path 68

Translation $\quad 69$

$\begin{array}{ll}\text { Rotation } & 69\end{array}$

$\begin{array}{ll}\text { SDA Representation } & 70\end{array}$

$\begin{array}{ll}\text { Limitations of SDA Method } & 71\end{array}$

Section VI. Summary and Conclusion $\quad 72$

$\begin{array}{ll}\text { Section VII. Epilogue } & 74\end{array}$

$\begin{array}{ll}\text { List of References } & 76\end{array}$

$\begin{array}{ll}\text { Appendices } & 86\end{array}$

A. Sequential Perturbation Results $\quad 87$

B. Mean Peak to Valley Values and Extended Tukey Results 118

C. Condylar Path Plots 124

D. Rotation and Translation Plots 127

E. Two and Three-Dimensional Representation of the SDA 132

$\begin{array}{ll}\text { Vita } & 137\end{array}$ 


\section{List of Tables}

Table 1. X motion ANOVA results.

Table 2. Y motion ANOVA results.

Table 3. Maximum translation results along SDA.

58

Table 4. Maximum rotation results along SDA.

Table 5. Summary of screw displacement parameters.

Table A.1. One degree initial coordinate values.

Table A.2. One degree final coordinate values.

Table A.3. One degree original parameter results.

88

Table A.4. One degree parameter values after addition.

89

Table A.5. One degree parameter values after subtraction.

89

Table A.6. One degree sequential perturbation for kx.

Table A.7. One degree sequential perturbation for xo.

Table A.8. One degree sequential perturbation for ky.

Table A.9. One degree sequential perturbation for yo.

Table A.10.Two degree initial coordinate values.

Table A.11.Two degree final coordinate values.

Table A.12.Two degree original parameter results.

Table A.13.Two degree parameter values after addition.

Table A.14.Two degree parameter values after subtraction. 
Table A.16.Two degree sequential perturbation for xo.

Table A.17.Two degree sequential perturbation for ky.

Table A.18.Two degree sequential perturbation for yo.

Table A.19.Three degree initial coordinate values.

Table A.20.Three degree final coordinate values.

Table A.21.Three degree original parameter results.

Table A.22.Three degree parameter values after addition.

Table A.23.Three degree parameter values after subtraction.

Table A.24.Three degree sequential perturbation for $\mathrm{kx}$.

102

Table A.25.Three degree sequential perturbation for xo.

Table A.26. Three degree sequential perturbation for ky.

Table A.27.Three degree sequential perturbation for yo.

105

Table A.28.Four degree initial coordinate values.

106

Table A.29.Four degree final coordinate values.

106

Table A.30.Four degree original parameter results.

106

Table A.31.Four degree parameter values after addition.

107

Table A.32.Four degree parameter values after subtraction.

Table A.33.Four degree sequential perturbation for kx.

Table A.34.Four degree sequential perturbation for xo. 109

Table A.35.Four degree sequential perturbation for ky.

Table A.36.Four degree sequential perturbation for yo.

Table A.37.Five degree initial coordinate values. 
Table A.38.Five degree final coordinate values.

Table A.39.Five degree original parameter results.

Table A.40.Five degree parameter values after addition.

Table A.41.Five degree parameter values after subtraction.

Table A.42.Five degree sequential perturbation for kx.

Table A.43.Five degree sequential perturbation for xo.

Table A.44.Five degree sequential perturbation for ky.

Table A.45. Five degree sequential perturbation for yo.

Table B.1. X motion tukey results.

121

Table B.2. Y motion tukey results. 


\section{List of Figures}

Figure 1. Posselt's envelope of motion.

Figure 2. Screw displacement axis (SDA).

Figure 3. Movement of object illustrating the SDA.

Figure 4. Illustration of SDA.

Figure 5. Rotational angle illustrated by the SDA.

Figure 6. Explanation of area of uncertainty of SDA parameters.

Figure 7. Sample target data showing $\mathrm{Z}$ coordinate data versus time.

Figure 8. Experimental setup for four bar testing.

Figure 9. LEDs, macropore ${ }^{\mathrm{TM}}$ framework, and bite plate (sagittal).

Figure 10. LEDs, macropore ${ }^{\mathrm{TM}}$ framework, and bite plate (frontal).

Figure 11. Cranium with spectacles.

Figure 12. Subject ready for motion analysis.

Figure 13. Kx uncertainty values versus degree iterations.

Figure 14. Xo uncertainty values versus degree iterations.

Figure 15. Ky uncertainty values versus degree iterations.

Figure 16. Yo uncertainty values versus degree iterations.

Figure 17. Y coordinate data at differing velocities.

Figure 18. Experimental and theoretical paths of motion for a four bar linkage. 53

Figure 19. Condylar path for subject 1. 
Figure 20. Plot of translation of motion data for one cycle of opening and closing. 56

Figure 21. Rotation through one cycle of opening and closing for subject $1 . \quad 57$

Figure 22. Two-dimensional representation of SDA sagittal plane intercepts. 60

Figure 23. Definition of coordinate system for SDA. 61

Figure 24. Three-dimensional display of screw displacement axes for one cycle of mandibular motion.

Figure 25. Mean values of sagittal plane intercepts (opening). 63

Figure 26. Mean values of sagittal plane intercepts (closing). 64

Figure B.1 Average peak to valley values for targets undergoing motion along the $\mathrm{x}$-axis.

Figure B.2 Average peak to valley values for targets undergoing motion along the y-axis.

$\begin{array}{lll}\text { Figure C.1 Condylar path plot for subject two. } & 125\end{array}$

Figure C.2 Condylar path plot for subject three. 125

Figure C.3 Condylar path plot for subject four. 126

Figure C.4 Condylar path plot for subject five. 126

Figure D.1 Rotation about the SDAs for subject two. 128

Figure D.2 Translation along the SDAs for subject two. 128

Figure D.3 Rotation about the SDAs for subject three. 129

Figure D.4 Translation along the SDAs for subject three. 129

Figure D.5 Rotation about SDAs for subject four. 130

Figure D.6 Translation along the SDAs for subject four. 130

Figure D.7 Rotation about the SDAs for subject five. 131

Figure D.8 Translation along the SDAs for subject five. 131 
Figure E.1 Two and three-dimensional representation of the SDA for subject two. 133

Figure E.2 Two and three-dimensional representation of the SDA for subject three.134

Figure E.3 Two and three-dimensional representation of the SDA for subject four. 135

Figure E.4 Two and three-dimensional representation of the SDA for subject five. 136 


\section{Section I: Introduction}

The temporomandibular joint may be characterized figuratively as an evangelic joint which, by nature of its evolution, proclaims itself truly a "special creation" in mammals and not an adaptation of a previously existing structure. Among joints, it is a hereditary pseudoarthrosis that struggles postnatally for both its cartilage and contour, an iconoclast whose embryology repeats its phylogeny, a transgressor which dwells clinically in the limbo between medicine and dentistry. It reigns as the paladin of joints, for, having served as the evolutionary deliverer of the middle ear, it gallantly became the enduring hinge on which woman's emancipation continually swings. Its versatility fills us with respect for a structure so magnificent in function that at one moment it is the sliding pivot of trituration and mastication, at the next, the gnashing safety valve of rage and fury, and, in moments of sublime creativity, the proprioceptive junction for poetry and song. Sing jubilation for the anatomic accomplishments of this, the youngest joint in biologic history, the joint whose 'epiphyseal' growth cartilage never develops an epiphysis, the arthrologist's delight, the temporomandibular joint.

Moffett (1965:1) offers this spirited and colorful description of the temporomandibular joint (TMJ) that summarizes the complexity with which this structure is comprised. The TMJ is a part of the human anatomy that has captured the attention of both medical and dental doctors for the past fifty years. Bottlang (1998) considers the TMJ the secondmost difficult anatomical structure to analyze, with the spinal column being the most difficult. Due to the underlying complexity of morphology and movement, the TMJ continues to be examined with the goal of achieving a sounder basis from which to create criteria for diagnosing disorders of the joint.

Temporomandibular disorder (TMD) has become a health problem for many patients who find little comfort in the treatments offered (Okeson, 1998). Although treatment modalities have improved the prognosis of TMD, the ability to properly 
diagnose this disorder nevertheless continue to be problematic for both patient and doctor (Gallo, 1997).

The complexity of properly identifying and treating temporomandibular disorders reflects the complexity of the joint itself. The temporomandibular joint works not only as a combination of bone and ligament, but also as a coordination of muscle and teeth. The anatomic composition of the TMJ presents multiple variables for dysfunction. Temporomandibular dysfunction, therefore, serves as a generic term to label any set of clinical signs or symptoms stemming from a physiological abnormality or neurological response in or surrounding the temporomandibular joint. Sometimes TMD presents as a traumatic, monoarticular abnormality of the musculoskeletal system that responds to orthopedic treatment. On other occasions it can be a complex problem in which occlusion plays only a small, if any, role, and successful treatment may prove to be elusive (Okeson, 1998).

Not only is the temporomandibular joint a complex joint to understand, but it also is an anatomical structure presenting various signs and symptoms that cause difficulty for proper diagnosis. Three specific areas contribute in difficulty for diagnosis and proper management of TMD: (1) other craniofacial or craniocervical pain disorders can be mistaken for TMD and treated as such; (2) the patient's TMD can be influenced by an emotional or behavioral component that is better treated by nonorthopedic means; (3) the TMD can be part of a generalized myofascial and ligamentous disorder linked to the neck or shoulder, thus, subject to noxious feedback (Solberg and Seligman, 1985). Temporomandibular disorders are viewed as multifactorial problems involving stress- 
induced muscle hyperactivity, adverse loading due to structural abnormalities, and sprains and strains produced or exacerbated by microtrauma (Griffiths, 1983).

The diagnosis of TMD should be based on specific characteristics rather than being generalized as craniofacial pain. In order to understand the specific characteristics of disorders of the TMJ, it is necessary to understand the joint anatomically, including changes in ligament or disc structure during movements such as the masticatory cycle (Beek et al., 2001). Technological improvements now make it possible to demonstrate joint and disc movement three-dimensionally. Both magnetic resonance imaging and computed tomography, along with computer software refinements such as the screw axis helical parameters, allow a greater understanding of the TMJ by analysis of anatomic structure in a nonstatic environment (Tanaka et al., 2001). While lack of understanding concerning TMJ motion is only one area of a broad-ranging multifactorial problem known as TMD, greater illustration of the moving joint should nevertheless provide insight and enhanced understanding of what is normal, thereby improving the diagnosis of TMD.

The three-fold focus of this thesis is (1) to define the anatomy of the temporomandibular joint (2) to summarize the prevalence and etiological factors of TMD and (3) to detail specific research aimed at analyzing the motion of the TMJ upon specific actions such as jaw opening and closing. 


\section{Section II: Review of the Literature}

\section{Anatomy of the Temporomandibular Joint}

The temporomandibular joint (TMJ) provides the articulation between the mandible and the temporal bone of the skull. It is a bilateral articulation in that the right and left sides work as a unit. The TMJ has three articulating parts: (1) capitulum of the mandibular condyle; (2) the mandibular fossa and articular eminence of the temporal bone; and (3) the articular disc. A fibrous connective tissue capsule, which supplies synovial fluid for joint lubrication and nourishment, encloses these parts (Moore, 1992).

The mandibular condyle, also known as the condylar process, is located on the posterior border of the vertical portion of the mandible, also known as the ramus, and forms the articulating surface of the mandible. The condyle is divided into an inferior part called the neck (collum) and a superior or articular part (capitulum). The shape of the condyle is highly variable, and may appear irregular radiographically with many of these irregularities in the bony contour are covered by a thick layer of fibrocartilage. The condylar head appears strongly convex when viewed laterally, but when viewed from the posterior, it exhibits a much wider oblong shape. The superior aspect of the condyle is convex and fits into the mandibular fossa of the temporal bone (Moore, 1992).

The mandibular fossa is an elliptical depression in the temporal bone positioned anterior to the external auditory canal. Its shape is concave and conforms to the superior portion of the mandibular condyle. The fossa is considered to be a nonfunctioning part of the TMJ due to the fact that when the teeth are in centric occlusion there is no 
coinciding locked position between the mandibular condyle, the disc, and the concave section of the fossa (Okeson, 1998). The articular eminence is a ridge of bone that borders the anterior limit of the mandibular fossa. The fact that the surface of the articular eminence is covered with a thicker layer of fibrous connective tissue than in the fossa indicates that the eminence is the functional region of the temporal bone during jaw articulation (Moore, 1992).

The articular disc (meniscus) is located between the articular eminence and mandibular fossa of the temporal bone and the condyle of the mandible. The main functions of the disc are to dampen loading spikes and reduce sliding friction (Patonay, 2002). It consists mainly of dense fibrous tissue and is separated into three regions: the pars anterior, pars intermedia, and pars posterior. The disc is thinner in the pars intermedia and widens at the anterior and posterior ends. The upper surface of the disc is concave anteroposteriorly and convex mediolaterally, conforming to the shape of the articular eminence against which it rests. The lower surface of the disc is concave in both directions, fitting to the geometry of the condylar head and attaches to the medial and lateral poles of the condylar process by transversely aligned collagen fibers from the pars anterior and pars posterior. Posteriorly the disc continues as a thick double layer of connective tissue termed the bilaminar zone. The main function of the bilaminar zone is to aid in the stability of the disc throughout joint motion. The upper layer of the bilaminar zone attaches to the post glenoid process and the anterior wall of the cartilage forming the external auditory meatus. The lower layer attaches to the posterior portion of the condylar process directly below the articulating part of the condyle (Moore, 1992). 
The ligaments involved in the temporomandibular joint have three main functions: stabilization, guidance of movement, and limitation of movement. The temporomandibular, stylomandibular, and sphenomandibular ligaments are the three primary ligaments of the TMJ. The temporomandibular ligament is the strong reinforcement of the lateral wall of the joint capsule. The fibers of the temporomandibular ligament pass in an inferior and posterior direction from the lateral part of the articular eminence to the posterior portion of the collum of the mandibular condyle. This ligament limits the motion of jaw opening and retrusion. The stylomandibular ligament runs from the styloid process of the temporal bone to the gonial angle of the mandible. Opposed to the temporomandibular joint, it is relaxed during jaw opening and limits protrusive and mediotrusive movements. The sphenomandibular ligament originates in the spine of the sphenoid bone and petrotympanic fissures and runs to the lingula of the mandible. Like the stylomandibular ligament, it limits protrusive and mediotrusive movements (Okeson, 1998).

The primary muscles concerned with closing mandibular motion are the temporalis, masseter, and medial pterygoid. The temporalis is a flat, fan-shaped muscle that originates in the temporal fossa and inserts on the coroniod process and the anterior edge of the ramus of the mandible. It functions as if composed of three distinct parts. The muscle fibers of the anterior part pull upward and serve as elevators. The medial section of the muscle effects jaw closure, with retrusion being a lesser function. The posterior part is involved mainly in retrusion. The masseter is an elevator muscle providing much of the power required for crushing food. It also assists in protrusion. The origin of the masseter muscle arises on the zygomatic arch, and its insertion occurs 
over the area of the gonial angle of the mandible extending both anteriorly and up the lateral aspect of the ascending ramus. The medial pterygoid muscle originates from the medial surface of the pterygoid plate of the sphenoid bone. Its muscle fibers run in the same direction as those of the masseter muscle, extending downward and laterally on the inner surface of the mandibular ramus and insert on the medial surface of the mandible just superior to the gonial angle. In addition to functioning as an elevator of the mandible, the medial pterygoid aids in lateral positioning and is active during protrusion (Okeson, 1998).

Opening motion of the temporomandibular joint is carried out by the lateral pterygoid and suprahyoid musculature. The lateral pterygoid muscle has two sites of origin. Its lower head arises from the outer surface of the lateral pterygoid plate, and the upper head arises from the greater wing of the sphenoid bone. Both heads of the muscle insert on the anterior neck of the condyle and on the joint capsule. The upper and lower head of the lateral pterygoid muscle display an antagonistic relationship. The upper head is active during jaw closing, retrusive, and laterotrusive movements, and the lower head is active during jaw opening, protrusive, and mediotrusive movements. The suprahyoid musculature consists mainly of the digastric, mylohyoid, and geniohyoid muscles. The digastric muscle has two bellies. The posterior belly of the muscle originates medial to the mastoid process, and its fibers extend anteriorly, inferiorly, and medially to the hyoid bone. At the hyoid bone the posterior belly attaches to the anterior belly by means of an intermediate tendon. The anterior belly originates from the inner side of the mandible at the digastric fossa. The mylohyoid muscle stretches from the body of the hyoid bone to the mylohyoid line on the inner side of the corpus of the mandible. The geniohyoid 
muscle arises from the inferior mental spine on the posterior surface of the symphysis menti of the mandible. It extends as a narrow strap, passing posteriorly and inferiorly to insert into the medial and superior section of the body of the hyoid bone (Moore, 1992).

\section{Temporomandibular Disorder}

Temporomandibular disorder continues to be a problem for patient and doctor. The need to further examine and better understand this condition warrants research into the anatomical constituents of the joint and the illustration of movement of the joint. As both patient and doctor become more cognizant of the symptoms surrounding TMD, the resolution of the disease becomes more urgent and relevant within the medical and dental communities.

\section{Prevalence of Temporomandibular Disorder}

The otolaryngologist James Costen in 1934 described a group of symptoms that were centered on the ear and temporomandibular joint (Costen, 1934). These symptoms became known as Costen Syndrome. In 1959 Shore introduced the term temporomandibular joint dysfunction syndrome, which was later refined to functional temporomandibular joint disturbances by Ramfjord and Ash (Okeson, 1998). Although various terminology has been applied in an effort to describe the malcondition, Bell (1983) coined the label temporomandibular disorder (TMD), which has gained popularity due to the term's acknowledgement of the joint and the masticatory system. 
The American Dental Association adopted the name temporomandibular disorder in 1983 to avoid confusion in an already difficult area of diagnosis (Griffiths, 1983).

The diagnosis of TMD paralled the naming of the condition. During the 1950's TMD became a diagnosable condition acknowledged by most dental professionals (Okeson, 1998). The prevalence of signs and symptoms attributable to TMD has increased tremendously over the past half century due to increased awareness by both patient and doctor.

Numerous epidemiological studies have examined the frequency of TMD in various groups. Nilner and Lassig (1981) reported that $36 \%$ of their subjects $(158 / 440)$ possessed at least one symptom, and 72\% (317/440) possessed at least one clinical sign of TMD. Gazit (1984) reported that $56 \%$ of the subjects $(207 / 369)$ possessed at least one symptom, while 44\% (162/369) possessed at least one sign of TMD. Pullinger (1988) reported that $39 \%$ of the subjects $(87 / 222)$ possessed at least one symptom of TMD, and $48 \%(107 / 222)$ possessed at least one sign of TMD. Swanljung and Rantanen (1979) reported that $59 \%$ of the subjects $(344 / 583)$ possessed at least one symptom, while $86 \%$ $(501 / 583)$ possessed at least one sign of TMD. Although these epidemiological studies encompassed large sample sizes, they are not representative of the population at large due to the specific nature of each sample; that is all subjects were children or adult, or country specific. It seems logical, nevertheless, to infer that $40 \%$ to $60 \%$ of the general population would have some sign of TMD (Okeson, 1998).

Solberg (1979), who conducted a detailed study of TMD among university students, designed his study to include both clinical examination of the TMJ as well as a questionnaire to be filled out by the subject being examined. He discovered that 
approximately $50 \%$ of the 739 subjects possessed signs that were not reported as symptoms. Furthermore, it was found that only $10 \%$ of the group (74/739) had symptoms that were severe enough for them to seek treatment. It is generally assumed that approximately $25 \%$ of the population will report symptoms of TMD, while only $10 \%$ of the population will seek treatment for the condition. Solberg's study is acknowledged by the dental community as a more accurate reflection of the prevalence of TMD in the general population. Most epidemiological studies report that the majority of patients seeking treatment for their TMD fall within the age range of 20 to 40 years, although children, young adults, and those over 60 report having symptoms of TMD.

According to the National Institutes of Health (NIH, 1996), population based epidemiological data indicate the prevalence of self-reported symptoms to range from $5 \%$ to $15 \%$, with no gender difference and with peak prevalence in young adults between 20 and 40 years of age. The NIH, however, acknowledges the conflicting percentages among epidemiological studies concerning TMD prevalence and urges further exploration aimed at TMD research, specifically more longitudinal studies.

\section{Etiology of Temporomandibular Disorder}

Symptoms of TMD can arise when normal function is coupled with an event that exceeds physiological tolerance (Emshoff et al., 2002). Such an event can be local and/or systemic. A local event may be a change in sensory input arising from an improperly occluding crown, or it can be secondary to trauma that involves local tissues, 
such as a post-injection response following local anesthesia. Trauma can also arise from unaccustomed use of the dentition such as the onset of bruxism.

The overwhelming cause in terms of frequency of a systemic event is stress. Emotional centers of the brain influence muscle function as the hypothalamus, reticular system, and the limbic system affect the muscle systems through gamma efferent pathways, causing the intrafusal fibers of the muscle spindles to contract. The muscle spindle can thereby be sensitized so that any slight stretching of the muscle causes a reflex contraction, increasing tonicity of the muscle (Carlsson, 1973).

When the body is stressed, the stress must be released (Okeson, 1988). That release of stress occurs in two forms, external and internal. Externally released stress manifests itself as shouting, cursing, throwing objects, and so on. Internally released stress manifests itself as a psychophysiological disorder such as hypertension, asthma, increased tonicity of head and neck muscles, or a parafunctional habit such as bruxism (Solberg and Seligman, 1985).

Why some individuals tolerate stress better than others or channel stress into different arenas is poorly understood. What is understood is that different individuals have differing physiological tolerances and that tolerance levels can be influenced by local and systemic factors. When the masticatory system is orthopedically stable, it is better suited to withstand local factors. Orthopedic stability of the mandible, maxilla, temporal bones plus surrounding muscles and ligaments, is achieved when the mandibular condyles are seated with their heads against the posterior slope of the articular eminences in the most superoposterior position with the articular discs properly superimposed. There should also be evenly distributed contacts on all teeth directing 
forces through the long axes of the teeth. From the aforementioned position, the mandible moves eccentrically and the anterior teeth contact, discluding the posterior teeth (Okeson, 1998). Orthopedic instability may result from poor occlusion, diseased TMJ, or both. A lack of coincidence among stable muscular position and stable occlusal contacts may also increase instability and predispose the subject to future TMD (Solberg and Seligman, 1985).

There are numerous systemic factors affecting physiological tolerance. Each individual possesses unique characteristics that form his constitution. These include genetic predisposition, physiology, gender, and diet. Other variables such as acute or chronic diseases and the overall physical conditioning of the patient can further affect his physiological tolerance. It should be noted that if the individual's effectiveness in pain modulation is not optimal, the system becomes more vulnerable to encountered events (Okeson, 1998). Lastly, Grassi and Passatore (1988) illustrated that sympathetic activity can increase muscle tone leading to painful muscle conditions, which further modulates a person's response to a stressor. Since emotional stress can influence sympathetic activity, it presents as a factor in two areas: a systemic event and a systemic factor affecting physiological tolerance.

\section{The Role of Malocclusion in Temporomandibular Disorder}

Although malocclusion has been implicated as an etiological factor of temporomandibular disorder (Perry, 1969; Roberts, 1974; Roth, 1982), clinical studies verifying this relationship have been equivocal (Hultgren et al., 1978; Mohlin and Kopp, 
1978). Mohlin and Kopp (1978) showed no association between incisor overbite and TMD.

Conversely, there have been several studies suggesting a strong association between anterior crossbites and anterior open bites predisposing an individual to TMD (Mohlin et al., 1980; Egermark-Eriksson et al., 1983). Anterior crossbites and extreme deepbites, such as $100 \%$ overbite, appear to cause neuromuscular dysfunction and mandibular repositioning that create disharmonies in the masticatory cycle. Such a disharmony may be sufficient to produce ischemic circulatory effects that predispose the individual to TMD (Solberg and Seligman, 1985).

Lastly, asymmetric occlusal contacts and interferences have been associated with functional disturbances (Ingervall et al., 1980; Egermark-Eriksson et al., 1983). These interferences have been correlated with temporomandibular joint sounds, thus strengthening the association with dysfunction. Although some studies have reported statistically significant associations between TMD and apertognathia, crossbites, and occlusal interferences, it is still doubtful that malocclusion alone can serve as the etiological factor of TMD. Occlusion and malocclusion are only one contributing factor to a complex problem (Solberg and Seligman, 1985).

\section{The Role of Bruxism in Temporomandibular Disorder}

Bruxism and other parafunctional habits seem to predispose individuals to future TMD. Granados (1979) showed that loss of cusp height due to attrition can lead to arthritic changes in the condyle and in the articular eminence. There has also been a 
correlation established between bruxism and masseter muscle tenderness and limited mandibular opening (Woo et al., 1979). Olkinvora (1979) further established a familial predisposition to bruxism, so two categories of bruxers exist: those that are predisposed through familial traits and those who brux as an internal release from emotional stress (Solberg and Seligman, 1985).

Ramfjord and Ash (1983) also noted that occlusal interferences induce bruxism, although Egermark-Eriksson et al. (1983) dispute this claim. Again, as with malocclusion, bruxism seems to be just one precipitating factor that, alone, is not likely to lead to TMD, but may serve as a useful sign for patient and doctor's proactive intervention of future TMD.

\section{Motion of the Mandible}

Mandibular movement arises from a complex sequence of interrelated threedimensional rotational and translational actions. The main motions of the jaw, namely opening and closing, are a combination of both translation and rotation. The translational and rotational components are not combined equally through the whole of the motion (Merlini and Palla, 1988). In the initial phase of the opening cycle the movement is primarily rotational, but after approximately the first $20 \mathrm{~mm}$ of jaw opening, translation becomes more pronounced as the condyles and discs slide anteriorly along the posterior slope of the articular eminence. Maximum opening occurs when there is between 40 and $60 \mathrm{~mm}$ distance between the upper and lower incisors and is limited by the temporomandibular ligament and the joint capsule. Closing movement 
begins with a phase in which posterior translation predominates. The jaw closes with translation as its major component until about two-thirds of maximal opening is attained. At this time the condyles and discs have returned either to the height or the posterior slope of the articular eminence. Once this happens, closing occurs as a smooth combination of translatory and rotatory motion. Occlusal position is then attained primarily, though not entirely, by rotational motion (Nevarki, 1956).

A point located between the incisal edges of the lower central incisors, termed the incisal point, is usually used to describe the movement of the mandible. The Posselt diagram (Fig. 1) outlines the border movements of the incisal point. The initial position of the incisal point is called centric occlusion, and at this position the occlusal surfaces are in maximum contact. The sagittal Posselt figure can be divided into 4 segments.

In the first segment, called the maximal rear opening (MRO) period, the jaw rotates approximately 10 degrees about an axis that intersects the center of the condyles. If the mandible opens farther, a protrusion starts, and the final rear opening (FRO) period can be considered as the combined movement of the rotation about the axis and a protrusion. After this period the maximal opening (MO) is reached. The maximal frontal path (MFP) is described as a rotation around the axis accompanied by maximal protrusion. At the upper border the mandible is only in maximum protrusion and can return to its initial position of centric occlusion by a retrusive motion.

The anatomical considerations involving the TMJ are complex and varied depending on the medical condition of the patient. Nevertheless, basic principles of anatomy must be understood in order to evaluate accurately any movement surrounding the joint. 


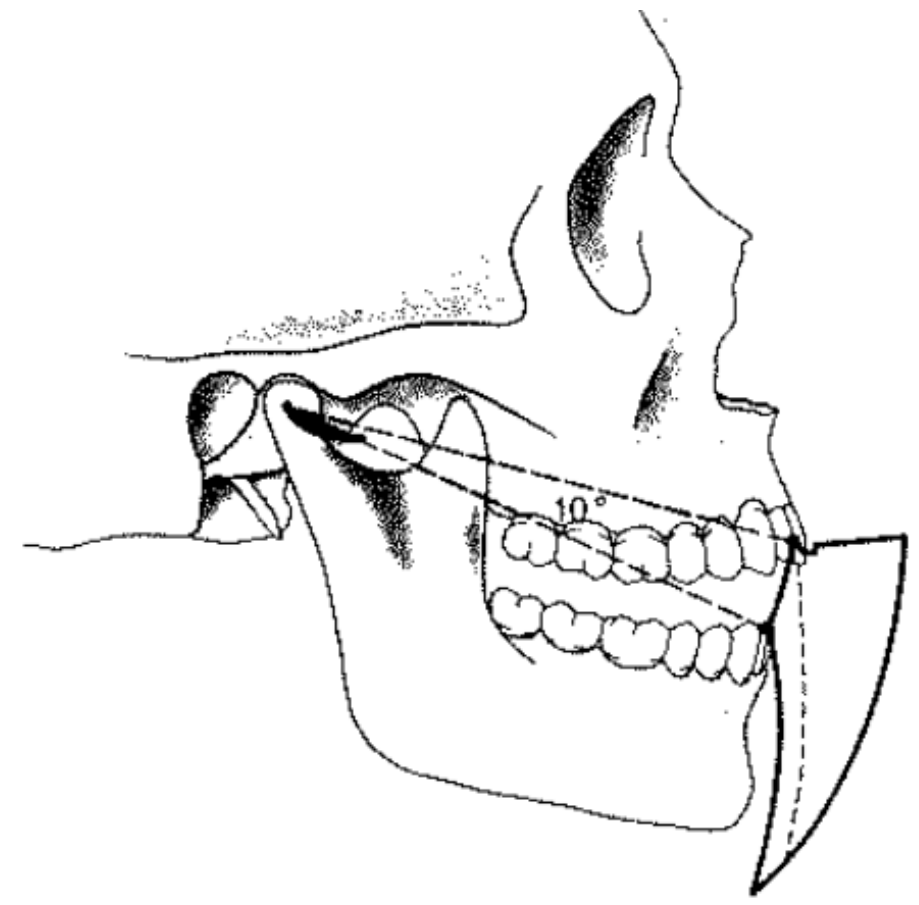

Fig. 1: Posselt's envelope of motion. 


\section{Three-Dimensional Analysis of Mandibular Motion}

The temporomandibular joint contains an upper and lower compartment separated by an articular disc. Mouth opening is achieved by both translation and rotation of the condyle and the articular disc complex within the glenoid fossa. The healthy patient exhibits a hinge motion between disc and condyle, with a translatory movement between disc and fossa (Rocabado, 1983; Smith, 1985; Mckay et al., 1992). Unlike the elbow joint, which rotates around a fixed axis, the wrist (Wilson et al., 1999), ankle (Chen et al., 1988), knee (Hart et al., 1991), and temporomandibular joint (Gallo et al., 1997) rotate around an axis moving in space that can be described mathematically by a helical axis model (Bottlang et al., 1998).

There have been few studies to characterize the compound movement of the temporomandibular joint in a three-dimensional manner. While most research relevant here has focused on classifying movements of the TMJ in a two-dimensional anteroposterior plane of space ( Panjabietal, 1979; Pertes et al., 1988; Mcmillan et al., 1989), the screw axis model (also known as the finite helical axis model) has been shown to be a reliable mathematical approach to model TMJ movements in the threedimensional domain (Spoor, 1989; DeLarge et al., 1990; Gallo et al., 1994; Airoldi et al., 1999). The use of the screw axis model overcomes two limitations of prior models, namely (1) movement in an anteroposterior plane and (2) ignoring the location of the axis about which rotation occurs (Gallo et al., 1997). These limitations are overcome by expressing the infinitesimal spatial motion of a rigid body through translation about an 
axis and the subsequent rotation around it, otherwise known as the instantaneous screw axis (Gallo et al., 1997).

During the movement of a rigid body (Fig. 2), the continuous pathway that changes position in space can be described by the screw displacement axis (SDA). The SDA or finite screw axis is calculated between consecutive motion steps in time-sampled systems and represents an approximation of the instantaneous screw axis of a continuous movement if the sampling frequency is high enough. Source data for the screw axis involves tridirectional translation and tri-axial rotation reports from a single receiver affixed to the moving body. Inferences of screw displacement axis parameters from this type of source data require algorithmic approaches that are different than those used to process multireceiver translation-only data (Bottlang, 1998).

The instantaneous screw axis and subsequently the SDA provide a good model for movement as it relates to the temporomandibular joint according to Fioretti et al. (1990) and Gallo et al. (1997). Although other techniques exist for description of movement, namely the Cartesian coordinate system, the screw axis method has been shown to be reliable, accurate, and easily repeatable. The reduction in mathematical computation makes the determination of rotation and translation easily managed through software analysis. Furthermore, research by Gallo and colleagues has demonstrated both the clinical and mathematical application of the screw displacement axis as it relates to movement of the asymptomatic mandible. Unlike other joints of the body, the TMJ provides an excellent anatomical structure for motion analysis as it concerns the screw displacement axis. 


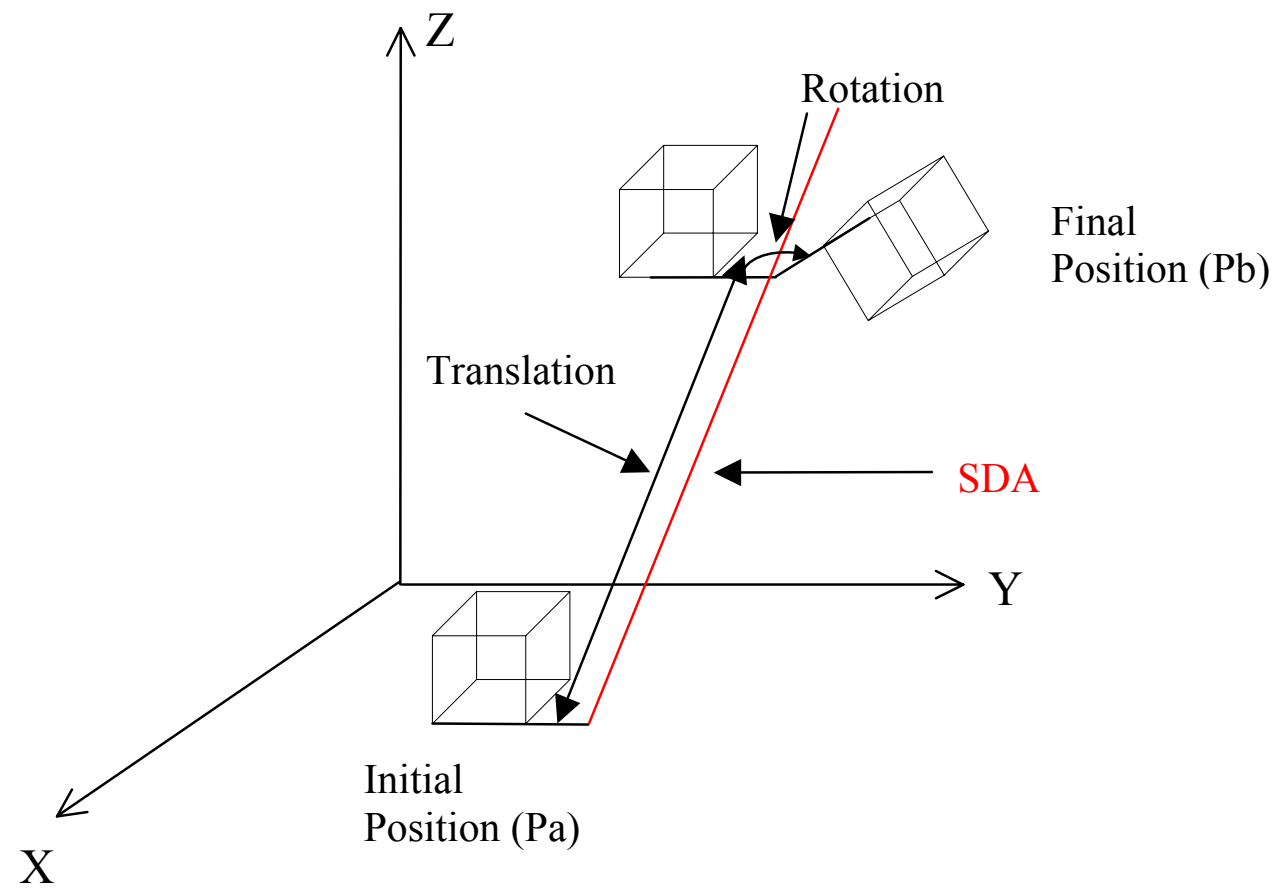

Fig. 2: Screw displacement axis (SDA). 


\section{Screw Axis Model}

The mathematical model of the helical axis or screw axis has been used to quantify three-dimensional anatomical joint movements (Woltring et al., 1985; Siegler et al., 1988; Fioretti et al., 1990; Gallo et al., 1997). By progressing from a twodimensional model to a three-dimensional model, researchers and clinicians can better understand the complex motions of the temporomandibular joint and how joint deviations explain popping and clicking in symptomatic patients (Krebs et al., 1994; Gallo et al., 1997; Fushing et al., 1995). According to Gallo et al. (1997), the opening and closing pathways among healthy subjects do not coincide when using the finite helical axis. Ramakrishnan and Kadaba (1991) reported on the orientation of the helical axis but not on its position during the whole gait cycle that consists of the continuous opening and closing motion of the oral cavity and subsequent motion of the temporomandibular joint. Hart et al. (1991) described the finite helical axis orientation and position during flexion of the knee but not during extension. Gallo explains that non-coincidence of the finite helical axis pathways during opening and closing is most likely due to the asymmetrical combination of rotations and translations since different muscles are used to open than to close the mandible. Gallo's research is the only prior work using the helical axis model to examine data obtained from condylar head movement during opening and closing of the mouth. Gallo's research has shown that the mandibular finite helical axis is an accurate predictor of temporomandibular joint motion in all three planes of space.

The screw axis is a mathematical model for describing and quantifying both the rotation and translation of the condylar capitulum on opening and closing, thus yielding a 
more comprehensive description of jaw movements than do the trajectories of a single mandibular point.

It has been proposed that condylar positioning problems and excessive loading of the joint produce major destructive and degenerative changes that lead to temporomandibular disorder (Tyndall et al., 1992; Tanake et al., 2002). Internal derangement of the disc and condyle complex, as well as excessive compression of the temporomandibular disc can cause popping, clicking, condylar resorption, or a combination of these that can lead to intolerable symptoms for the patient (Beek et al., 2001). Quantitative evaluation of the structural and mechanical status in the TMJ should allow for a better understanding of the causative mechanisms of TMD.

Through computerized three-dimensional magnetic resonance imaging reconstructions of the TMJ, Chu et al. (1995) illustrated considerable disc motion upon jaw opening and closing, concluding that the TMJ receives various loadings not only during clenching, but also during opening and closing. Tanaka et al. (2002) contends that there is still no clear understanding of the biomechanics of the TMJ.

Schreppers et al. (1990) suggested that deformable cartilage layers may influence the mechanics of diarthrodial joints. Beek et al. (1999) investigated this supposition with a three-dimensional finite element model of the TMJ. Their results showed that during translation of the condyle, from a jaw-closed position to a jaw-protrusion position, the loaded region of the disc shifted from the intermediate zone to its lateral side. It also was shown that when the disc complex is located against the articular eminence, the area that undergoes greater stresses is larger than when the condyle is located in the fossa. The 
disc, therefore, possesses a load-distributing capacity, indicating that wearing of the disc can occur in specific areas depending upon the abnormality in function.

\section{Computation of Screw Axis Parameters}

The calculation of helical axis parameters and the Screw Displacement Matrix for this study were based on Beggs' methods (1983). The following computation depends purely on the initial and final coordinates of three non-collinear points fixed to a moving rigid body. All the computation and results generated are relative to the same reference frame within which the initial and final positions of those three points are described.

Overall, there are five steps in the process to find the $4 \times 4$ screw displacement matrix [S], the translation ( $\mathrm{t}$ ) along the helical axis, the rotation $(\theta)$ about the screw axis, and the three-dimensional position and orientation parameters of the screw axis.

Initially a rigid body is at position $\mathrm{Pa}$ and it is then moved to a new position $\mathrm{Pb}$.

Step 1: Calculate final position from initial position ( $\mathrm{Pb}-\mathrm{Pa})$

Given: $[\mathrm{Pa}]=\left[\begin{array}{l}\mathrm{P} 1 \mathrm{a} \\ \mathrm{P} 2 \mathrm{a} \\ \mathrm{P} 3 \mathrm{a}\end{array}\right]=\left[\begin{array}{lll}\mathrm{x} 1 & \mathrm{y} 1 & \mathrm{z} 1 \\ \mathrm{x} 2 & \mathrm{y} 2 & \mathrm{z} 2 \\ \mathrm{x} 3 & \mathrm{y} 3 & \mathrm{z} 3\end{array}\right] \quad(1)$, and $[\mathrm{Pb}]=\left[\begin{array}{l}\mathrm{P} 1 \mathrm{~b} \\ \mathrm{P} 2 \mathrm{~b} \\ \mathrm{P} 3 \mathrm{~b}\end{array}\right]=\left[\begin{array}{lll}\mathrm{x} 1^{\prime} & \mathrm{y} 1^{\prime} & \mathrm{z} 1^{\prime} \\ \mathrm{x} 2^{\prime} & \mathrm{y} 2^{\prime} & \mathrm{z} 2^{\prime} \\ \mathrm{x} 3^{\prime} & \mathrm{y} 3^{\prime} & \mathrm{z} 3^{\prime}\end{array}\right]$ (2)

$[\mathrm{Pb}-\mathrm{Pa}]=\left[\begin{array}{lll}\mathrm{x} 1^{\prime}-\mathrm{x} 1 & \mathrm{y} 1^{\prime}-\mathrm{y} 1 & \mathrm{z} 1^{\prime}-\mathrm{z} 1 \\ \mathrm{x} 2^{\prime}-\mathrm{x} 2 & \mathrm{y} 2^{\prime}-\mathrm{y} 2 & \mathrm{z} 2^{\prime}-\mathrm{z} 2 \\ \mathrm{x} 3^{\prime}-\mathrm{x} 3 & \mathrm{y} 3^{\prime}-\mathrm{y} 3 & \mathrm{z} 3^{\prime}-\mathrm{z} 3\end{array}\right]$ 
Step 2: Find the translation along the helical axis and the directional cosines

For the three points $\mathrm{P} 1, \mathrm{P} 2$, and $\mathrm{P} 3$ fixed to the rigid body, there are vectors $\mathrm{A}, \mathrm{B}$, and $\mathrm{C}$. These vectors start from the initial positions of $\mathrm{P} 1, \mathrm{P} 2$ and $\mathrm{P} 3$ and point to their final positions, respectively:

$$
\mathrm{A}=\mathrm{P} 1 \mathrm{~b}-\mathrm{P} 1 \mathrm{a}, \mathrm{B}=\mathrm{P} 2 \mathrm{~b}-\mathrm{P} 2 \mathrm{a}, \mathrm{C}=\mathrm{P} 3 \mathrm{~b}-\mathrm{P} 3 \mathrm{a} \text { (4) }
$$

Within the same coordinate frame, move vectors A, B, and C parallel to themselves until they start at the origin. The helical axis also moves parallel to itself until it passes through the origin. Since the projections of A, B and C on the helical axis will all be the same, $t$, the tips of A, B, C, will form a plane perpendicular to the helical axis with the distance from the intersection of the plane and the helical axis to the origin being the translation $(t)$, as is shown in figures 3 and 4.

The projection of any vector on the screw axis can be obtained by $\mathrm{V} \cdot \mathrm{n}$, where $\mathrm{n}$ is the unit vector of the screw axis, which equals [Cxs, Cys, Czs]. Therefore, we have the relationship:

$$
\left[\begin{array}{l}
\mathrm{A} \\
\mathrm{B} \\
\mathrm{C}
\end{array}\right]\left[\begin{array}{c}
\mathrm{Cxs} \\
\mathrm{Cys} \\
\mathrm{Czs}
\end{array}\right]=\left[\begin{array}{l}
\mathrm{t} \\
\mathrm{t} \\
\mathrm{t}
\end{array}\right]
$$

From this general form a relationship can be drawn relating directional cosines of the helical axis and translation along the helical axis:

$$
\left[\begin{array}{lll}
\mathrm{x} 1^{\prime}-\mathrm{x} 1 & \mathrm{y} 1^{\prime}-\mathrm{y} 1 & \mathrm{z} 1^{\prime}-\mathrm{z} 1 \\
\mathrm{x} 2^{\prime}-\mathrm{x} 2 & \mathrm{y} 2^{\prime}-\mathrm{y} 2 & \mathrm{z} 2^{\prime}-\mathrm{z} 2 \\
\mathrm{x} 3^{\prime}-\mathrm{x} 3 & \mathrm{y} 3^{\prime}-\mathrm{y} 3 & \mathrm{z} 3^{\prime}-\mathrm{z} 3
\end{array}\right]\left[\begin{array}{c}
\mathrm{Cxs} \\
\mathrm{Cys} \\
\mathrm{Czs}
\end{array}\right]=\left[\begin{array}{c}
\mathrm{t} \\
\mathrm{t} \\
\mathrm{t}
\end{array}\right]
$$




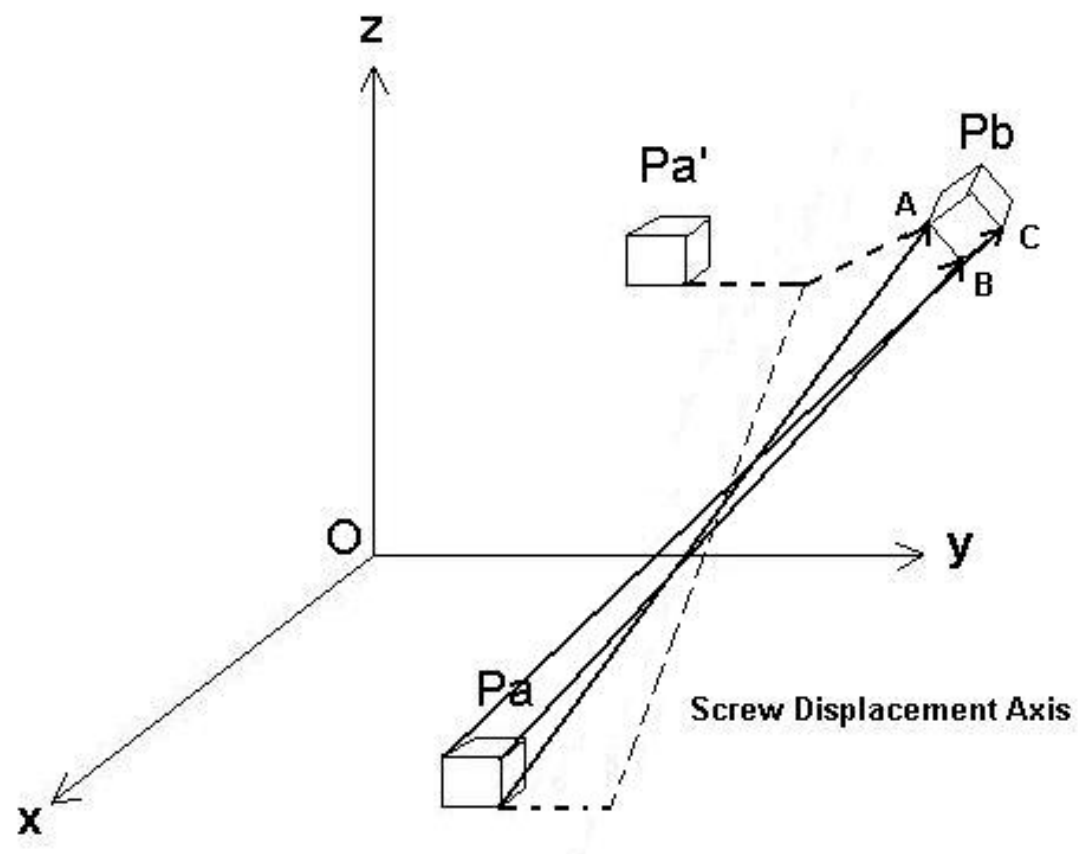

Fig. 3: Movement of object illustrating the SDA. 


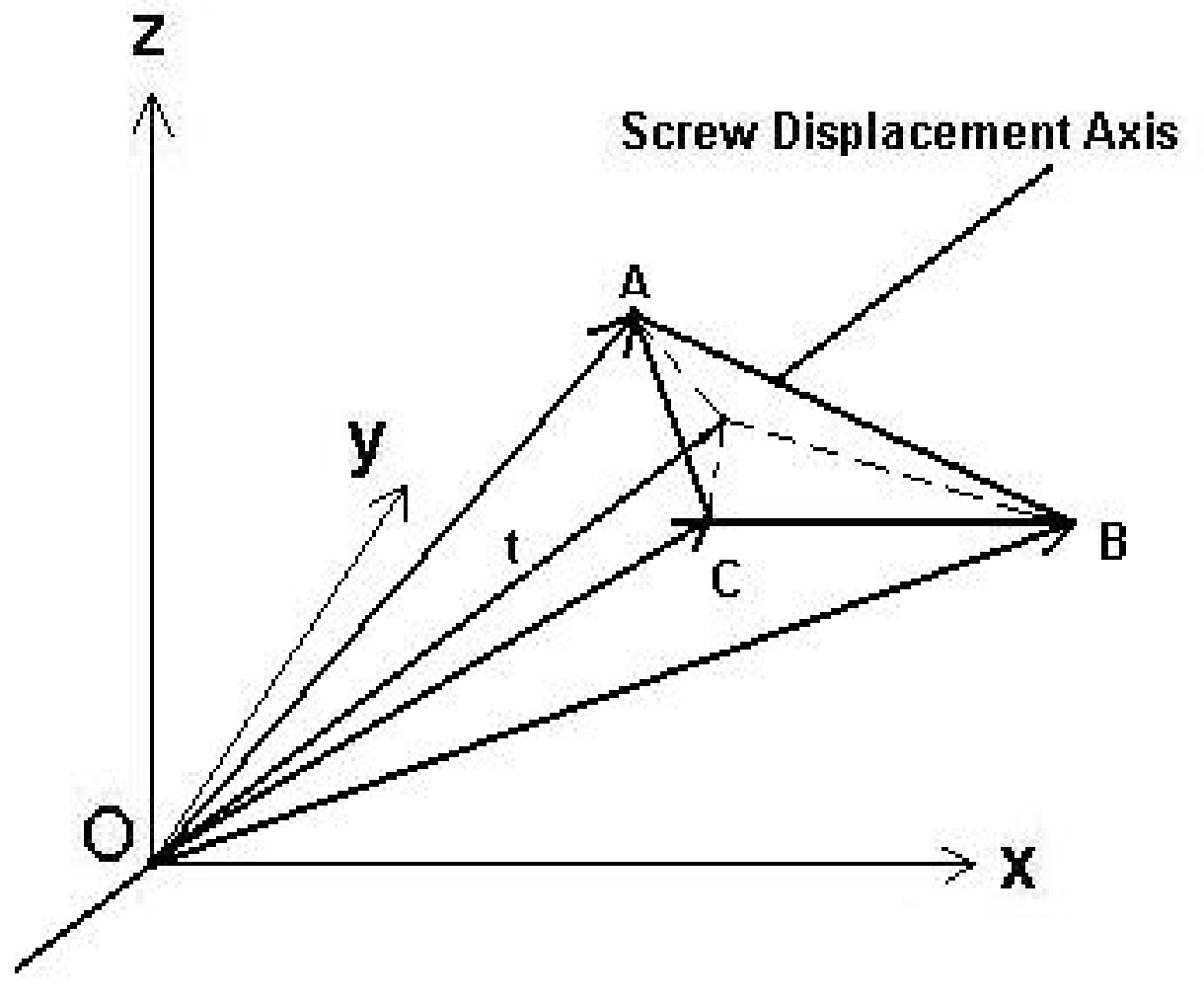

Fig. 4: Illustration of SDA. 
$\mathrm{t}$ is the magnitude of translation along the screw axis, and Cxs, Cys, Czs denote the directional cosines of the helical axis. Hence,

$$
\begin{aligned}
& {\left[\begin{array}{l}
\text { Cxs } \\
\text { Cys } \\
\text { Czs }
\end{array}\right]=\left[\begin{array}{lll}
\mathrm{x} 1^{\prime}-\mathrm{x} 1 & \mathrm{y} 1^{\prime}-\mathrm{y} 1 & \mathrm{z} 1^{\prime}-\mathrm{z} 1 \\
\mathrm{x} 2^{\prime}-\mathrm{x} 2 & \mathrm{y} 2^{\prime}-\mathrm{y} 2 & \mathrm{z} 2^{\prime}-\mathrm{z} 2 \\
\mathrm{x} 3^{\prime}-\mathrm{x} 3 & \mathrm{y} 3^{\prime}-\mathrm{y} 3 & \mathrm{z} 3^{\prime}-\mathrm{z} 3
\end{array}\right]^{-1}\left[\begin{array}{l}
\mathrm{t} \\
\mathrm{t} \\
\mathrm{t}
\end{array}\right]} \\
& \text { Let }[\mathrm{A}]=\left[\begin{array}{lll}
\mathrm{x} 1^{\prime}-\mathrm{x} 1 & \mathrm{y} 1^{\prime}-\mathrm{y} 1 & \mathrm{z} 1^{\prime}-\mathrm{z} 1 \\
\mathrm{x} 2^{\prime}-\mathrm{x} 2 & \mathrm{y} 2^{\prime}-\mathrm{y} 2 & \mathrm{z} 2^{\prime}-\mathrm{z} 2 \\
\mathrm{x} 3^{\prime}-\mathrm{x} 3 & \mathrm{y} 3^{\prime}-\mathrm{y} 3 & \mathrm{z} 3^{\prime}-\mathrm{z} 3
\end{array}\right]^{-1}
\end{aligned}
$$

Based on the properties of directional cosines in three-dimensional space,

$$
\begin{aligned}
& \mathrm{Cxs}^{2}+\mathrm{Cys}^{2}+\mathrm{Czs}^{2}=1 \\
& \text { Let }\left[\begin{array}{l}
\mathrm{A}_{1} \\
\mathrm{~A}_{2} \\
\mathrm{~A}_{3}
\end{array}\right]=\left[\begin{array}{l}
\mathrm{A}_{11}+\mathrm{A}_{12}+\mathrm{A}_{13} \\
\mathrm{~A}_{21}+\mathrm{A}_{22}+\mathrm{A}_{23} \\
\mathrm{~A}_{31}+\mathrm{A}_{32}+\mathrm{A}_{33}
\end{array}\right]
\end{aligned}
$$

Translation and direction cosines can now be computed:

$$
\begin{aligned}
& \mathrm{t}=\frac{1}{\sqrt{\mathrm{A}_{1}{ }^{2}+\mathrm{A}_{2}{ }^{2}+\mathrm{A}_{3}{ }^{2}}} \\
& {\left[\begin{array}{l}
\mathrm{Cxs} \\
\mathrm{Cys} \\
\mathrm{Czs}
\end{array}\right]=t \cdot\left[\begin{array}{l}
\mathrm{A}_{1} \\
\mathrm{~A}_{2} \\
\mathrm{~A}_{3}
\end{array}\right] \quad(12)}
\end{aligned}
$$

Step 3: Calculate the value of rotation angle $\theta$

Let $\mathrm{Va}$ be a vector fixed to the rigid body starting from $\mathrm{P} 1$ and pointing to $\mathrm{P} 2$, and $\mathrm{Vb}$ be the corresponding vector at the final body position.

$$
\mathrm{Va}=\mathrm{P} 2 \mathrm{a}-\mathrm{P} 1 \mathrm{a}(13), \quad \mathrm{Vb}=\mathrm{P} 2 \mathrm{~b}-\mathrm{P} 1 \mathrm{~b}(14)
$$


Figure 5 illustrates that the rotational angle is equal to the angle between vectors Ra and $\mathrm{Rb}$. P1 and $\mathrm{P} 2$ do not need to be aligned exactly as in equation 13. Any two points on the rigid body can be chosen to form $\mathrm{Va}$ and $\mathrm{Vb}$ as long as $\mathrm{Va}$ and $\mathrm{Vb}$ are not parallel to the screw axis. Let $\mathrm{Ra}=\mathrm{Va} \times \mathrm{n}$ and $\mathrm{Rb}=\mathrm{Vb} \times \mathrm{n}$, where $\mathrm{n}$ is the unit vector of the screw axis. $\mathrm{Ra}$ and $\mathrm{Rb}$ will then be perpendicular to $\mathrm{n}$. When the body rotates from initial to final position through an angle of $\theta$, Ra also rotates to $\mathrm{Rb}$ through $\theta$. By definition of dot product,

$$
\begin{aligned}
& \mathrm{Ra} \cdot \mathrm{Rb}=|\mathrm{Ra}||\mathrm{Rb}| \cos \theta \\
& \cos \theta=\frac{\mathrm{Ra}}{|\mathrm{Ra}|} \cdot \frac{\mathrm{Rb}}{|\mathrm{Rb}|}
\end{aligned}
$$

This gives the absolute value of $\theta, 0 \leq \theta \leq \pi$. Similarly,

$$
\sin \theta=\frac{\mathrm{Ra}}{|\mathrm{Ra}|} \times \frac{\mathrm{Rb}}{|\mathrm{Rb}|}
$$

The numerator can be expanded to

$$
\left[\begin{array}{lll}
\mathrm{Va} & \mathrm{Vb} & \mathrm{n}
\end{array}\right] \mathrm{n}-\left[\begin{array}{lll}
\mathrm{n} & \mathrm{Vb} & \mathrm{n}
\end{array}\right] \mathrm{Va} \quad(18),
$$

in which the second term is zero since the first and the third vectors are parallel.

Therefore, the $\operatorname{sign}$ of $\sin \theta$ is determined by the sign of the determinant of the $3 \times 3$ square matrix:

$$
\left[\begin{array}{c}
\mathrm{Va} \\
\mathrm{Vb} \\
\mathrm{n}
\end{array}\right]
$$

in which, $\mathrm{n}=[\mathrm{Cxs}, \mathrm{Cys}, \mathrm{Czs}]$. 


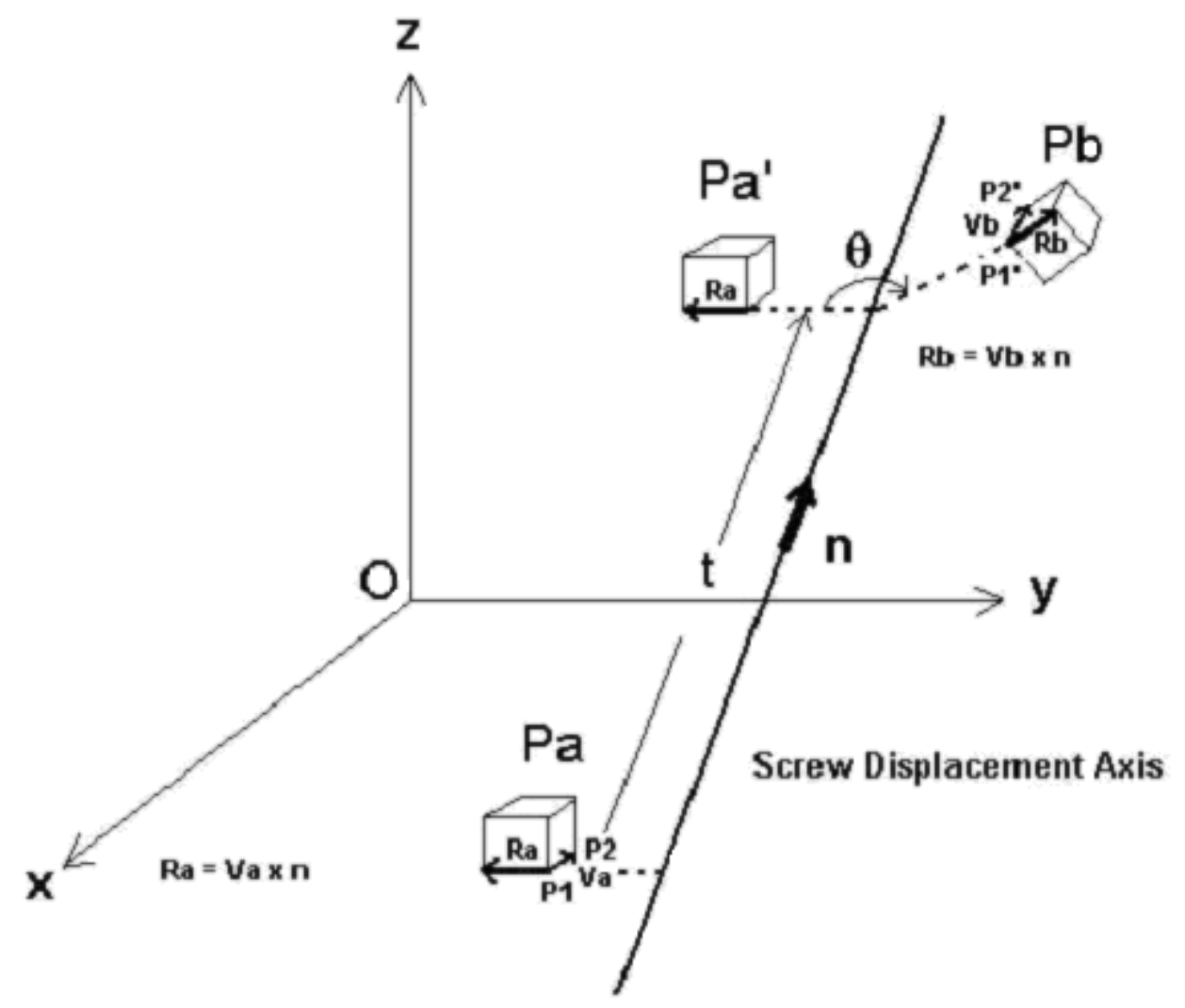

Fig. 5: Rotational angle illustrated by the SDA. 
Step 4: Generate the Screw Displacement Matrix [S].

Below is the Screw Displacement Matrix:

\begin{tabular}{|c|c|c|c|}
\hline 1 & 0 & 0 & 0 \\
\hline $\mathrm{tCxs}-\mathrm{x}\left(\mathrm{S}_{22}-1\right)-\mathrm{yS}_{23}-\mathrm{zS}_{24}$ & $\cos \theta+\operatorname{ver} \theta \mathrm{Cxs}^{2}$ & $-\sin \theta$ Czs + ver $\theta$ CxsCys & $\sin \theta$ Cys + ver $\theta$ CzsCxs \\
\hline $\mathrm{tCys}-\mathrm{xS}_{32}-\mathrm{y}\left(\mathrm{S}_{33}-1\right)-\mathrm{zS}_{34}$ & $\sin \theta$ Czs + ver $\theta$ CxsCys & $\cos \theta+\operatorname{ver} \theta$ Cys $^{2}$ & $-\sin \theta$ Cxs + ver $\theta$ CysCzs \\
\hline $\mathrm{tCzs}-\mathrm{xS}_{42}-\mathrm{yS}_{43}-\mathrm{z}\left(\mathrm{S}_{44}-1\right)$ & $-\sin \theta$ Cys + ver $\theta$ CzsCxs & $\sin \theta$ Cxs + ver $\theta$ CysCzs & $\cos \theta+\operatorname{ver} \theta \mathrm{Czs}^{2}$ \\
\hline
\end{tabular}

The above matrix is represented by $[\mathrm{S}]$, where:

t: $\quad$ Translation along screw axis.

$\theta$ : $\quad$ Rotation around screw axis (in radians).

ver $\theta$ : Since $(1-\cos \theta)$ appears frequently in the matrix, it is denoted as versine, or ver $\theta$

$\mathrm{S}_{\mathrm{ij}}$ : Element at Row $\mathrm{i}$ and Column $\mathrm{j}$ in $[\mathrm{S}]$.

$\mathrm{x}, \mathrm{y}, \mathrm{z}$ : Coordinate of any point on screw axis.

Cxs, Cys, Czs: Directional cosines of screw axis.

In order to obtain elements $\mathrm{S}_{21}, \mathrm{~S}_{31}, \mathrm{~S}_{41}$ of the Screw Displacement Matrix it is necessary to cut out matrix [C] from [S] by deleting the first row and the first column of

[S]. $\mathrm{S}_{21}, \mathrm{~S}_{31}, \mathrm{~S}_{41}$ can then be computed using equation (21):

$$
\left[\begin{array}{l}
\mathrm{S}_{21} \\
\mathrm{~S}_{31} \\
\mathrm{~S}_{41}
\end{array}\right]=\mathrm{P} 1 \mathrm{~b}-[\mathrm{C}] \mathrm{P} 1 \mathrm{a}
$$

When the Screw Displacement Matrix is calculated, the final position (P') for any point in the rigid body with known initial position $(\mathrm{P})$ can be found by using the equation:

$$
\mathrm{P}^{\prime}=[\mathrm{S}] \mathrm{P}(22)
$$


Step 5: Generate the screw axis

Since in the Screw Displacement Matrix $x, y$, and $z$ are the coordinates of any point in the screw axis, these relationships exist:

$$
\begin{aligned}
& \mathrm{tCxs}-\mathrm{x}\left(\mathrm{S}_{22}-1\right)-\mathrm{yS}_{23}-\mathrm{zS}_{24}=\mathrm{S}_{21}(23) \\
& \mathrm{tCys}-\mathrm{xS}_{32}-\mathrm{y}\left(\mathrm{S}_{33}-1\right)-\mathrm{zS}_{34}=\mathrm{S}_{31}(24)
\end{aligned}
$$

If $\mathrm{z}$ is set as a constant, equations (23) and (24) can be solved for variables $\mathrm{x}$ and $\mathrm{y}$ :

$$
\begin{aligned}
& {\left[\left(\mathrm{S}_{33}-1\right)\left(\mathrm{S}_{22}-1\right)-\mathrm{S}_{23} \mathrm{~S}_{32}\right] \mathrm{x}=\left[\mathrm{S}_{23} \mathrm{~S}_{34}-\mathrm{S}_{24}\left(\mathrm{~S}_{33}-1\right)\right] \mathrm{z}} \\
& +\mathrm{S}_{23} \mathrm{~S}_{31}-\left(\mathrm{S}_{33}-1\right) \mathrm{S}_{21}+\mathrm{t}\left[\mathrm{Cxs}\left(\mathrm{S}_{33}-1\right)-\mathrm{Cys}_{23}\right](25) \\
& {\left[\left(\mathrm{S}_{33}-1\right)\left(\mathrm{S}_{22}-1\right)-\mathrm{S}_{23} \mathrm{~S}_{32}\right] \mathrm{y}=\left[\mathrm{S}_{32} \mathrm{~S}_{24}-\mathrm{S}_{34}\left(\mathrm{~S}_{22}-1\right)\right] \mathrm{z}} \\
& +\mathrm{S}_{21} \mathrm{~S}_{32}-\left(\mathrm{S}_{22}-1\right) \mathrm{S}_{31}+\mathrm{t}\left[\mathrm{Cys}\left(\mathrm{S}_{22}-1\right)-\mathrm{CxsS}_{32}\right](26)
\end{aligned}
$$

Note: $\left(\mathrm{S}_{33}-1\right)\left(\mathrm{S}_{22}-1\right)-\mathrm{S}_{23} \mathrm{~S}_{32}=2(1-\cos \theta) \mathrm{Czs}^{2}(22)$

Equations (25) and (26) can be reduced to the format of:

$$
\begin{aligned}
& x=k_{x} z+x_{o} \\
& y=k_{y} z+y_{o}
\end{aligned}
$$

where $\mathrm{k}_{\mathrm{x}}$ and $\mathrm{k}_{\mathrm{y}}$ are the slopes of the screw axis relative to $\mathrm{z}$-axis, and $\mathrm{x}_{\mathrm{o}}$ and $\mathrm{y}_{\mathrm{o}}$ are $\mathrm{x}$ and $y$ coordinates of the interception point where the screw axis penetrates $x-y$ plane, where $z$ equals zero. By varying $\mathrm{z}$ within an appropriate range and calculating the corresponding $\mathrm{y}$ and $\mathrm{z}$ values, the helical axis can be plotted within a certain three-dimensional volume determined by the range of $\mathrm{z}$. 


\section{Previous Research Utilizing the Screw Axis Model}

The screw axis model has been used in numerous biomechanical studies for anatomical joints, such as the wrist (Wilson et al., 1999), spine (Osterbauer et al.,), ankle (Chen et al., 1998), and knee (Hart et al., 1991). Presently, however, mandibular motion has been described through the screw axis method in only three studies. Gallo et al. has conducted two studies including the use of the screw axis in describing mandibular motion (Gallo et al., 1997, 2000). The first study showed that the screw axes are not localized within the condyles. They also observed that opening and closing pathways of the axes do not coincide. Their second study analyzed the behavior of the screw axis during unilateral mastication in asymptomatic subjects. There is only one other study by Sadat-Khonsari et al. (2003), and results in it showed that the pathway of the screw axes started near the condyle and followed an elliptical path proceeding vertically downward and posteriorly, then progressing anteriorly and finally vertically upward and posteriorly close to its starting position. 


\section{Section III: Materials and Methods}

Testing for this study consisted of two main phases. The first objective was to conduct a thorough analysis of how systematic error limited the accuracy with which the screw displacement axis (SDA) parameters were calculated. The second part was to track the mandibular motion of five asymptomatic subjects.

\section{Accuracy and Error Assessment}

A detailed analysis was conducted in order to gain a better understanding of error, identify those factors that influence its magnitude, and identify ways to reduce error. The device used to gather three-dimensional coordinate data for calculating the Screw Displacement Axis was the DynaSight ${ }^{\mathrm{TM}}$ Sensor made by Origin Instruments.

Initial testing revealed the sensor had a large systematic error as targets moved in its field of vision.

Bottlang et al. (1998) and Duck et al. (2004) have previously published studies that evaluated the accuracy of screw displacement tracking systems. However, their studies differed by using electromagnetic tracking systems. They found that higher rotational iterations and filtering/smoothing techniques eliminated known system inaccuracy. Crisco et al. (1994) explored the optimal placement of makers in instantaneous center (IC) calculations. They found that the closer the target center was 
to the center of rotation the more accurate the calculation. Accuracy also increased as distance between marker points increased.

\section{Error Propagation}

In the present study, the propagation of error throughout the set of equations used to calculate the helical axis was approached using the method of sequential perturbation.

Theoretical motion data (x,y,z coordinates, and angle rotation) of a four bar

linkage was produced in a vector loop analysis program. The coordinates of three points were saved at rotations of 1, 2, 3, 4, and 5 degrees. The theoretical data were then sequentially perturbated by introducing an error of \pm 20 microns added to each independent variable input into the SDA calculation program. The error of \pm 20 microns was chosen because it was the highest resolution of the motion measurement system. The total number of independent variables that had to be perturbated was 18 because there were $9 \mathrm{X}, \mathrm{Y}, \mathrm{Z}$ coordinates for the initial target positions and $9 \mathrm{X}, \mathrm{Y}, \mathrm{Z}$ coordinates for the final target positions. The output of the SDA calculating program consisted of $\mathrm{k}_{\mathrm{x}}$ and $\mathrm{k}_{\mathrm{y}}$ of the slopes of the screw axis relative to z-axis, and $\mathrm{x}_{\mathrm{o}}$ and $\mathrm{y}_{\mathrm{o}}$, the $\mathrm{x}$ and $\mathrm{y}$ coordinates of the interception point where the screw axis penetrates $x-y$ plane when $z$ equals zero. The output error field can be seen in figure 6 . 


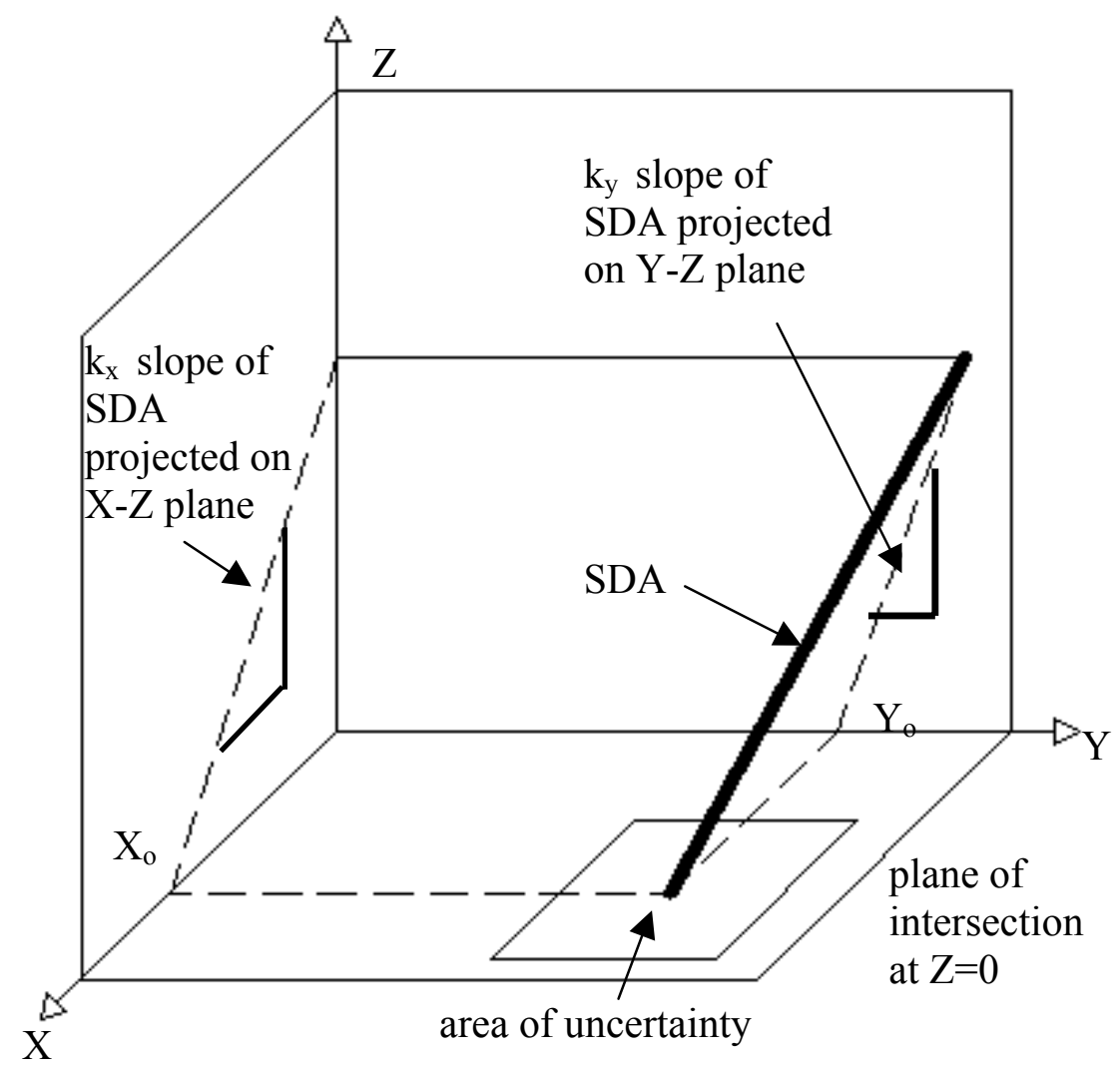

Fig. 6: Explanation of area of uncertainty of SDA parameters. 


\section{Target Placement Area}

A number of conditions were tested to find conditions that reduced the magnitude of error for tracking targets with the motion measurement system. Three testing conditions were used to explore differences in the error. In the first condition, the velocity of a target was varied through a similar path of motion. Three data sets were taken at constant velocities $(0.2 \mathrm{~mm} / \mathrm{sec}, 0.4 \mathrm{~mm} / \mathrm{sec}$, and at $0.8 \mathrm{~mm} / \mathrm{sec}$. $)$. In the second condition, three targets were attached to a rigid body in a row (at differing distances of approximately $100 \mathrm{~mm}, 60 \mathrm{~mm}$, and $20 \mathrm{~mm}$ from the origin defined as the camera) and moved at a constant velocity along an axis. In the third condition, the distance from the camera in which the plane of motion that a target underwent constant velocity was altered ( $Z$ distances from the camera were set at $200 \mathrm{~mm}, 250 \mathrm{~mm}$, and $300 \mathrm{~mm}$ ). These three conditions were tested for both movement along the $\mathrm{X}$-axis and $\mathrm{Y}$-axis. After the coordinate data for each test were taken, the first 15 to 20 peak-to-trough differences for the error were measured for each test. The sets of peak-to-trough displacements for each test were then used in a one-way ANOVA $(\alpha=0.05)$ to discover if there was a significant difference between the varied velocities, displacements, or $\mathrm{Z}$ distances. If a significant difference in the peak-to-trough values was observed between any of the groups in the ANOVA analyses, the Tukey multiple comparison procedure was used to find which of the treatments differed from one another. 


\section{Theoretical and Experimental Data Comparison}

In order to compare how well the tracking system was acquiring data, a comparison was made to theoretical measurements and experimentally obtained data. To perform the comparison, a simple motion needed to be produced theoretically as well as experimentally (Fig. 7). This was accomplished by using the three dimensional coordinate and IC data of the four bar linkage used in the sequential perturbation study for rotations from 1 to 15 degrees in 1-degree steps. To reproduce the data experimentally a four bar linkage of the same dimensions as the virtually designed linkage was constructed out of steel. A target array was fastened to the coupler link and motion was controlled by a programmable testing system (Fig. 8). The experimental linkage was set in an initial configuration matching the initial settings of the virtual linkage. Target coordinate data were then recorded through 15 degrees of motion. The experimental data were processed by a program that calculates helical/SDA axes at a set rotational angle of 10 degrees. The screw axis measurements were taken to represent a path of data starting from 1 to 10 degrees and ending from a 5 to 15 degree increment. Theoretical screw axis and experimental screw axis data were then reduced to intersections through the plane in which the linkage laid in order to compare them to instantaneous center coordinates. All coordinates were compared to see how well the paths of motion matched. 


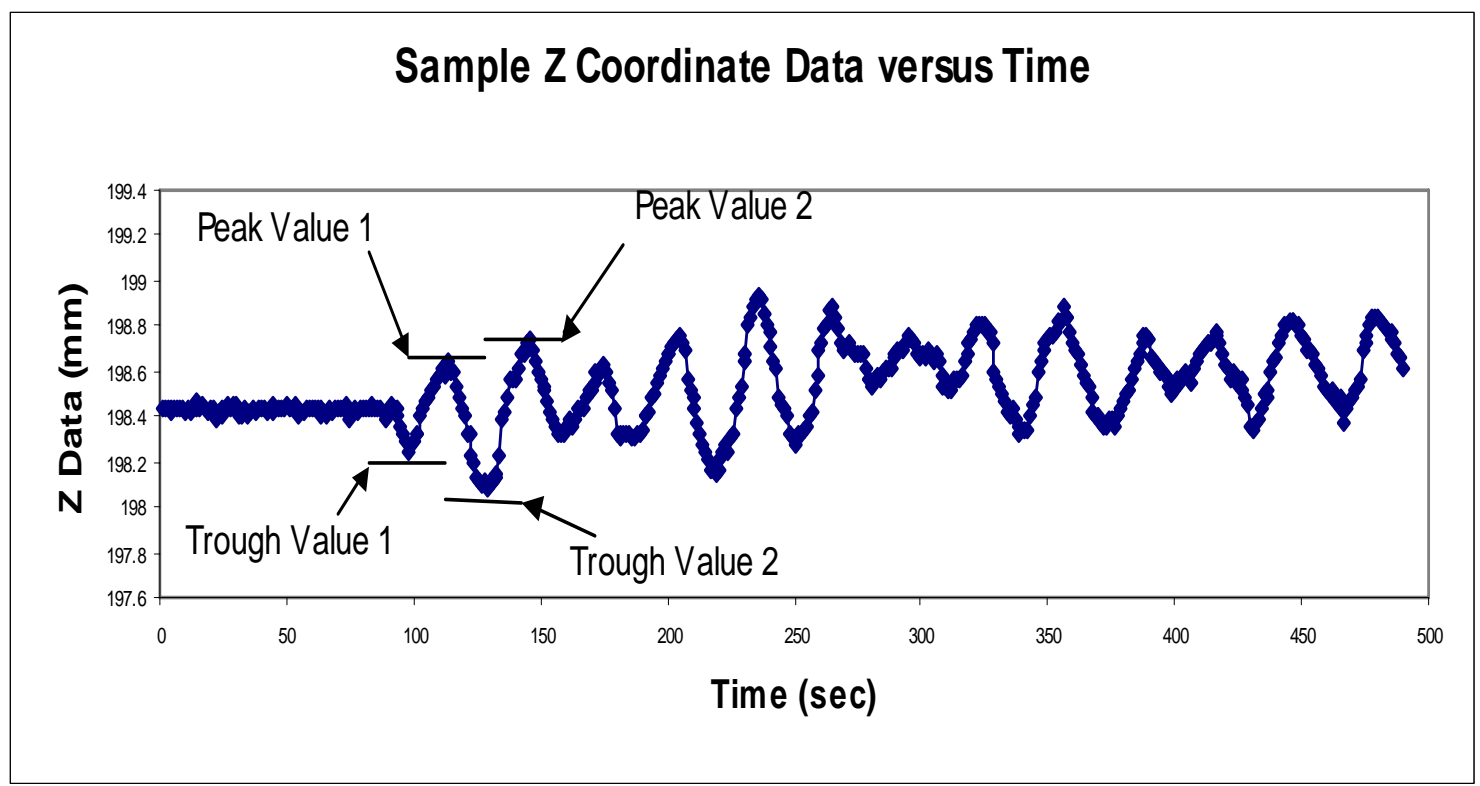

Fig. 7: Sample target data showing $\mathrm{Z}$ coordinate data versus time. 

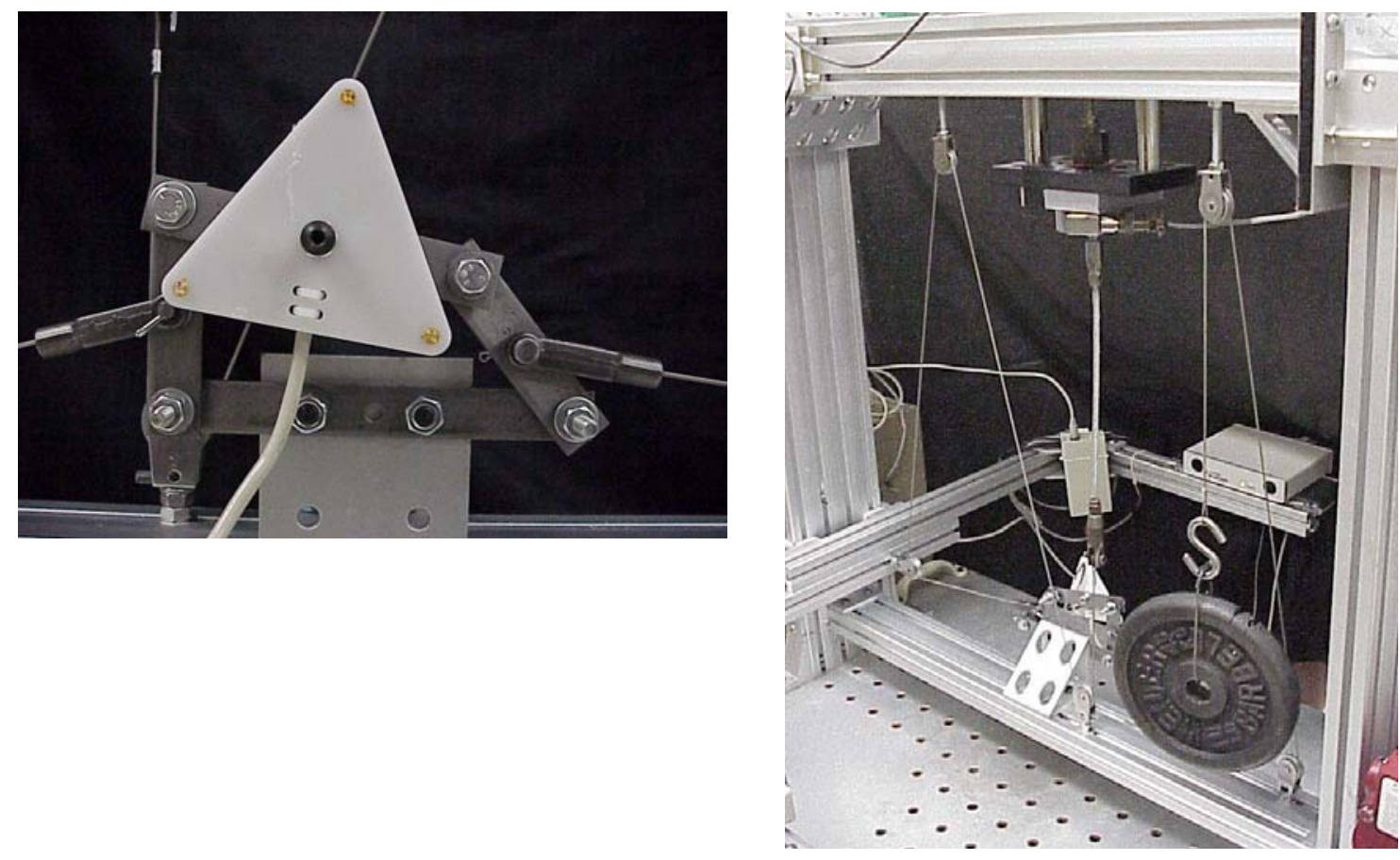

Fig. 8: Experimental setup for four bar testing. 


\section{In Vivo Testing}

The present research focuses on modeling the rotation and translation of the TMJ of healthy human subjects during opening and closing activities. Subjects for this project were chosen from the Department of Orthodontics and Department of Biomedical Engineering at the University of Tennessee Health Science Center (UTHSC). An initial questionnaire narrowed potential subjects to those who did not have a history of any temporomandibular disorders and had a negative medical history concerning craniofacial disorders, bone pathology, or compromised/impaired craniofacial structures, such as past jaw surgery or facial trauma. Independent clinical examinations were performed on each potential subject by two clinicians from the Department of Orthodontics. Each subject was checked for a full dentition ignoring third molars allowing for restorations including crowns or amalgams/composites, but excluding any other dental repair such as an implant or removable partial denture. Each subject was examined for any popping or clicking of the TMJ, pain upon opening or closing, restriction of maximum opening, occlusal interferences upon lateral excursion (only those with canine disclusion or group function were selected), and palpation for sensitivity of masticatory, neck and shoulder muscles. Those subjects eliciting any sign or symptom of the aforementioned were excluded from this study.

Finally, five subjects (five males), aged 26 to 29 (mean age 27.8 years) with an Angle Class I occlusion were chosen to participate in this research. Each subject had a panoramic radiograph taken and was examined for any major dental or skeletal 
discrepancy, and each subject submitted verbal consent to participate in this study. The clinical evaluation of each subject was approved by the Department of Orthodontics.

The condylar movement of each subject was measured with 6 LEDs (light emitting diodes). Three diodes registered the cranial base by means of a spectacle framework that was adjustable and removable. The other three diodes were fixed to a triangular target frame approximating the right condylar head that were attached by a screw positioned in an acrylic bite plate that was placed intraorally. The color coded acrylic (Dentsply) bite plate was subject-specific, was removable, and did not interfere with the opening or closing motion of the subjects as the occlusal coverage was removed from each bite plate.

The target frame was attached to the bite plate by means of a moldable template. The template was made of Macropore ${ }^{\mathrm{TM}}$ mesh (MacroPore OS). The mesh framework was stabilized by a series of small screws that allowed for rigid fixation as well as minimization of vibration.

Once the equipment was properly adjusted, measurement of the motion commenced. The sensor was centered approximately $200 \mathrm{~mm}$ from the target sets. This distance was used because previous target placement data showed this range to be optimal to reduce system error. Subjects were instructed to begin from an initial closed position and proceed to the maximum open position. A visual timer was provided so that subject could monitor his own movement with one cycle of motion taking approximately 5 seconds to open and 5 seconds to return to the original closed position. This period was selected to ensure that enough data points were captured by the $10 \mathrm{~Hz}$ frequency of 
the tracking system. Each subject underwent 3 runs consisting of three opening/closing cycles for each run (Figs. 9 through 12).

\section{Data Analysis}

The data from these runs were scanned for any sensor tracking errors. Using the coordinate data from the second target set, the raw coordinate data were zeroed. Then coordinate data from every run were plotted to find the most uniform, smoothest cycle for each subject. These cycles were then isolated from the rest of the data. Condylar path plots were constructed from the zeroed data. The zeroed data were then imported into a LabView routine designed to output screw/helical axis parameters defining motion from the initial position to each subsequent position regardless of the amount of rotation. This was done to find maximum translation and rotation values for each subject. Maximum translation and rotation values were averaged and the standard deviation was found. The same data were also imported into a LabView program that output only screw axis parameters at 10-degree intervals. All output parameters defining motion less than 9 degrees of rotation and exceeding 11 degrees of rotation were automatically omitted from the LabView output files. The output parameters were then plotted using equations 23 and 24 to plot the $\mathrm{Z}$ plane (sagittal plane) intercepts. The plane of interception was approximated to lie inside the condyle by setting the $\mathrm{Z}$ input distance medially an additional $15 \mathrm{~mm}$ (Gallo et al., 1997). The average and standard deviation of all the interception points were calculated from each subject. Threedimensional plots of the screw axes were also produced using a simple MatLab routine. 


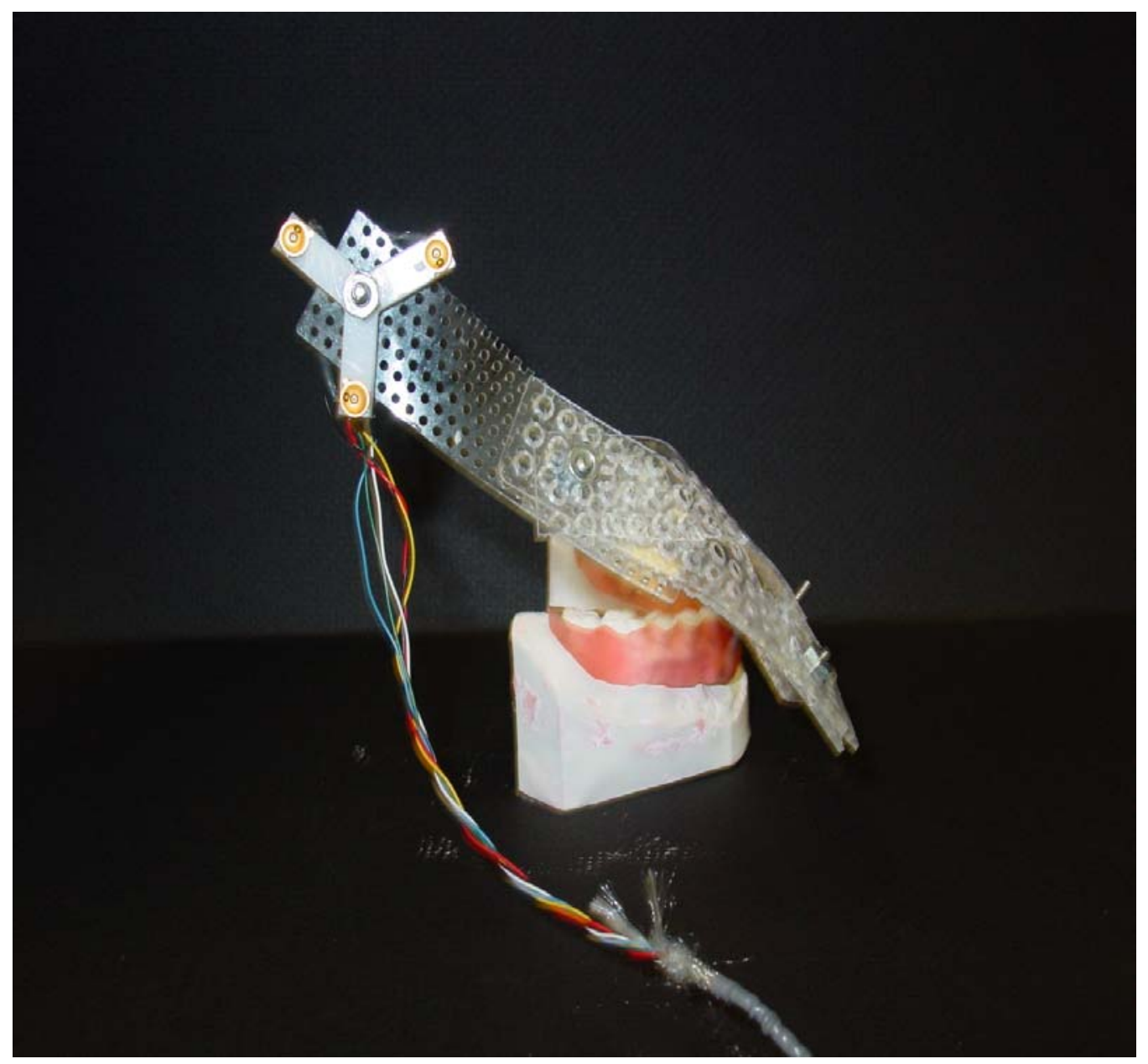

Fig. 9: LEDs, macropore ${ }^{\mathrm{TM}}$ framework, and bite plate (sagittal). 


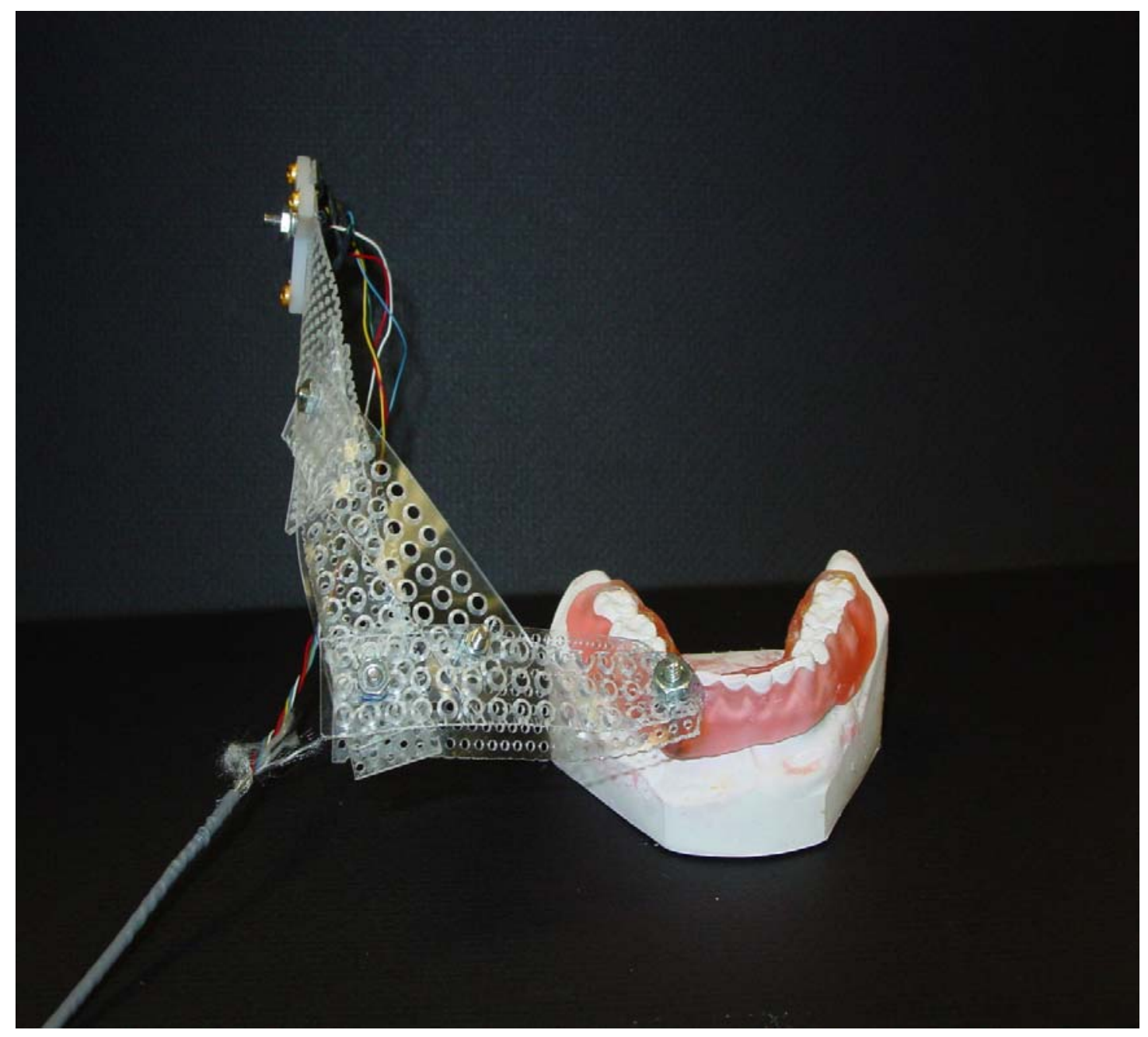

Fig. 10: LEDs, macropore ${ }^{\mathrm{TM}}$ framework, and bite plate (frontal). 


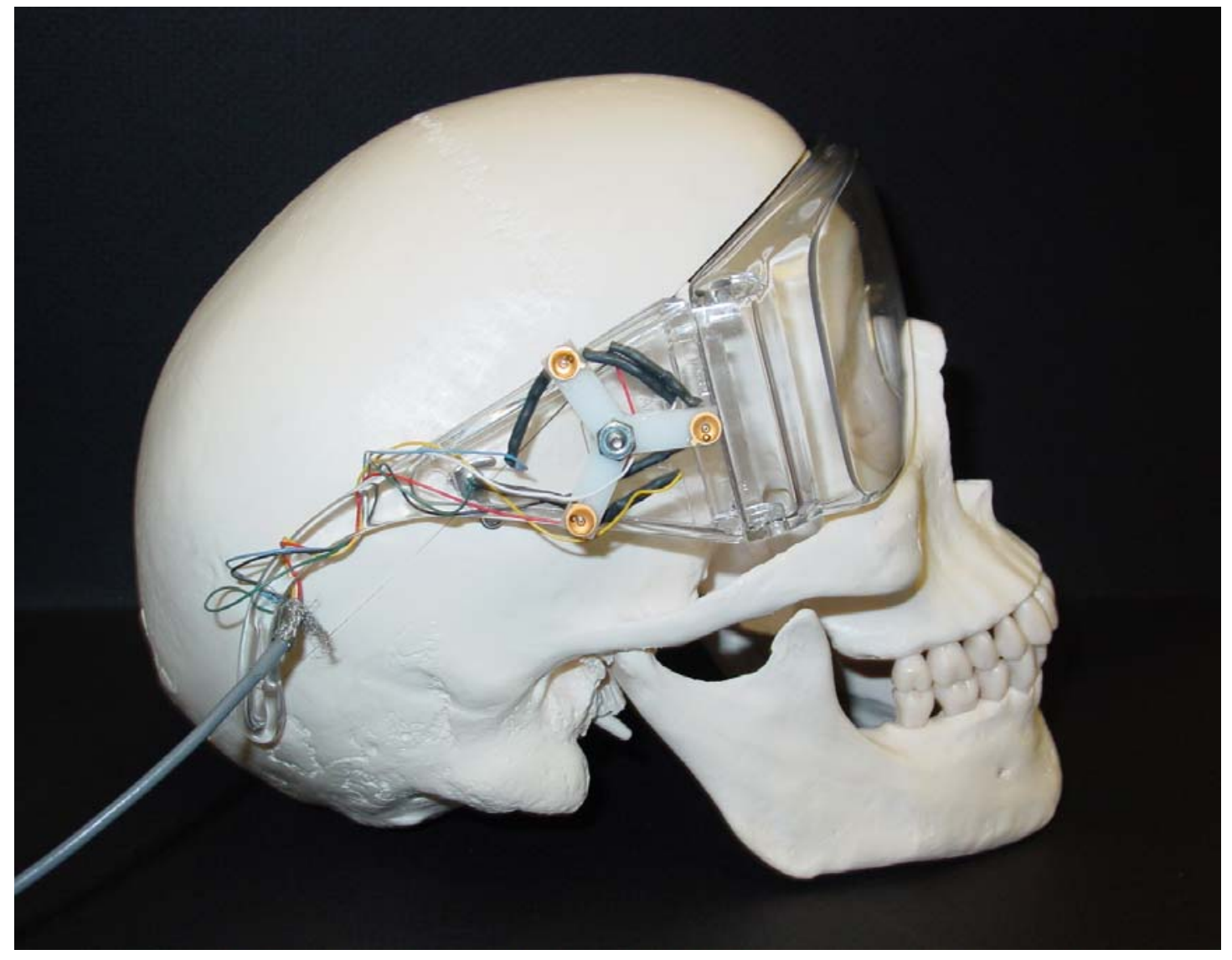

Fig. 11: Cranium with spectacles. 


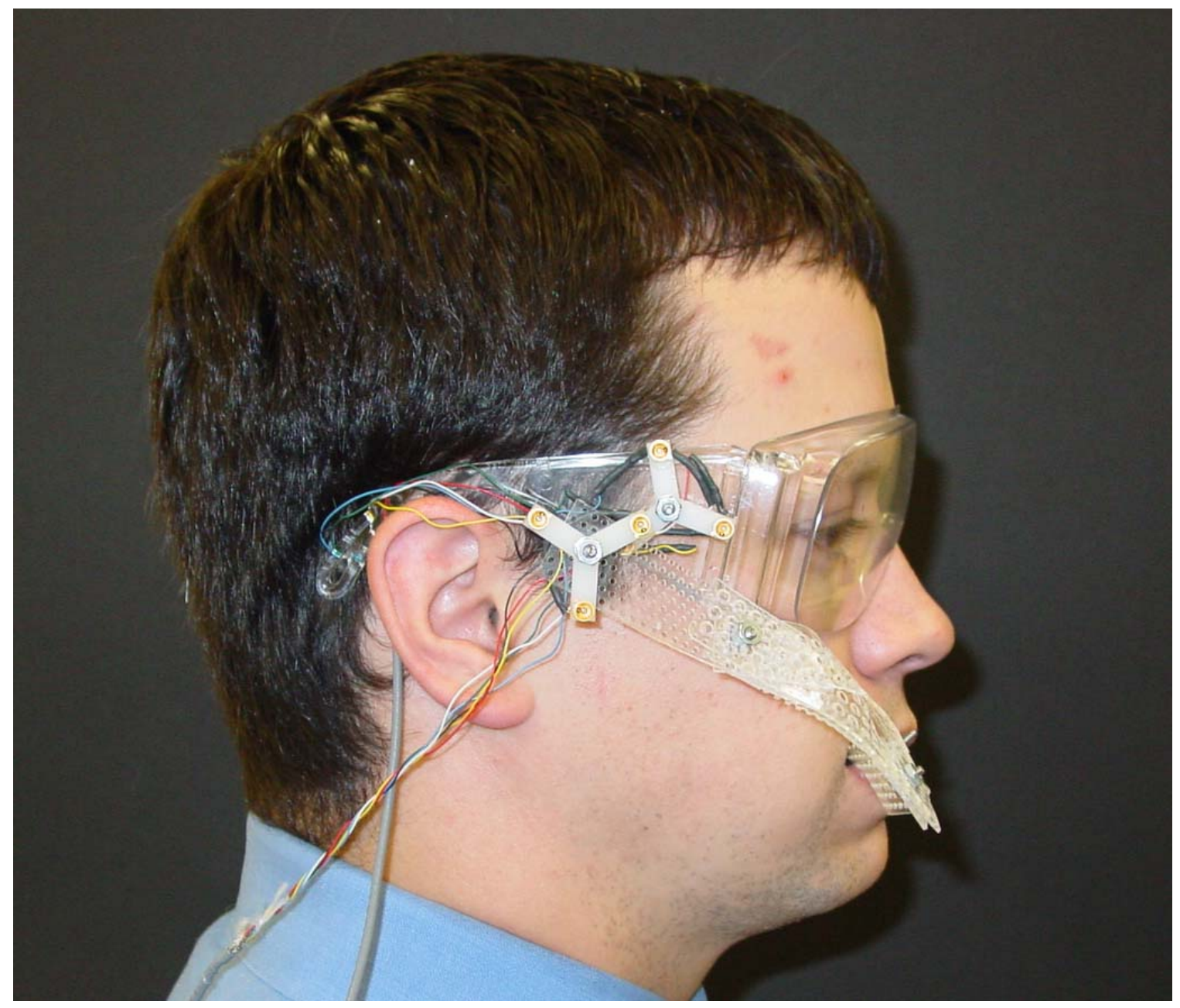

Fig. 12: Subject ready for motion analysis. 


\section{Section IV: Results}

In this research a three-part study was executed to better understand the camera error and the effect it had on the SDA calculation. The first part explored how error propagates through the equations for calculating the SDA by introducing a known amount of error to theoretically-obtained coordinate data. The second part assessed the roles differing conditions played in the amplitude of the error produced in the camera. The last part involves the process used to verify how well theoretical and experimental data compare.

A second focus of this research was to obtain in vivo jaw motion data and compare the findings with the description of mandibular motion in previous studies. Data presented contain rotational and translational components of the condylar path calculated from screw displacement axis equations, and interception points to the sagittal plane in the condylar space, as well as three-dimensional representation of the screw displacement axes for all subjects.

\section{Error Propagation and Uncertainty Values}

The Sequential Perturbation analysis yielded uncertainty values for both slope coefficients $\mathrm{k}_{\mathrm{x}}$ and $\mathrm{k}_{\mathrm{y}}$, and $\mathrm{x}_{\mathrm{o}}$ and $\mathrm{y}_{\mathrm{o}}$ the intercepts. The results of the perturbation can be seen in figures 13 through 16 and detailed results can be seen in Appendix A. 


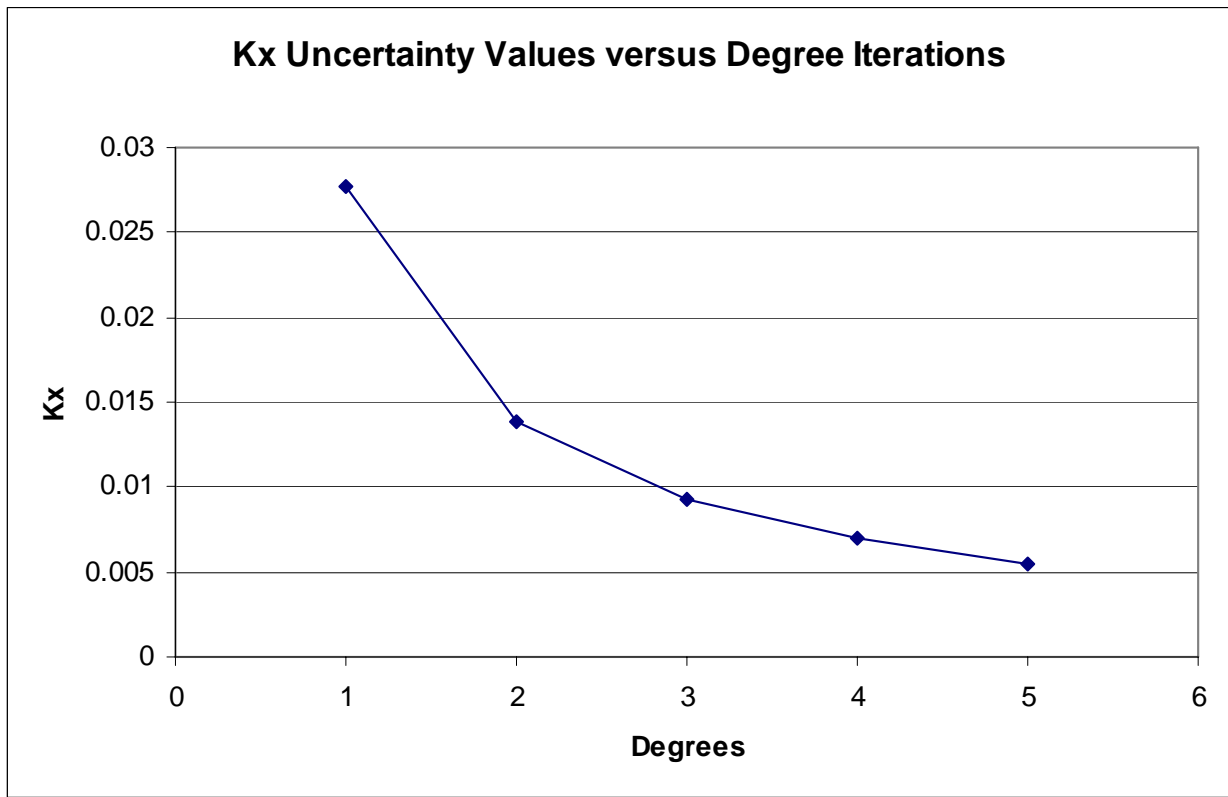

Fig. 13: Kx uncertainty values versus degree iterations.

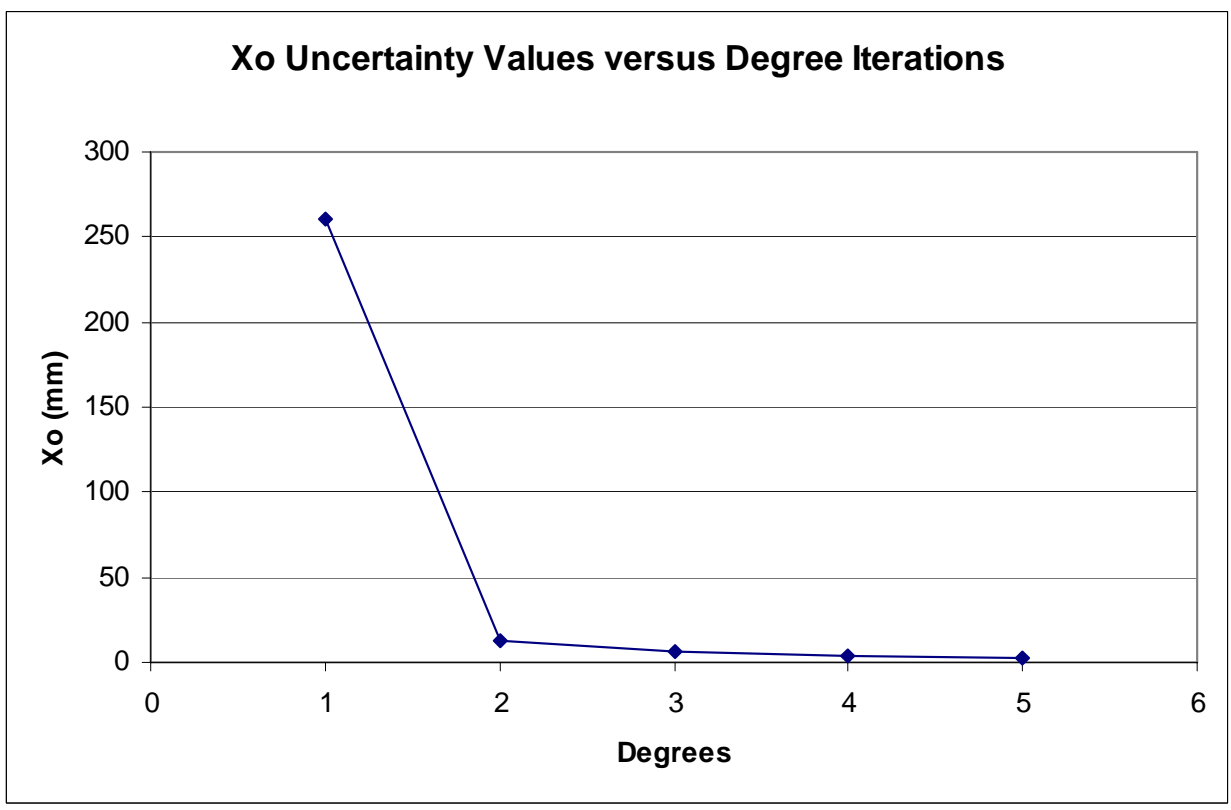

Fig. 14: Xo uncertainty values versus degree iterations. 


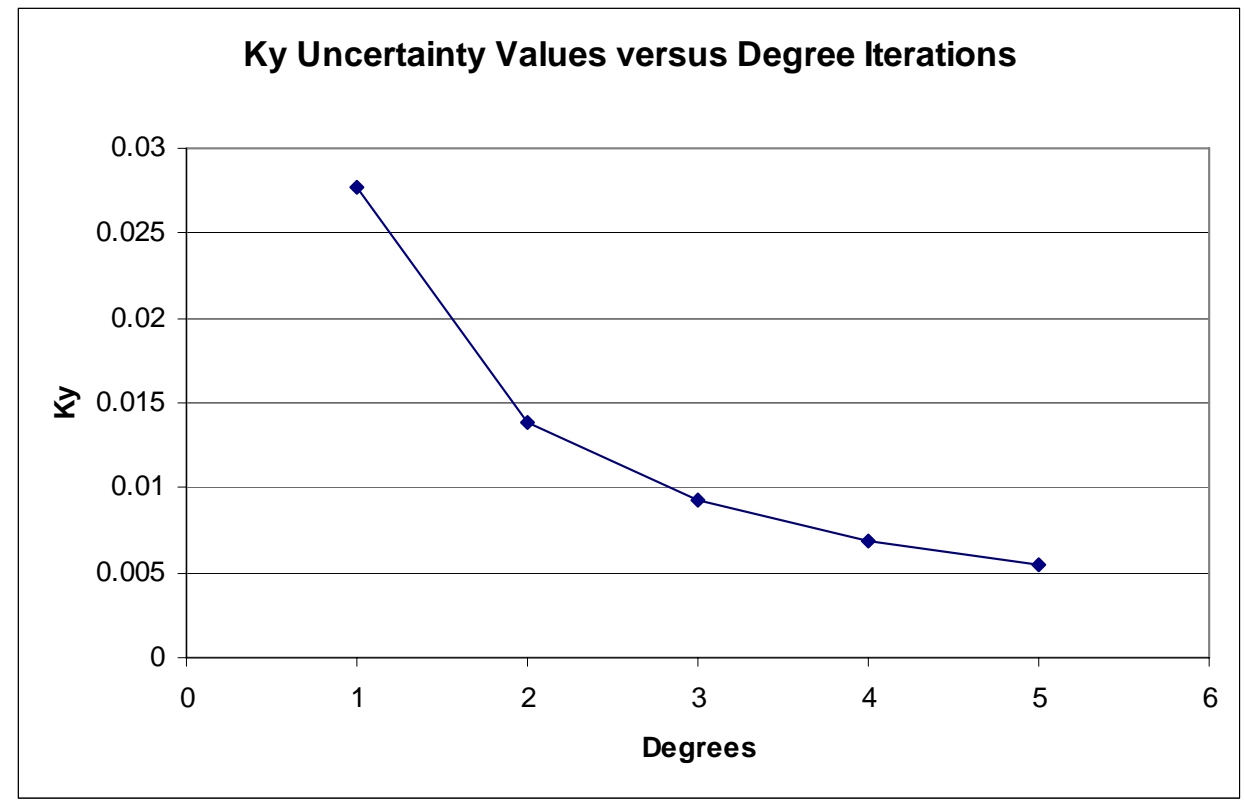

Fig. 15: Ky uncertainty values versus degree iterations.

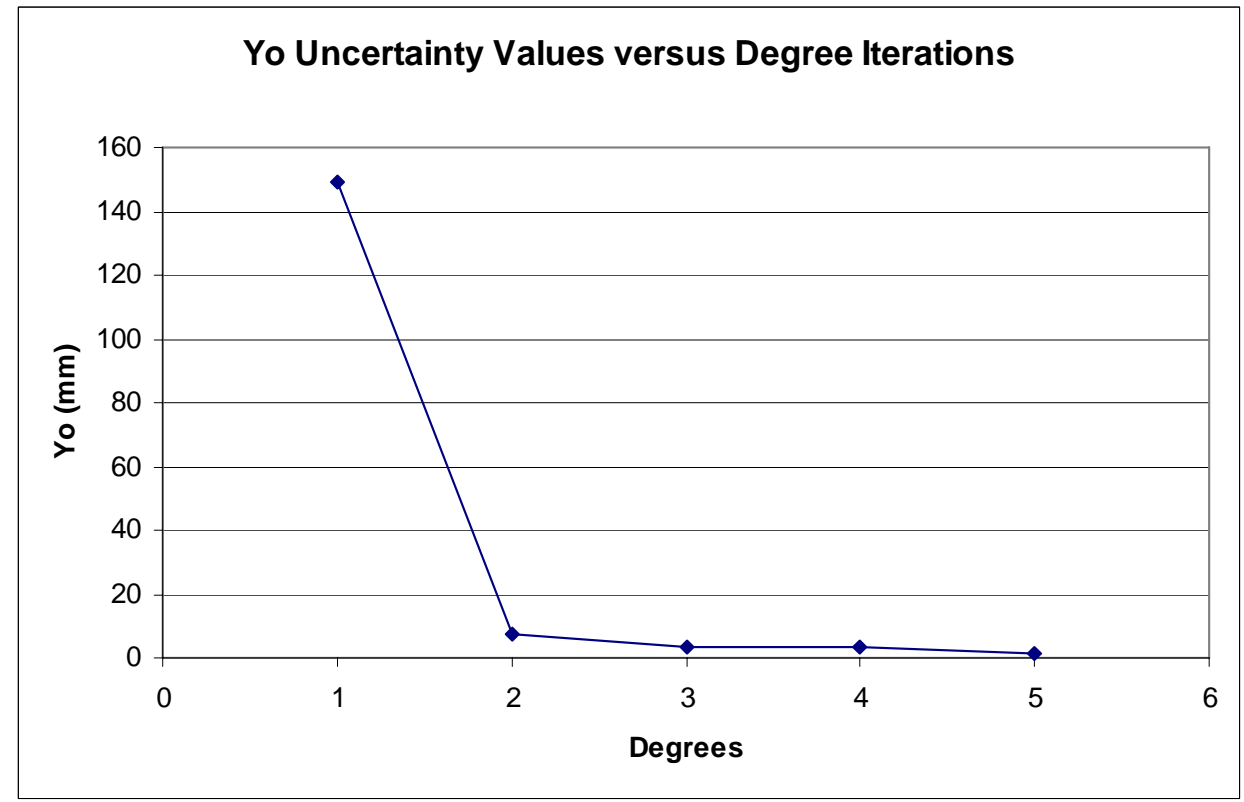

Fig. 16: Yo uncertainty values versus degree iterations. 


\section{Target Area Placement}

Results of the ANOVA showed that during constant motion along the X-axis no differing treatment introduced to the system produced a significant difference in the error amplitude of the $\mathrm{Y}$ coordinate data. The amplitude of the error in the $\mathrm{Z}$ coordinate data was statistically affected by varying $\mathrm{Y}$ coordinate distances from the origin and the distances from the camera in which the motion took place ( $\mathrm{Z}$ distances). The results and F-ratios for motion along the $\mathrm{X}$-axis are summarized in table 1. In conditions of varying the $\mathrm{Y}$ distance from the origin and the $\mathrm{Z}$ distance from the camera, further analysis using the Tukey multiple comparison test had to be conducted to find which treatments in two conditions differed. Tukey analysis of the treatments in the Y distance condition yielded a significant difference between all treatments. There was significant difference in the error amplitudes between $20 \mathrm{~mm}$ versus $60 \mathrm{~mm}, 60 \mathrm{~mm}$ versus $100 \mathrm{~mm}$, and $20 \mathrm{~mm}$ versus $100 \mathrm{~mm}$ treatments. In changing the $\mathrm{Z}$ distances, Tukey analysis displayed a significant difference between $300 \mathrm{~mm}$ versus $200 \mathrm{~mm}$ and $300 \mathrm{~mm}$ versus $250 \mathrm{~mm}$ cases.

Table 1: $\mathrm{X}$ motion ANOVA results.

\begin{tabular}{|l|c|c|c|}
\hline \multicolumn{1}{|c|}{ Condition } & F & F crit & $\begin{array}{l}\text { Treatments differ } \\
\text { statistically }\end{array}$ \\
\hline Y peak to trough varied velocity & 0.039 & 3.220 & No \\
\hline Y peak to trough varied Y dist. & 3.111 & 3.220 & No \\
\hline Y peak to trough varied Z dist. & 0.423 & 3.220 & No \\
\hline Z peak to trough varied velocity & 0.248 & 3.220 & No \\
\hline Z peak to trough varied Y dist. & 5.927 & 3.220 & Yes \\
\hline Z peak to trough varied Z dist. & 4.743 & 3.220 & Yes \\
\hline
\end{tabular}


Detailed ANOVA and Tukey comparison as well as mean peak to valley data for X motion can be seen in Appendix B.

Analyses for motion along the $\mathrm{Y}$-axis were performed the same way as for motion along the $\mathrm{X}$-axis. For the $\mathrm{X}$ coordinate data, change of any of the conditions resulted in a significant difference in the error amplitude. These results are provided in table 2. Tukey analysis for the variation of velocity displayed a significant difference between all treatments. Altering the distance from the origin and from the camera exhibited significant differences between all treatments as well. The amplitude of the error in the $\mathrm{Z}$ coordinate data was statistically affected by varying the $\mathrm{X}$ coordinate distances from the origin and the distances from the camera, but no discernible difference was produced by varying the velocity of the moving object. These results are summarized in table 2. Tukey analysis for error amplitude in the $\mathrm{Z}$ coordinate data showed that altering the distance from the origin and camera exhibited significant differences between all treatments. In depth ANOVA and Tukey calculations as well as mean peak to valley data for Y motion data can be seen in Appendix B.

Table 2: Y motion ANOVA results.

\begin{tabular}{|l|c|c|c|}
\hline \multicolumn{1}{|c|}{ Condition } & $F$ & $F$ crit & Treatments differ statistically \\
\hline X peak to trough varied velocity & 3.320 & 3.220 & Yes \\
\hline X peak to trough varied X dist. & 9.363 & 3.220 & Yes \\
\hline X peak to trough varied Z dist. & 11.795 & 3.220 & Yes \\
\hline Z peak to trough varied velocity & 0.085 & 3.220 & No \\
\hline Z peak to trough varied X dist. & 9.086 & 3.220 & Yes \\
\hline Z peak to trough varied Z dist. & 19.298 & 3.220 & Yes \\
\hline
\end{tabular}


The inability of varying the velocity to result in a statistical difference in three out of four cases prompted further investigation. Y coordinate data for the same path but differing velocities were superimposed on one graph (Fig. 17).

\section{Experimental Data Validation}

The paths of motion for a four bar linkage are shown in figure 18. The loop equation series represents the instantaneous center path of motion (centrode) based on loop equation analysis (Hobson and Torfason, 1975) through 15 degrees of motion at onedegree increments. The SDA theoretical series plots the Z-plane intercepts of screw displacement axes for identical four-bar motion with theoretically obtained X, Y coordinate data from the loop analysis equations. In representation of two-dimensional

four bar motion there should be no change in the plane of the Z-axis; so it was chosen to remain at an arbitrary distance from the sensor. The SDA series consists of 10-degree iterations between data points; that is, the first point displays the axis based on an initial coordinate set at 1 degree of rotation and a final coordinate set at 11 degrees of rotation. The theoretical series displays the finite center of rotation (FCR) values based on Crisco's (Crisco et al., 1994) formulas for 10-degree increments. The SDA experimental series shows screw displacement axis intercepts to the $\mathrm{Z}$ plane at 10-degree iterations with coordinate data supplied by the motion tracking system. 


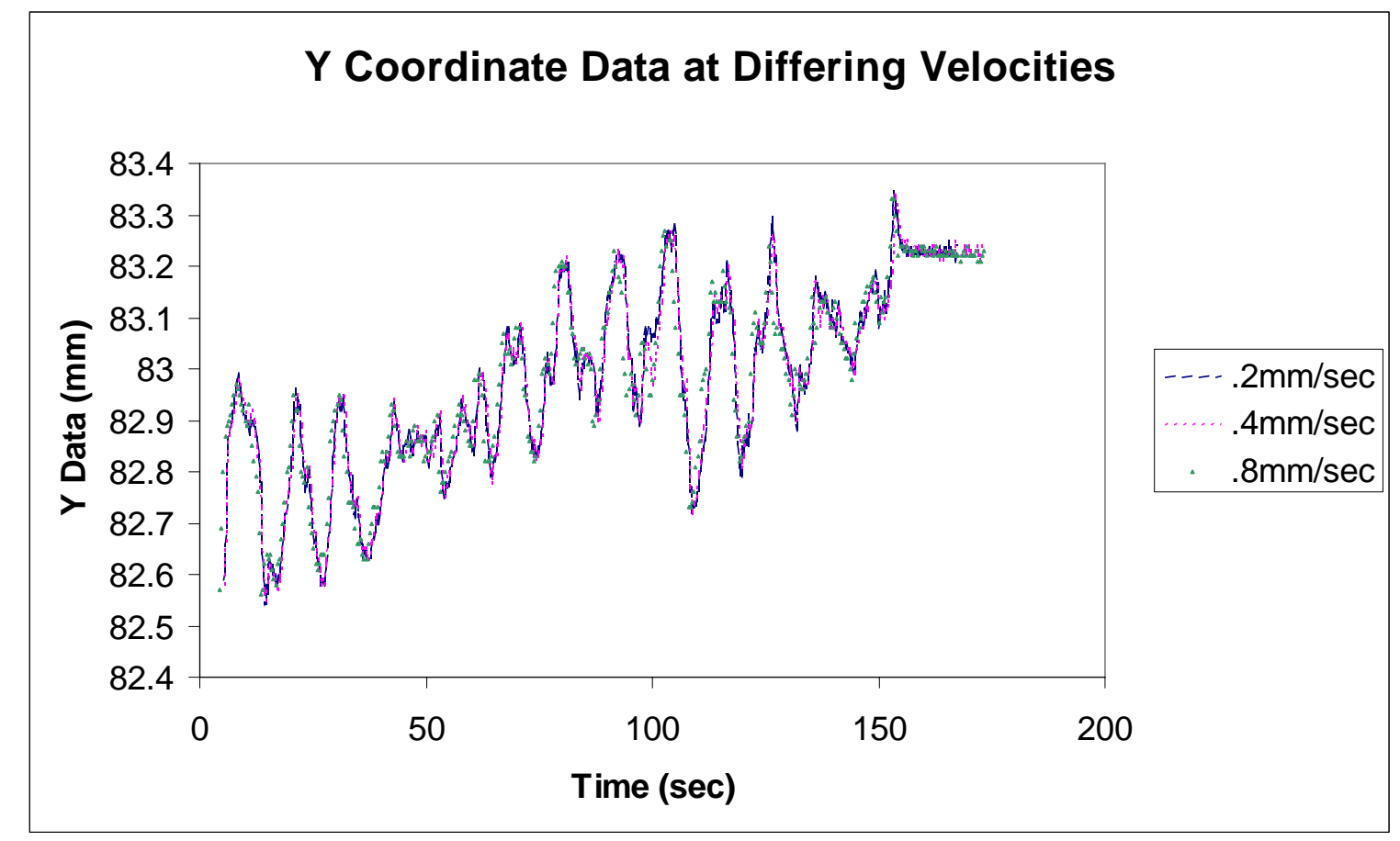

Fig. 17: $Y$ coordinate data at differing velocities. Data are observed through the same path of motion with varying velocities. 


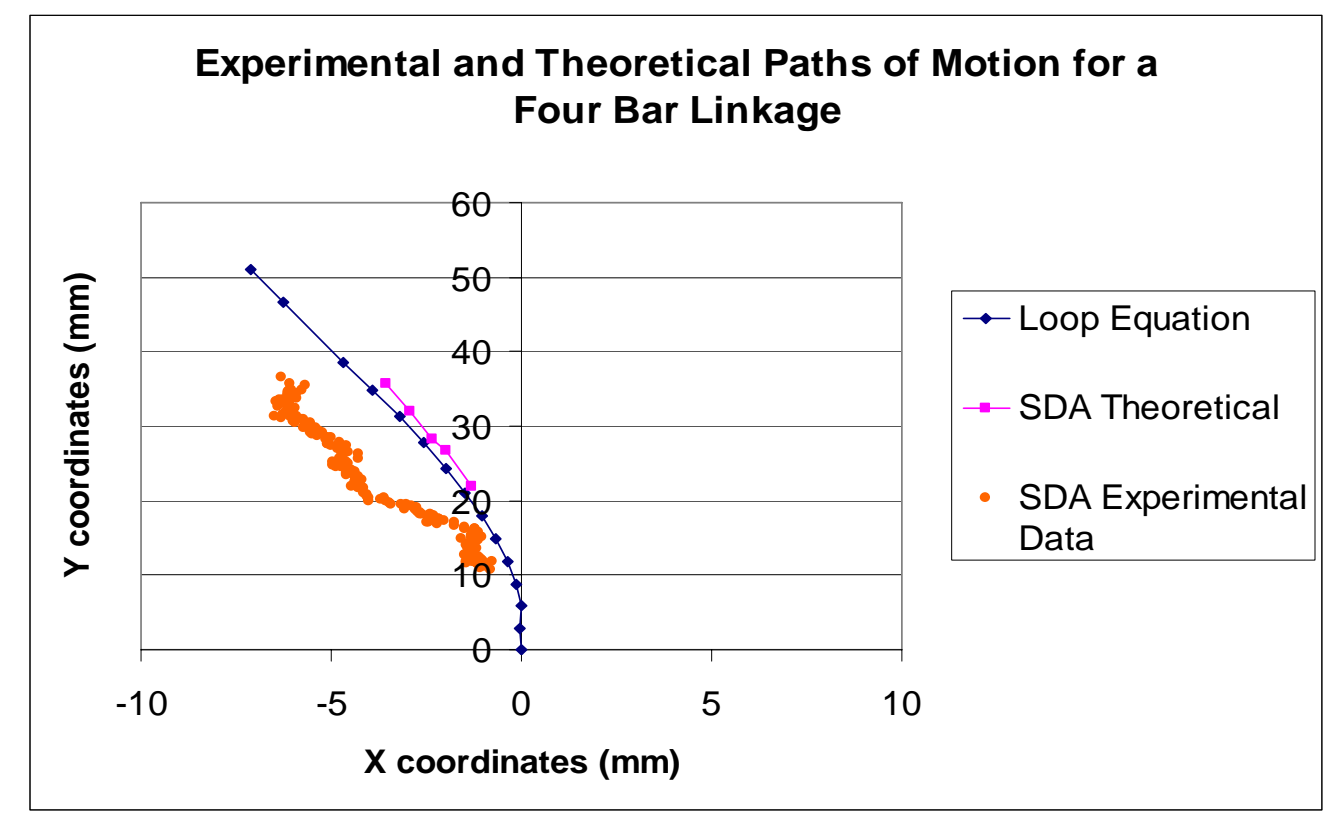

Fig. 18: Experimental and theoretical paths of motion for a four bar linkage. 


\section{In Vivo Mandibular Motion}

Motion data for each asympotomatic subject was obtained and processed by means of the SDA software and motion tracking system.

\section{Condylar Path}

The condylar path for each subject was plotted with zeroed coordinate data. The results for subject 1 are shown in figure 19; similar results occurred for the remaining subjects and are included in Appendix C. All paths proceeded anteriorly and inferiorly during opening and then posteriorly and superiorly during closing. All motions ended within a $2.5 \mathrm{~mm}$ radius of initial position.

\section{SDA Translation and Rotation Motion of the Jaw}

Translation and rotation were plotted for each subject as seen in figures 20 and 21 (see Appendix D). Maximum values were taken from each data set, and means and standard deviations of maximum values were computed and displayed in tables 3 and 4 . 


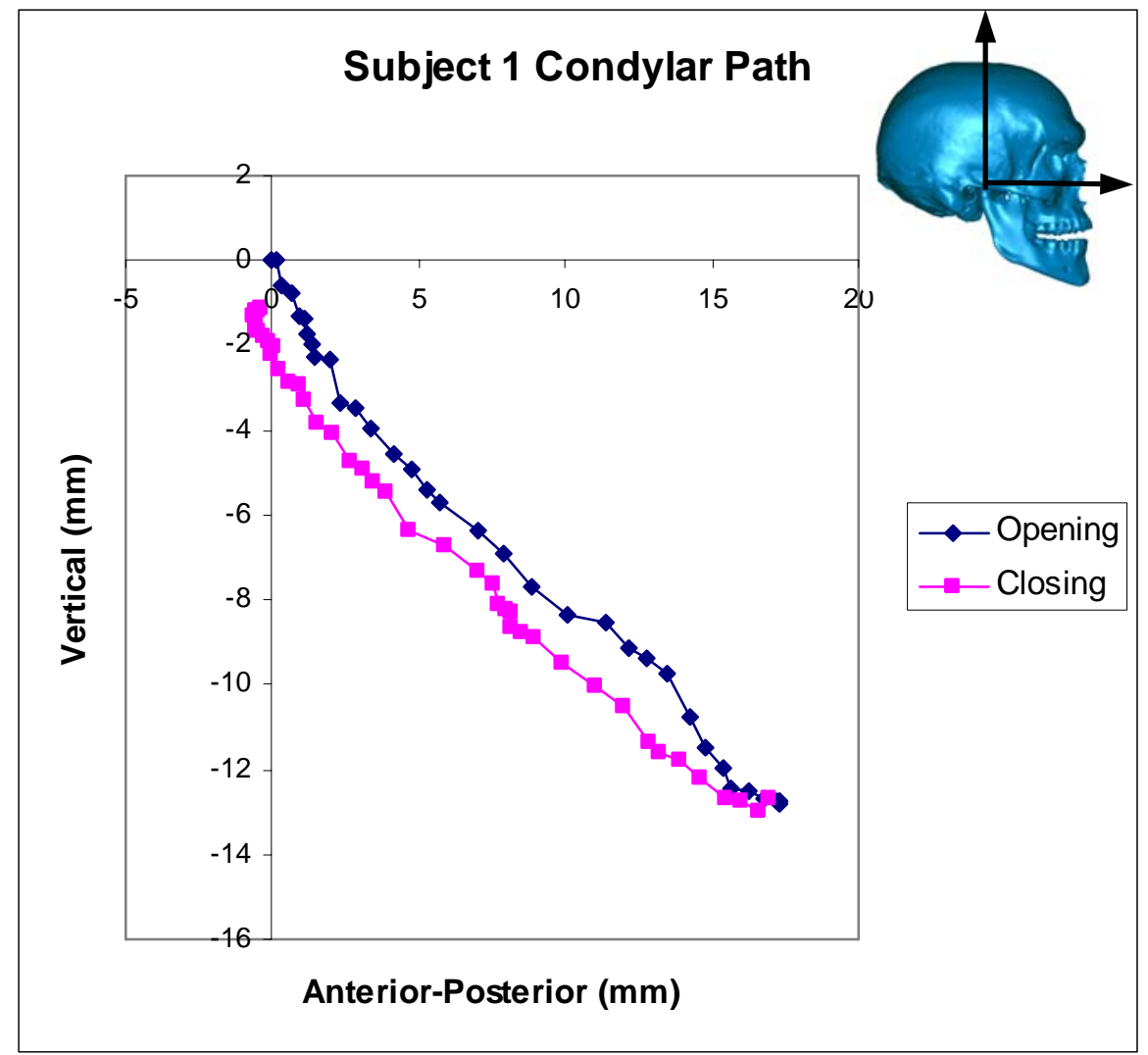

Fig. 19: Condylar path for subject 1. Origin is in the center on the condyle. 


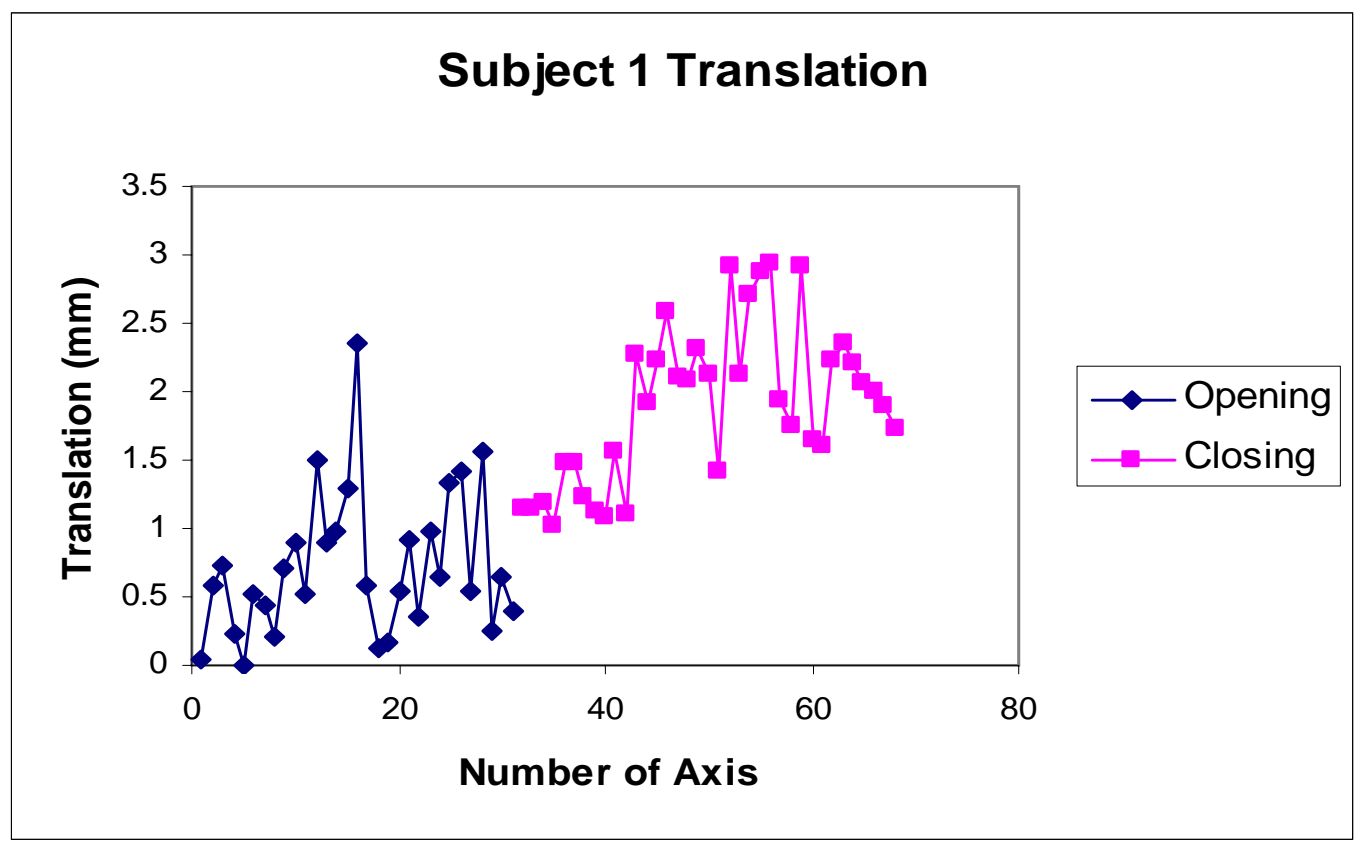

Fig. 20: Plot of translation of motion data for one cycle of opening and closing. 


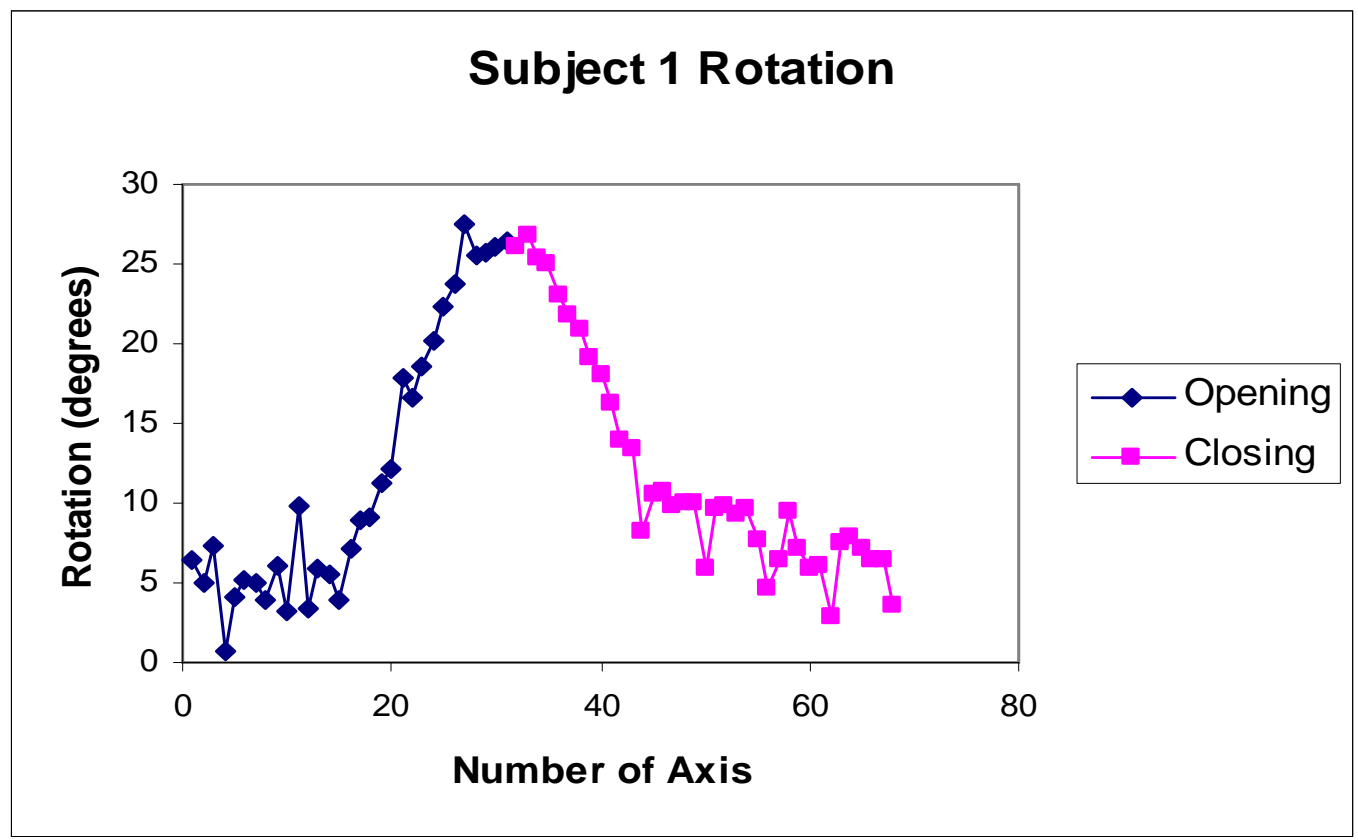

Fig. 21: Rotation through one cycle of opening and closing for subject 1. 
Table 3: Maximum translation results along SDA.

\begin{tabular}{|c|c|}
\hline Subject & $\begin{array}{c}\text { Maximum } \\
\text { Translation }(\mathrm{mm})\end{array}$ \\
\hline 1 & 2.9 \\
\hline 2 & 2.9 \\
\hline 3 & 1.4 \\
\hline 4 & 1.8 \\
\hline 5 & 2.5 \\
\hline Mean & 2.3 \\
\hline Std. Dev. & 0.7 \\
\hline
\end{tabular}

Table 4: Maximum rotation results along SDA.

\begin{tabular}{|c|r|}
\hline Subject & \multicolumn{2}{|c|}{$\begin{array}{c}\text { Maximum } \\
\text { Rotation } \\
\text { (degrees) }\end{array}$} \\
\hline 1 & 27.6 \\
\hline 2 & 21.5 \\
\hline 3 & 19.8 \\
\hline 4 & 28.6 \\
\hline 5 & 27.4 \\
\hline Mean & 25.0 \\
\hline Std. Dev. & 4.0 \\
\hline
\end{tabular}




\section{Two-Dimensional and Three-Dimensional Representation of SDA}

A plot of interception points of screw displacement axes into the sagittal plane of the condyle was created to display a two-dimensional analysis comparable to previous IAR studies (Fig. 22). The SDA parameters were further plotted three-dimensionally for transversal width of $\pm 15 \mathrm{~mm}$ from the estimated condylar sagittal plane as seen in figures 23 and 24. The plots for subjects 2 through 5 are shown in Appendix E. The locations of the condyle and condylar axis also are displayed on all figures. Mean Sagittal plane intercepts were plotted to give a description of the relation of the paths between subjects (Figs. 25 and 26). A summary of SDA parameters is also provided (Table 5) and compared to the results of Gallo et al. (1997). A Student t-test found a significant difference of $p \leq 0.05$. 


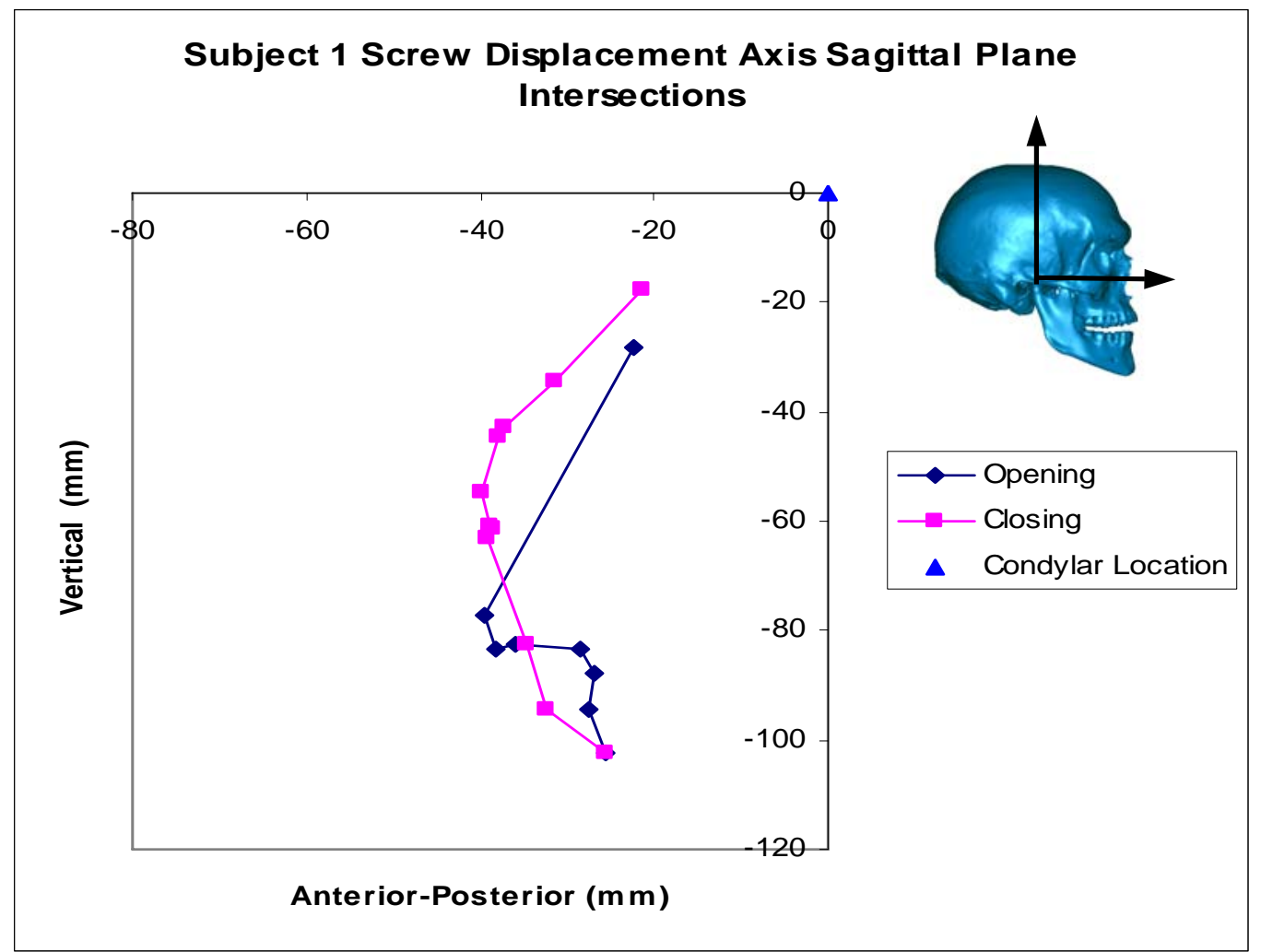

Fig. 22: Two-dimensional representation of SDA sagittal plane intercepts. 


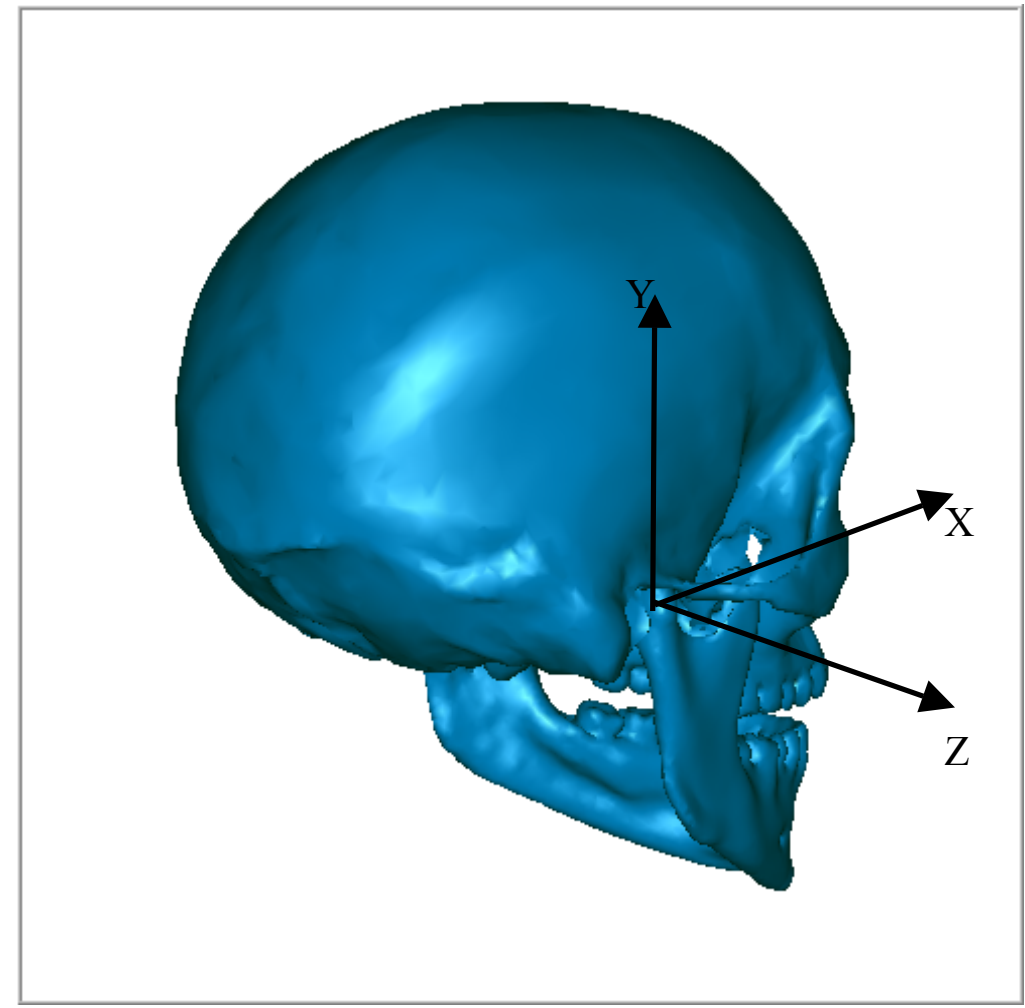

Fig. 23: Definition of coordinate system for SDA. 


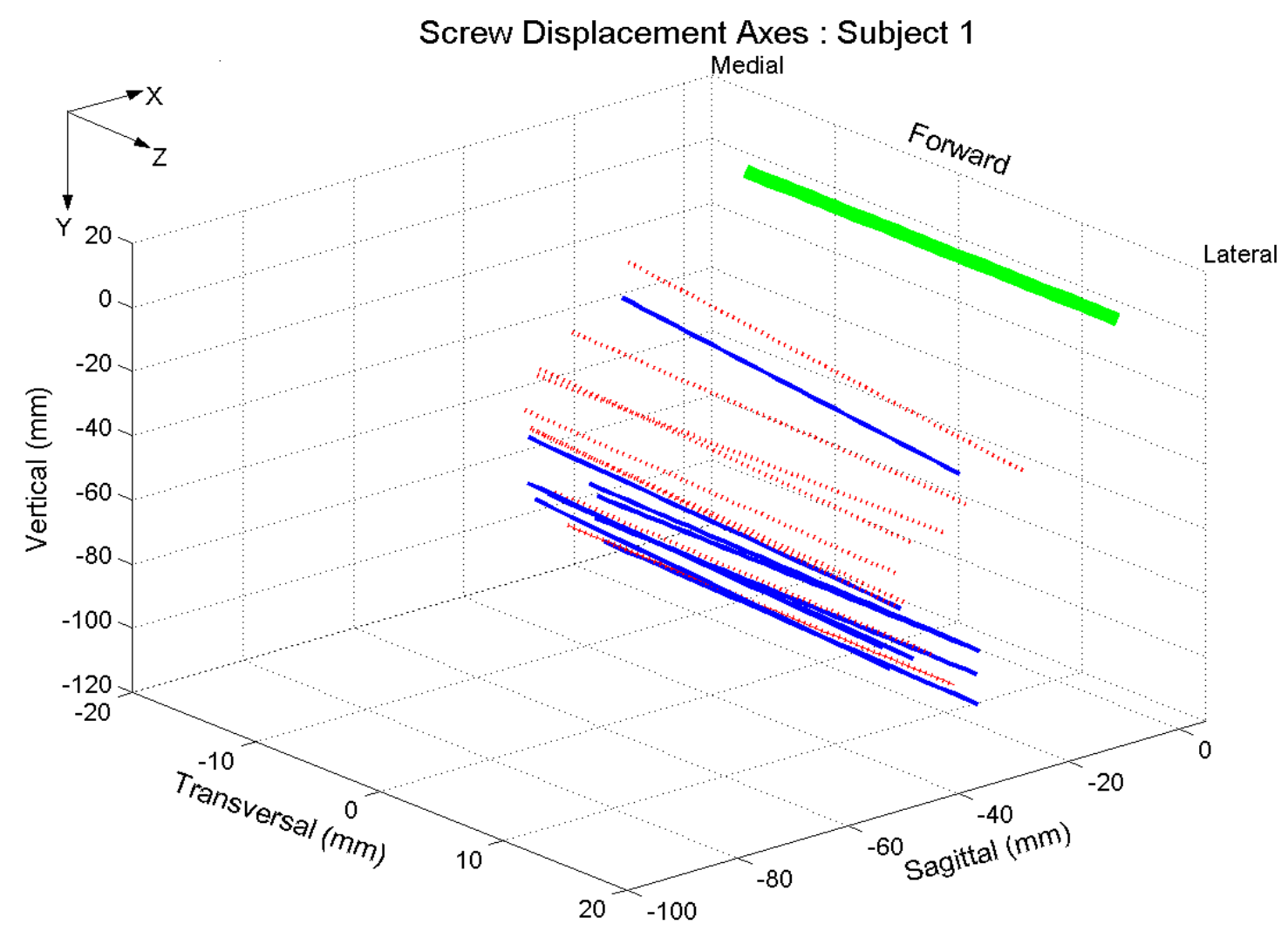

Fig. 24: Three-dimensional display of screw displacement axes for one cycle of mandibular motion. The solid blue axes denote opening motion and the dashed red axes denote closing motion. The thick green line is the axis of the condyles. 


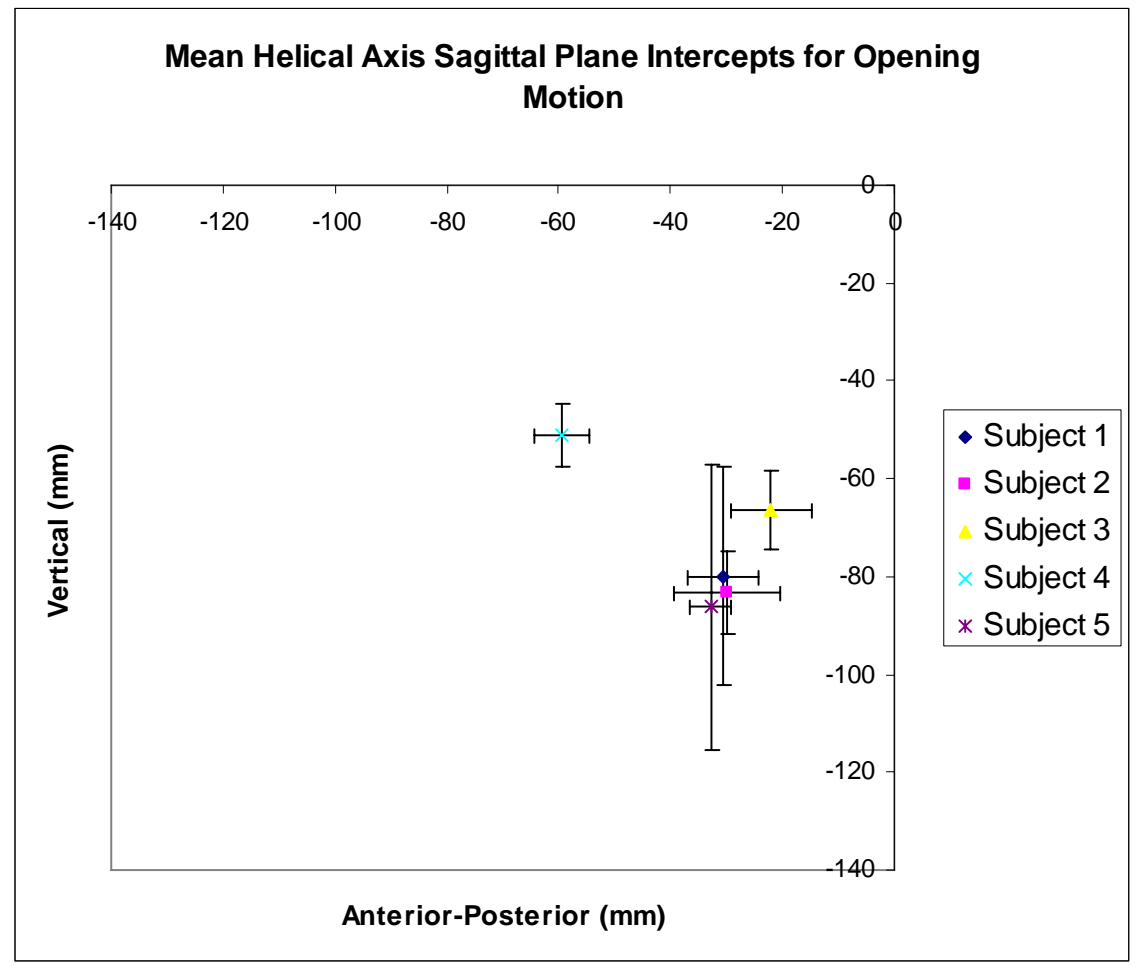

Fig. 25: Mean values of sagittal plane intercepts (opening). ( \pm standard deviation) The selected center of the condyle lies at the origin. 


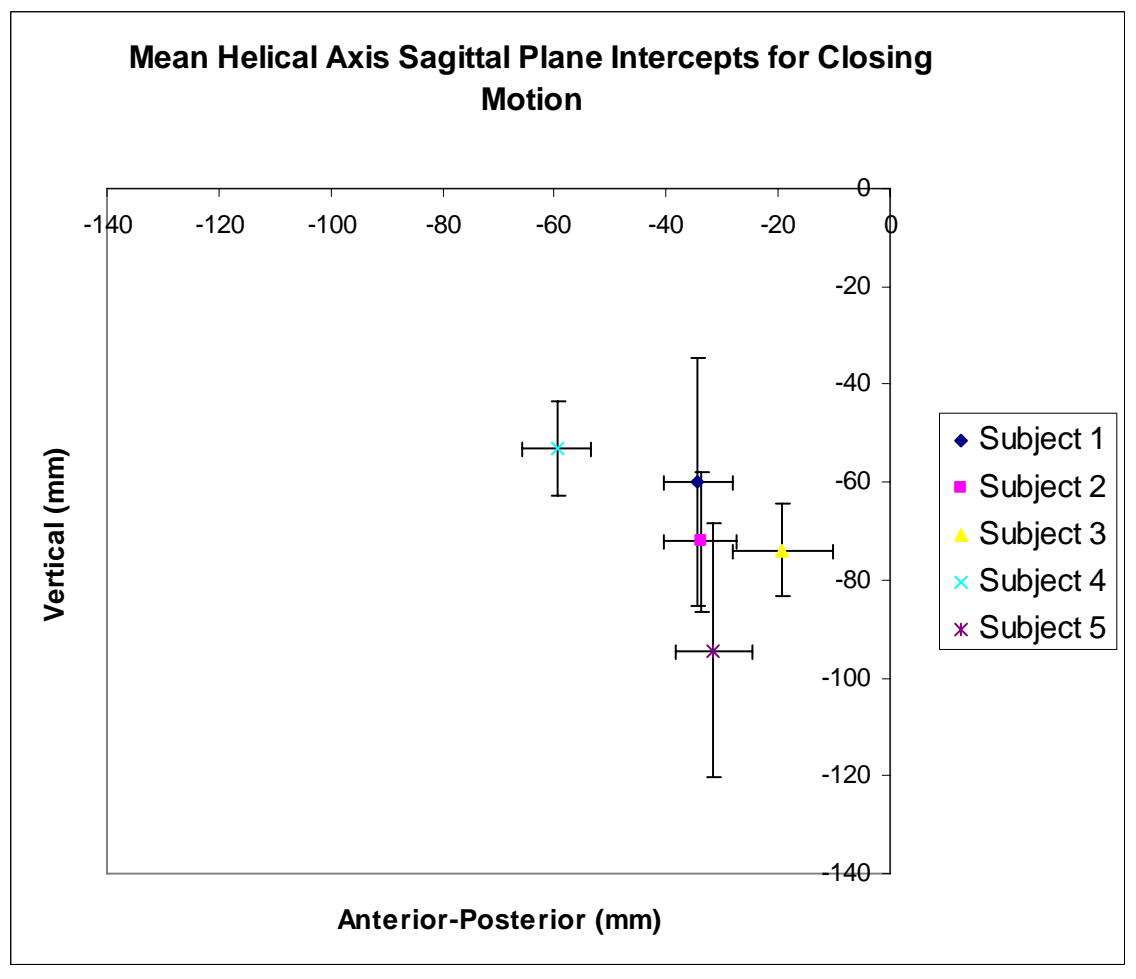

Fig. 26: Mean values of sagittal plane intercepts (closing). ( \pm standard deviation) The selected center of the condyle lies at the origin. 
Table 5: Summary of screw displacement parameters (Gallo 1997 results in parentheses).

\begin{tabular}{|l|c|c|c|}
\hline \multicolumn{1}{|c|}{ Parameter } & Mean & Std. Dev. & $\begin{array}{c}\text { Difference in } \\
\text { Means }\end{array}$ \\
\hline Maximum anterior displacement $\mathrm{x}_{\mathrm{a}-\mathrm{p} \max }(\mathrm{mm})$ & $-25.3(4.7)$ & $16.3(9.2)$ & Yes \\
\hline Maximum posterior displacement $\mathrm{x}_{\mathrm{a}-\mathrm{p} \min }(\mathrm{mm})$ & $-44.6(-27.6)$ & $14.6(5.0)$ & Yes \\
\hline Maximum superior displacement $\mathrm{x}_{\mathrm{vertmax}}(\mathrm{mm})$ & $-40.5(-12.4)$ & $15.5(6.8)$ & Yes \\
\hline Maximum inferior displacement $\mathrm{x}_{\mathrm{vertmin}}(\mathrm{mm})$ & $-91.3(-44.5)$ & $19.5(9.8)$ & Yes \\
\hline Mean Orientation relative to X-axis $\Theta_{\mathrm{x}}($ degrees $)$ & $88.7(89.2)$ & $6.4(4.0)$ & No \\
\hline Mean Orientation relative to Y-axis $\Theta_{\mathrm{y}}($ degrees $)$ & $93.6(91.3)$ & $8.6(3.9)$ & No \\
\hline Mean Orientation relative to Z-axis $\Theta_{\mathrm{z}}($ degrees) & $13.12(7.5)$ & $8.8(3.2)$ & Yes \\
\hline Mean Translation along SDA t $(\mathrm{mm})$ & $2.3(0.9)$ & $0.7(0.7)$ & Yes \\
\hline Mean Maximum Rotation about SDA $\Theta($ degrees $)$ & $25.0(24.3)$ & $4.0(4.2)$ & No \\
\hline
\end{tabular}

$* \alpha .=0.05$ and $\mathrm{p} \leq 0.05$ 


\section{Section V: Discussion}

\section{Uncertainty}

This study's analysis of the uncertainty encountered with screw displacement axis calculations extended Bottlang's (Bottlang et al., 1998) analysis and matched Duck's (Duck et al., 2004) study by simulating error produced at initial and final positions of motion by a moving body. Error was chosen to be a constant 20 microns since that is the highest resolution of the Dynasight ${ }^{\mathrm{TM}}$ sensor. At small rotation increments figures 13 through 14 show a large uncertainty when a small amount of target position error is introduced into the SDA calculation formulas. Screw displacement axis position and orientation parameters displayed an inverse relationship relative to the rotational increment. As rotational increments approached 5 degrees, there was little change in the uncertainty values, indicating that data should be processed at increments of at least 4 to 5 degrees. This outcome agrees with the results presented in Bottlang et al. (1998) and Duck et al. (2003).

\section{Target Placement}

Coordinate data obtained with the tracking system displayed an error as seen in figure 7. This error was not present when the targets were stationary, nor did it change with a change in velocity (Fig. 14). These observations lead to the idea that the error associated with the tracking system relies purely on the position of the target. Also, the 
error is repeatable based on target position. This shows that the error is systematic and does not follow a random path. The coordinate data, therefore, cannot be improved using traditional methods of filtering or smoothing (Figliola and Beasley, 2000). The only way to counter the error of the system was to raise the rotational increments in data processing and find an area in the viewing field of the sensor that produces the least error. The results of testing for an ideal area for the sensor to view the targets produced some conclusive data. The first test showed that there was no relation between velocity changes and the $Z$ data inaccuracy $(p=0.782)$. The second test showed there was a significant difference in induced $\mathrm{Z}$ data inaccuracy when the $\mathrm{Y}$ position was changed ( $\mathrm{p}$ $=0.0045)$. However, no trend was observed in the mean peak-to-trough values of the three testing conditions. This suggests there is no way of finding an optimum Y value area. The third test $(\mathrm{p}=0.0139)$ achieved significance between two of the three testing conditions. More importantly, a trend was noticed in the mean $\mathrm{Z}$ inaccuracies. As the $\mathrm{Z}$ distance from the camera decreased so did mean inaccuracy. However, by bringing the targets closer to the camera in the $\mathrm{Z}$ axis, the viewing area of the camera decreases. The closest the targets can be brought to the camera while maintaining a viewing area large enough to test jaw motion is in the range of 150-200 $\mathrm{mm}$ from the sensor.

\section{Data Validation}

Instantaneous center path of motion representation obtained from the loop analysis program shows the best theoretical representation of motion. The SDA intercept and FCR paths of motion taken at 10-degree increments display identical paths, showing 
that the SDA is a three dimensional representation of the FCR. These paths also display less information about the path of motion produced by the four bar mechanism. Information from the beginning and end of the motion is lost due to the use of finite measurements.

The experimental data obtained from the SDA intercepts at 10-degree iterations of the four bar linkage show a path similar to the results of the theoretical analyses. There is a small offset and larger scatter than the theoretical 10-degree iterations show, but this can be attributed to the inaccuracy of the motion testing system.

\section{Condylar Path}

Numerous studies have evaluated the performance of temporomandibular joints using the trajectory of condylar paths (Clayton, 1985; Gsellmann et al., 1998; Nagerl et al., 1999; Piehslinger and Ertl, 1995; Sadat-Khonsari et al., 2003; Zwijnenburg et al., 1996). In the present study all condylar paths proceeded anteriorly and inferiorly during opening and then posteriorly and superiorly during closing returning to within a $2.5 \mathrm{~mm}$ radius of the starting position. These results agree with the study by Lindauer et al., but many follow-up studies have shown that the course of the condylar path during opening and closing movement depends mainly on the position of the reference point (Lindauer $e t$ al., 1995; Nagerl et al., 1999; Zwijnenburg et al., 1996). This implies that if differing reference points are selected for the same motion, significantly different paths of motion will be reproduced. The reliance on reference point position may give rise to the misinterpretation of data and lessen the diagnostic relevance of condylar path results. 


\section{Translation}

Lateral mandibular movement can be expressed by translation along the screw displacement axes. Mean translation along the screw displacement axes of this study was $2.3 \mathrm{~mm}$ with a standard deviation of $0.68 \mathrm{~mm}$, disclosing very little lateral deviation. There is only one comparable study displaying screw displacement axis translation during opening and closing cycles (Gallo et al., 1997). Their mean translation value was $0.9 \mathrm{~mm}$ with a standard deviation of $0.7 \mathrm{~mm}$. The translation values from the Gallo study were lower than the translation values for the present study. However, this can probably be attributed to the larger step size of 10 degrees used rather than the step size of 1 degree.

\section{Rotation}

The mean maximum rotation around the screw displacement axes for this study was 25.0 degrees with a standard deviation of 4.0 degrees. Gallo et al. (1997) is the only published study providing maximum rotational values about screw displacement axes for mandibular motion. Their mean rotation value was 24.3 degrees with a standard deviation of 4.2 degrees. There was no statistical difference $(\alpha=0.05)$ between these results and the results of Gallo, showing that maximum rotation agreement between the two studies is high. 


\section{SDA Representation}

Both the SDA intersection with the sagittal plane of the condyle and the threedimensional plots of the screw displacement axes were displayed for clarity. The data shown are described in relation to the position of the condylar head. This was done to make clear whether the path of the screw displacement axes lay through the condyle. The SDA intersection plots showed that the paths of motion for all subjects were posterior and inferior to the condyle. During opening, paths start nearer to the condyle and travel inferiorly and anteriorly. Jaw closing caused an opposite direction of path (superior and posterior), and the final motion approximated the area of the initial axis. The results produced by Sadat-Khonsari et al. displayed the same SDA path but with an additional anterior and superior motion at the end of the opening phase of the cycle. This discrepancy could be accounted for by the difference in degree iterations of the two studies. A 10-degree iteration would cut a larger amount of data from the beginning and the end of the motion cycles than a 1-degree iteration. Mean SDA intercepts with the sagittal plane of the condyle were positioned posterior and inferior of the selected center of the condyle. This finding coincided with the center of rotation results by Lindauer et al. (Lindauer et al., 1995). Maximum anterior and posterior displacements of SDAs from the condylar point were significantly $(\alpha=0.05)$ posterior to the results obtained by Gallo et al. (1997). Maximum superior and inferior displacements of SDAs from the condylar point were significantly inferior to the results obtained from Gallo et al. (1997). Mean orientation of the screw displacement axes relative to the anterioposterior and vertical axes of the subjects were both close to 90 degrees and were statistically the same 
as the findings of Gallo et al. The mean orientation of the SDAs relative to the lateral axis of the subjects was 13.1 degrees, which disclosed a significant difference from the value of Gallo et al. (8.8 degrees).

\section{Limitations of SDA Method}

The screw displacement axis method does have limitations. A main disadvantage is the need for rotation to occur in the described motion. If only translational motion occurs, the SDA is undefined. The SDA method is also very prone to measurement error. At low rotational increments, large error of the SDA parameters can be encountered from a small inaccuracy in measurement data. However, small rotational increments are necessary to reliably approximate the continuous movement through a series of finite calculations. A balance is therefore required between these two opposing error sources (Woltring et al., 1985). In order to reduce measurement data error, studies have used smoothing techniques (de Lange et al., 1990; Spoor, 1984; Woltring et al., 1985). In the present study, because the error from the measurements had a systematic non-random nature, normal smoothing techniques can not be used to reduce the error. 


\section{Section VI: Summary and Conclusions}

Error propagation through the equations for calculation of the SDA followed an inverse relationship to rotation. As rotation step-size increased, uncertainty decreased. Without smoothing or filtering, experimental data should be processed at a step size of at least 4 to 5 degrees.

Analysis of the tracking system showed there was no relation between varying the velocity and the $\mathrm{Z}$ data inaccuracy. There was a significant difference in induced $\mathrm{Z}$ data inaccuracy when the $\mathrm{Y}$ position was changed. However, no trend was observed in the mean peak-to-valley values of the three testing conditions. This suggests that there is no way of finding an optimum $\mathrm{Y}$ value area. A trend was noticed in the mean $\mathrm{Z}$ inaccuracy values. As the $\mathrm{Z}$ distance from the camera decreased, so did mean inaccuracy, but, by bringing the targets closer to the camera in the $\mathrm{Z}$ axis, the viewing area of the camera decreased. The closest the targets can be brought to the camera while maintaining a viewing area large enough to test motion is approximately $150 \mathrm{~mm}$ to 200 $\mathrm{mm}$.

In the comparison between the experimental and theoretical data for the four bar motion, the paths of motion were similar. Data were lost, however, in the beginning and terminal segments of motion because of the large increments needed to produce the screw displacement axes. It was best to have smaller increments to better characterize the true motion, but due to the effect that error had on the calculation of the screw displacement axis, this step size was not possible. 
In vivo motion of the mandible produced paths of screw displacement axes that laid inferior and posterior to the condyle of the mandible. During the beginning and end of the opening phase of motion the screw displacement axes laid closer to the condyle, indicating that more rotation occurred at the condyle during these phases. The results found in this research resembled those reported in previous literature, and they provide a better understanding of mandibular motion compared to studies involving the finite center of rotation or condylar path analysis.

The ability to more easily obtain and process screw displacement parameters, and thereby determine an accurate path of mandibular motion, make the present research more applicable to the clinician and patient. With further investigation and streamlining of the process, this SDA technique could become a means of illustrating and characterizing temporomandibular joint motion and predicting temporomandibular joint disorder for asymptomatic and symptomatic patients.

Studies indicate that temporomandibular disorder continues to be a problem in two arenas: diagnosis and treatment. The techniques described in this thesis for measuring joint motion could prove to be an invaluable piece to the TMD puzzle. 


\section{Section VII: Epilogue}

Harold Perry wrote that orthodontists would be wise to gather information from all possible sources. He detailed the vexing complexity of the temporomandibular joint as related to growth, adaptability, function, and disorder. Perry explains, "In the broad spectrum of knowledge that the professional man is expected to have, there are often areas of darkness...fortunately, the location of the 'blind spots' in each spectrum is not universal...thus we are able to call upon those who are better qualified or better versed to shed light upon our areas of uncertainty..." (1966:137).

Through the utilization of technological improvements, computer applications, and mathematical approaches, the lack of understanding surrounding the motion of the temporomandibular joint and associated disorders may no longer prove to be an uncertainty cloaked in anecdotal evidence or hidden under the guise of multifactoral relationships, but rather an anatomical consideration effectively addressed by those professionals who have sought the answer through multiple avenues of understanding.

Three-dimensional analysis of the TMJ has not only elucidated the specific motion of bony movement, but also the movement of the entire cartilage and bony complex within the glenoid fossa. Bottlang (1998) states that the screw displacement software and tracking system is a powerful tool for real-time detection and characterization of complex joint kinematics, especially when evaluating the TMJ. As technology continues to improve diagnostic imaging, so will our understanding of TMJ abnormalities and predispositions toward specific joint disorders. 
Just as Costen understood that there is a specific disorder involving the TMJ and ear, so too may our understanding of TMD increase to the point where we no longer use terminology and treatment modalities from the last century, but develop our own classification system and preemptive techniques for treating TMD. 
List of References 
Airoldi RL, Gallo LM, Palla S. Precision of the jaw tracking system Jaws 3D. J Orofac Pain 1994:8:155-64.

Ash MM, Nelson SJ. The temporomandibular joints, muscles, teeth, and their functions. In: Wheeler RC. Wheeler's Dental Anatomy, Physiology, and Occlusion. St. Louis: Saunders; 2003; p. 411-36.

Barclay P, Hollender LG, Maravilla KR, Truelove EL. Comparison of clinical and magnetic resonance imaging diagnosis in patients with disc displacement of the TMJ. Oral Surg Oral Med Oral Pathol Oral Radiol Endod 1999:88:37-43.

Beek M, Koolstra JH, van Ruijven LJ, van Eijden TMGJ. Three-dimensional finite element analysis of the cartilaginous structures in the human temporomandibular joint. J Dent Res 2001:80:1913-8.

Beek M, Koolstra JH, van Ruijven LJ, van Eijden TMGJ. Three-dimensional finite element analysis of the human temporomandibular joint disc. J Biomech 2000:33:307-16.

Bell WE. Clinical management of temporomandibular disorders. Chicago: Year Book Medical Publishers:1982.

Bogini A, Fraccari F, Mauro G, Caudana R, Pregarz M. The role of MRI in the anatomic and functional assessment of the TMJ. Minerva Stomatol 1990:39:76076.

Bottlang M, Marsh JL, Brown TD. Factors influencing accuracy of screw displacement axis detection with a d.c.-based electromagnetic tracking system. J Biomech Eng 1998:120:430-5. 
Bumann A, and Lotzmann U. Anatomy of the masticatory system. In: Rateitschak $\mathrm{KH}$ and Wolf HF, editors. TMJ disorders and orofacial pain: The role of dentistry in a multidisciplinary diagnostic approach. New York: Thieme:2002: p.11-52.

Carlsson GE, Ingervall B, Lewin T, Mohlin C. Relation between functional disturbances of the masticatory system and some anthropometric physiological and psychological variables in Swedish men. J Oral Rehab 1973:3:305-10.

Chen J, Siegler S, Schenck CD. The three-dimensional kinematics and flexibility characteristics of the human ankle and subtalar joint, Part II: flexibility charteristics. J Biomech Eng 1988:110:374-85.

Chu SA, Suvinen TI, Clement JC, Price J. Computerized three-dimensional magnetic resonance imaging reconstructions of temporomandibular joints for both a model and for patients with temporomandibular pain dysfunction. Oral Surg Oral Med Oral Pathol Oral Rad Endod 1995:80:604-11.

Clayton JA. A pantographic reproducibility index for use in diagnosing TMJ function: a report on research. J Pros Dent 1985:54:827-31.

Costen JB. Syndrome of ear and sinus symptoms dependent upon functions of the TMJ. Ann Otol Rhinol Laryngol 1934:3:1-4.

De Lange A, Huikes R, Kauer JM. Effects of data smoothing on the reconstruction helical axis parameters in human joint kinematics. J Biomechan Eng 1990:112:107-13.

Duck TR, Ferreira LM, King GJ, Johnson JA. Assessment of screw displacement axis accuracy and repeatability for joint kinematic description using an electromagnetictracking device. J Biomech 2004:37:163-7. 
Egermark-Eriksson I, Ingervall B, Carlsson GE. The dependence of mandibular dysfunction in children on functional and morphologic occlusion. Am J Orthod 1983:3:187-94.

Emshoff R, Brandlmaier I, Bosch R, Gerard S, Rudisch A, Bertram S. Validation of the clinical diagnostic criteria for temporomandibular disorders for the diagnostic subgroup-disc derangement with reduction. J Oral Rehab 2002:29:1139-45.

Figliola RS and Beasley DE. Theory and design for mechanical measurements. New York: John Wiley and Sons, Inc.: 2000.

Fiorettis, Jetto L, Leo T. Reliable in vivo estimation of the instantaneous helical axis in human segmental movements. IEEE Trans Biomed Eng 1990:37:398-409.

Gallo LM. Mandibular helical axis pathways during mastication. J Dent Res 2000:79:1566-72.

Gallo LM, Airoldi GB, Airoldi RL, Palla S. Description of mandibular finite helical axis pathway in asymptomatic subjects. J Dent Res 1997:76:704-13.

Gallo LM, Salaorni C, Airoldi AL, Palla S. Classification of anterior displacement vs. condylon rotation patterns in healthy TMJ's. J Dent Res 1993:72:372 (Abstract).

Goulet JP, Lavigne GJ, Lund JP. Jaw pain prevalence among French-speaking Canadians in Quebec and related symptoms of TMD. J Dent Res 1995:74:173844.

Granados J. The influence of the loss of teeth and attrition on the articular eminence. J Pros Dent 1979:42:78-85. 
Griffiths RH. Report of the president's conference on the examination, diagnosis, and management of temporomandibular disorders. J Am Dent Assoc 1983:106:75-7.

Gsellmann B, Schmid-Schwap M, Piehslinger E, Slavicek R. Lengths of condylar pathways measured with computerized axiography (CADIAX) and occlusal index in patients and volunteers. J Oral Rehabil 1998:25:146-52.

Hall RK. The role of CT, MRI, and 3D imaging diagnosis of the TMJ and other orofacial disorders in children. Aust Orthod J 1994:13:86-94.

Hart RA, Mote CD Jr., Skinner HB. A finite helical axis as a landmark for kinematic reference of the knee. J Biomechan Eng 1991:113:215-22.

Ingervall B, Mohlin B, Thilander B. Prevalence of symptoms of functional disturbances of the masticatory system in Swedish men. J Oral Rehab 1980:7:18597.

Krebs M, Gallo LM, Aitoldi RL, Meier D. Boesiger P, Palla S. Three dimensional animation of the temporomandibular joint. Tech Health Care 1994:2:193-207.

Lindauer SJ, Sabol G, Issacson RJ, Davidovitch M. Condylar movement and mandibular rotation during jaw opening. Am J Orthod Dentofacial Orthop 1995:107:573-77.

McKay GS, Yemm R, Cadden SW. The structure and function of the temporomandibular joint. Br Dent J 1994:173:127-32.

McMillan AS, McMillan DR, Darvel BW. Centers of rotation during jaw movements. Acta Odontol Scand 1989:47:323-8. 
Merlini L, Palla S. The relationship between condylon rotation and anterior translation in health and clicking temporomandibular joints. Schweiz Monatsschr Zahnmed 1998:98:1191-9.

Moffett BC. The morphogenesis of the temporomandibular joint. Am J Orthod 1966:52:401-15.

Mohl ND. Reliability and validity of diagnostic modalities for temporomandibular disorders. Adv Dent Res 1993:7:113-9.

Mohlin B, Kopp S. A clinical study on the relationship between malocclusions, occlusal interferences, and mandibular pain and dysfunction. Swed Dent J 1978:2:105-12.

Moore KL. Clinically oriented anatomy, 3rd ed. Baltimore: Williams and Wilkins: 1992.

Nagerl H, Kubein-Meesenburg D, Schwestka-Polly R, Thieme KM, Fanghanel J, Miehe B. Functional condition of the mandible: physical structures of free mandibular movement. Ant Anz 1999:181:41-44.

Nebbe B, Major PW, Prasad NG, Hatcher D. Quantitative assessment of temporomandibular joint disc status. Oral Surg Oral Med Oral Pathol Oral Radiol Endod 1998:85:598-607.

Nevakari K. A new triangle transfer method for studying mandibular movements on the basis of cephalometric roentgenograms; preliminary report. Acta Odontol Scand 1955:12:293-300.

Okeson JP. Management of temporomandibular disorders and occlusion. St. Louis: CV Mosby Press:1998. 
Olkinvora M. A psychometric study of bruxism with emphasis on mental strain and familial predisposition factors. Proc Finn Dent Soc 1972:68:110-23.

Osterbauer PJ, Derickson KL, Peles JD, Deboer KF, Fuhr AW, Winters JM. Threedimensional head kinematics and clinical outcome of patients with neck injury treated with spinal manipulative therapy: a pilot study. J Manipulative Physiol Ther 1992:15:501-11.

Panjabi MM. Centers and angles of rotation of body joints: a study of errors and optimization. J Biomechan 1979:12:911-20.

Panjabi MM, Goel VR, Walter SD, Schicks. Errors in the center and angle of rotation of a joint; an experimental study. J Biomechan Eng 1982:104:232-7.

Passatore M, Grassi C. Action of the sympathetic system on skeletal muscle. J Neurol Sci 1988:9:23-8.

Patonay L, Nagy K, Engelke W. Real-time endoarticular ultrasound imaging of the TM new diagnostic possibility? A cadaver study. Int J Oral Maxillofac Surg 2002:31:553-7.

Perry H. Relation of occlusion to temporomandibular joint dysfunction: the orthodontic viewpoint. J Am Dent Assoc 1970:79:137-41.

Pertes RA, Attanasio R, Cinotti WR, Balbo M. The temporomandibular joint in function and dysfunction. Clin Prev Dent 1988:10:23-9.

Pieruci P, Chassagne JF, Briche D, Dinh DG. Value of MRI in the visualization of the meniscus in temporomandibular joints. Rev Stomatol Chir Maxillofac 1991:92:149-54.

Posselt U. Movement areas of the mandible. J Prosthet Dent 1957:7:375-84. 
Pullinger AG, Seligman DA, Soldberg WK. Temporomandibular disorders. Part I: functional status, dentomorphologic features, and sex differences in a nonpatient population. J Pros Dent 1998:59:228-35.

Ramakrishnan HK, Kadaba MP. On the estimation of joint kinematics during gait. J Biomed 1991:24:969-77.

Ramfjord SP, Ash MM. Occlusion. Philadelphia: W.B. Saunders; 1966.

Rocabado M. Arthro kinematics of the temporomandubular joint. Dent Clin North Am 1983:27:573-94.

Roth RH. Temporomandibular joint disturbances and its relation to diagnosis and treatment planning. In: Ricketts RM, editor. Orthodontic Diagnosis and Planning. Denver: Rocky Mountain Data:1982.

Sadat-Khonsari R, Fenske C, Kahl-Nieke B, Kirsch I, Jude HD. The helical axis of the mandible during the opening and closing movement of the mouth. J Orofac Orthop 2003:64:178-85.

Schiffman EL, Fricton JR, Haley DP, Shapiro BL. The prevalence and treatment needs of subjects with temporomandibular disorders. J Am Dent Assoc 1990:120:295-303.

Schreppers GJMA, Sauren AAHJ, Huson A. A numerical model of the load transmission in the tibio-femoral contact area. Proceed Instit Mech Eng J Engin Med 1990:204:53-9.

Schulte J, Rooney D, Erdman A. The hinge axis transfer procedure: a threedimensional error analysis. J Pros Dent 1984:51:247-51. 
Siegler S, Chem J, Schneck CD. The three dimensional kinematics and flexibility characteristics of the human ankle and subtalar joints, Part I: kinematics. J Biomechan Eng 1988:110:364-73.

Smith RJ. Functions of condyle translation in human mandibular movement. Am J Orthod 1985:88:191-202.

Solberg W, Seligman D. Temporomandibular orthopedics: a new vista in orthodontics. In: Johnston L, editor. A new vista in orthodontics. Philadelphia: Lea and Febiger:1985. p.148-183.

Spoor CW. Explanation, verification and application of the helical axis error propagation formulas. Human Movement Sci 1984:3:95-117.

Tanaka E, Rodrigo P, Tanaka M, Kawaguchi A, Shabazaki T, Tanne K. Stress analysis in the TMJ during jaw opening by use of a three-dimensional finite element model based on magnetic resonance images. Int J Oral Maxillofac Surg 2001:30:421-30.

Tyndall D, Renner J, Phillips C, Matteson S. Positional changes of the mandibular condyle assessed by three-dimensional computed tomography. J Oral Maxillofac Surg 1992:50:1164-72.

Usumez S, Oz F, Guray E. Comparison of clinical and magnetic resonance imaging diagnoses in patients with TMD history. J Oral Rehabil 2004:31:52-6.

Vichaichalermvong S, Nilner M, Panmekiate S, Petersson A. Clinical follow-up with different disc positions. J Orofac Pain 1993:7:61-7. 
Von Korff M, Dworkin SF, LeResche L, Kruger A. Epidemiology of temporomandibular disorders: TMD pain compared to other common pain sites. In: Dubner R, Gebhard GF, Bond MR, editors. Pain research and clinical management. Amsterdam: Elsevier Science:1998. p.506-11.

Wilson DL,Zhu Q, Duerk JL, Mansor JM, Kilgore K, Crago PE. Estimation of tendon moment arms from three-dimensional magnetic resonance images. Ann Biomed Eng 1999:27:247-56.

Woltring HJ, Long K, Osterbauer PJ. Instantaneous helical axis estimation from three dimensional video data in neck kinematics for whiplash diagnostics. J Biomech 1994:27:1415-32.

Yatani H, Sonoyama W, Kuboki T, Matsuka Y, Orsini MG, Yamashita A. The validity of clinical examination for diagnosing anterior disc displacement with reduction. Oral Surg Oral Med Oral Pathol Oral Radiol Endod 1998:85:647-53.

Zwignenberg A, Megens CC, Naeije M. Influence of choice of reference point on the condylar movement paths during mandibular movements. J Oral Rehabil 1996:23:832-7. 
Appendices 
Appendix A:

Sequential Perturbation Results 


\section{Tables A.1-A.9: One Degree Sequential Perturbation Results}

Table A.1: One degree initial coordinate values.

\begin{tabular}{c|c|c|c|}
\cline { 2 - 4 } & $\mathbf{X}$ & $\mathbf{Y}$ & $\mathbf{Z}$ \\
\cline { 2 - 4 } Target 1 & -31.92 & 19.67 & 200.00 \\
\cline { 2 - 4 } Target 2 & 28.05 & -37.05 & 200.00 \\
\cline { 2 - 4 } Target 3 & 47.21 & 43.28 & 200.00 \\
\cline { 2 - 4 } & \multicolumn{2}{|c|}{}
\end{tabular}

Table A.2: One degree final coordinate values.

\begin{tabular}{c|c|c|c|}
\cline { 2 - 4 } & $\mathbf{X}$ & $\mathbf{Y}$ & $\mathbf{Z}$ \\
\cline { 2 - 4 } Target 1 & -32.24 & 19.11 & 200.00 \\
\cline { 2 - 4 } Target 2 & 28.72 & -36.55 & 200.00 \\
\cline { 2 - 4 } Target 3 & 46.47 & 44.10 & 200.00 \\
\cline { 2 - 4 } & & \multicolumn{3}{|c|}{}
\end{tabular}

Table A.3: One degree original parameter results.

\begin{tabular}{|l|l|}
\hline $\mathrm{kx}$ & 0.00 \\
\hline $\mathrm{x} 0$ & 0.04 \\
\hline $\mathrm{ky}$ & 0.00 \\
\hline $\mathrm{y} 0$ & 1.46 \\
\hline
\end{tabular}


Table A.4: One degree parameter values after addition.

\begin{tabular}{|c|c|c|c|c|c|c|c|c|c|}
\hline \multicolumn{10}{|c|}{ Initial Coordinates } \\
\hline & $\mathrm{X} 1$ & Y1 & $\mathrm{Z1}$ & $\mathrm{Z} 2$ & Y2 & $\mathrm{Z2}$ & X3 & Y3 & $\mathrm{Z3}$ \\
\hline $\mathrm{Kx}$ & 0.00 & 0.00 & 0.00 & 0.00 & 0.00 & 0.02 & 0.00 & 0.00 & -0.01 \\
\hline Xo & 142.28 & -9.20 & 0.76 & -10.11 & 106.19 & -3.03 & 0.04 & 0.04 & 2.38 \\
\hline $\mathrm{Ky}$ & 0.00 & 0.00 & -0.02 & 0.00 & 0.00 & 0.00 & 0.00 & 0.00 & 0.01 \\
\hline Yo & -83.22 & 7.07 & 4.59 & 7.13 & -57.79 & 0.53 & 1.46 & 1.46 & -0.72 \\
\hline
\end{tabular}

Final Coordinates

\begin{tabular}{|c|c|c|c|c|c|c|c|c|c|}
\cline { 2 - 10 } \multicolumn{1}{c|}{} & $\mathrm{X} 1$ & $\mathrm{Y} 1$ & $\mathrm{Z} 1$ & $\mathrm{Z} 2$ & $\mathrm{Y} 2$ & $\mathrm{Z} 2$ & $\mathrm{X} 3$ & $\mathrm{Y} 3$ & $\mathrm{Z} 3$ \\
\hline $\mathrm{Kx}$ & 0.00 & 0.00 & 0.00 & 0.00 & 0.00 & -0.02 & 0.00 & 0.00 & 0.01 \\
\hline $\mathrm{Xo}$ & -10.20 & 211.32 & -0.67 & 209.97 & -9.88 & 3.10 & 0.04 & 0.04 & -2.31 \\
\hline $\mathrm{Ky}$ & 0.00 & 0.00 & 0.02 & 0.00 & 0.00 & 0.00 & 0.00 & 0.00 & -0.01 \\
\hline $\mathrm{Yo}$ & 7.96 & -120.98 & -1.67 & -115.73 & 7.00 & 2.41 & 1.46 & 1.46 & 3.64 \\
\hline
\end{tabular}

Table A.5: One degree parameter values after subtraction.

\begin{tabular}{|c|c|c|c|c|c|c|c|c|c|}
\hline & $\mathrm{X} 1$ & $\mathrm{Y} 1$ & $\mathrm{Z1}$ & $\mathrm{Z2}$ & $\mathrm{Y} 2$ & $\mathrm{Z} 2$ & X3 & Y3 & $\mathrm{Z3}$ \\
\hline $\mathrm{Kx}$ & 0.00 & 0.00 & 0.00 & 0.00 & 0.00 & -0.02 & 0.00 & 0.00 & 0.01 \\
\hline Xo & -10.12 & 102.01 & -0.67 & 142.26 & -9.99 & 3.10 & 0.04 & 0.04 & -2.31 \\
\hline Ky & 0.00 & 0.00 & 0.02 & 0.00 & 0.00 & 0.00 & 0.00 & 0.00 & -0.01 \\
\hline Yo & 7.91 & -57.81 & -1.66 & -77.93 & 7.06 & 2.41 & 1.46 & 1.46 & 3.64 \\
\hline
\end{tabular}

Final Coordinates

\begin{tabular}{|c|c|c|c|c|c|c|c|c|c|}
\cline { 2 - 10 } \multicolumn{1}{c|}{} & $\mathrm{X} 1$ & $\mathrm{Y} 1$ & $\mathrm{Z} 1$ & $\mathrm{Z} 2$ & $\mathrm{Y} 2$ & $\mathrm{Z} 2$ & $\mathrm{X} 3$ & $\mathrm{Y} 3$ & $\mathrm{Z} 3$ \\
\hline $\mathrm{Kx}$ & 0.00 & 0.00 & 0.00 & 0.00 & 0.00 & 0.02 & 0.00 & 0.00 & -0.01 \\
\hline $\mathrm{Xo}$ & 210.11 & -9.09 & 0.77 & -10.21 & 219.53 & -3.02 & 0.04 & 0.04 & 2.41 \\
\hline $\mathrm{Ky}$ & 0.00 & 0.00 & -0.02 & 0.00 & 0.00 & 0.00 & 0.00 & 0.00 & 0.01 \\
\hline $\mathrm{Yo}$ & -123.15 & 6.99 & 4.58 & 7.18 & -121.06 & 0.52 & 1.46 & 1.46 & -0.74 \\
\hline
\end{tabular}


Table A.6: One degree sequential perturbation for $\mathbf{k x}$.

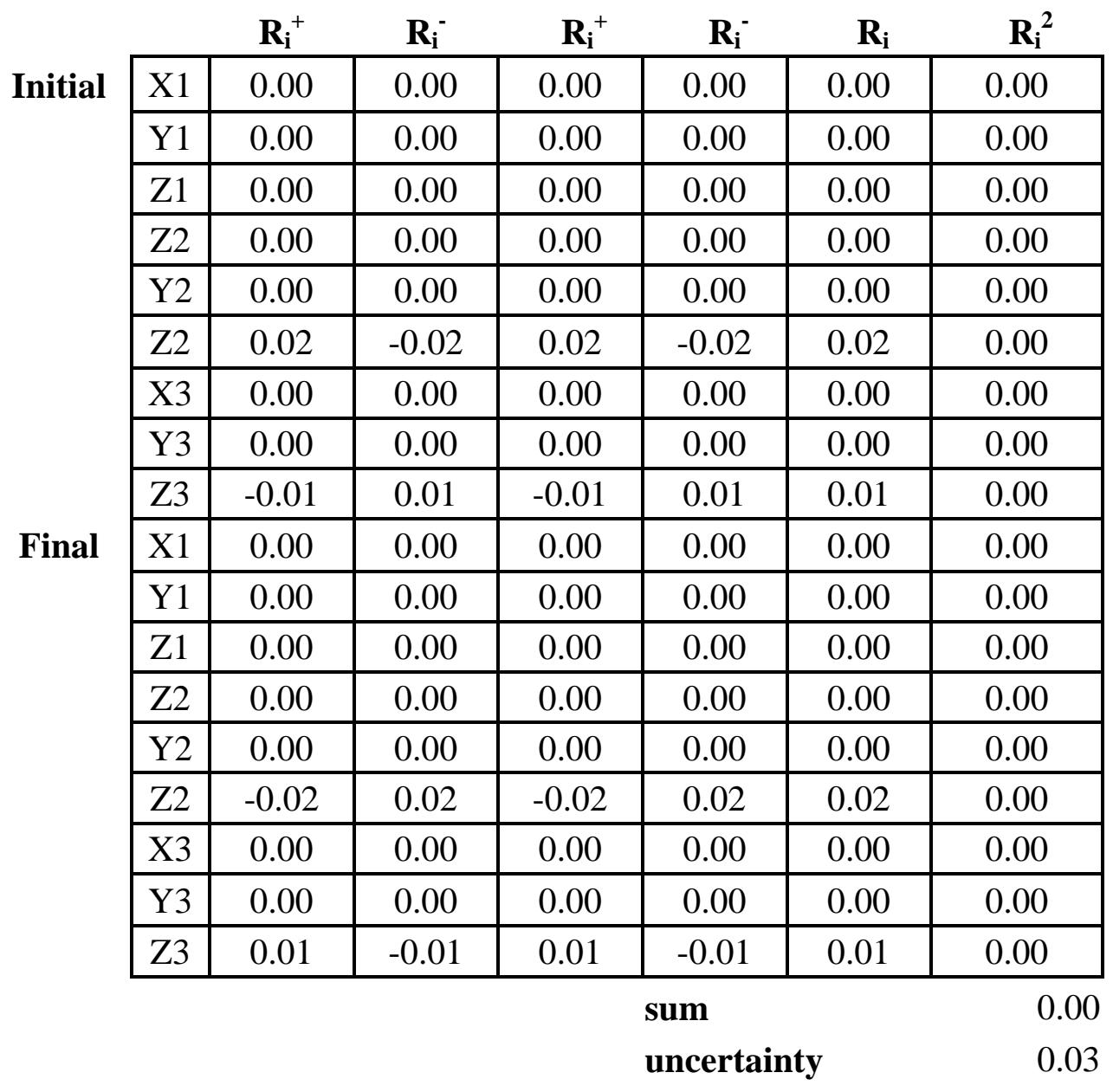


Table A.7: One degree sequential perturbation for xo.

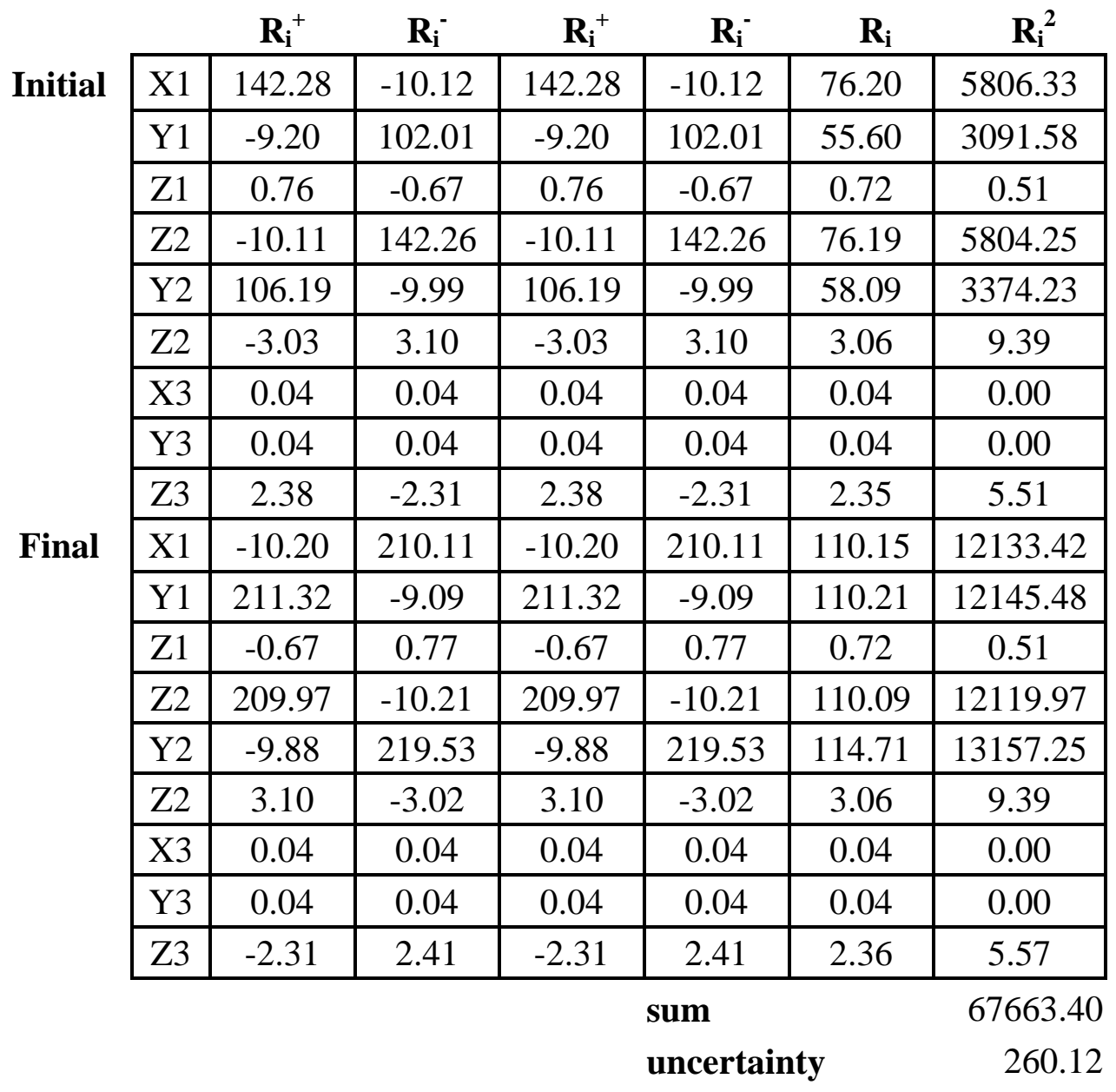


Table A.8: One degree sequential perturbation for ky.

\begin{tabular}{|c|c|c|c|c|c|c|c|}
\hline & & $\mathbf{R}_{\mathbf{i}}^{+}$ & $\mathbf{R}_{\mathbf{i}}^{-}$ & $\mathbf{R}_{\mathbf{i}}^{+}$ & $\mathbf{R}_{\mathbf{i}}^{-}$ & $\mathbf{R}_{\mathbf{i}}$ & $\mathbf{R}_{i}{ }^{2}$ \\
\hline \multirow[t]{2}{*}{ Initial } & $\mathrm{X} 1$ & 0.00 & 0.00 & 0.00 & 0.00 & 0.00 & 0.00 \\
\hline & $\mathrm{Y} 1$ & 0.00 & 0.00 & 0.00 & 0.00 & 0.00 & 0.00 \\
\hline \multirow{16}{*}{ Final } & $\mathrm{Z} 1$ & -0.02 & 0.02 & -0.02 & 0.02 & 0.02 & 0.00 \\
\hline & $\mathrm{Z} 2$ & 0.00 & 0.00 & 0.00 & 0.00 & 0.00 & 0.00 \\
\hline & Y2 & 0.00 & 0.00 & 0.00 & 0.00 & 0.00 & 0.00 \\
\hline & $\mathrm{Z} 2$ & 0.00 & 0.00 & 0.00 & 0.00 & 0.00 & 0.00 \\
\hline & $\mathrm{X} 3$ & 0.00 & 0.00 & 0.00 & 0.00 & 0.00 & 0.00 \\
\hline & Y3 & 0.00 & 0.00 & 0.00 & 0.00 & 0.00 & 0.00 \\
\hline & $\mathrm{Z3}$ & 0.01 & -0.01 & 0.01 & -0.01 & 0.01 & 0.00 \\
\hline & $\mathrm{X} 1$ & 0.00 & 0.00 & 0.00 & 0.00 & 0.00 & 0.00 \\
\hline & $\mathrm{Y} 1$ & 0.00 & 0.00 & 0.00 & 0.00 & 0.00 & 0.00 \\
\hline & $\mathrm{Z} 1$ & 0.02 & -0.02 & 0.02 & -0.02 & 0.02 & 0.00 \\
\hline & $\mathrm{Z} 2$ & 0.00 & 0.00 & 0.00 & 0.00 & 0.00 & 0.00 \\
\hline & $\mathrm{Y} 2$ & 0.00 & 0.00 & 0.00 & 0.00 & 0.00 & 0.00 \\
\hline & $\mathrm{Z} 2$ & 0.00 & 0.00 & 0.00 & 0.00 & 0.00 & 0.00 \\
\hline & $\mathrm{X} 3$ & 0.00 & 0.00 & 0.00 & 0.00 & 0.00 & 0.00 \\
\hline & $\mathrm{Y} 3$ & 0.00 & 0.00 & 0.00 & 0.00 & 0.00 & 0.00 \\
\hline & $\mathrm{Z3}$ & -0.01 & 0.01 & -0.01 & 0.01 & 0.01 & 0.00 \\
\hline & & & & & $\begin{array}{l}\text { um } \\
\text { ncer }\end{array}$ & & $\begin{array}{l}0.00 \\
0.03\end{array}$ \\
\hline
\end{tabular}


Table A.9: One degree sequential perturbation for yo.

\begin{tabular}{|c|c|c|c|c|c|c|c|}
\hline & & $\mathbf{R}_{\mathbf{i}}^{+}$ & $\mathbf{R}_{\mathbf{i}}^{-}$ & $\mathbf{R}_{\mathbf{i}}^{+}$ & $\mathbf{R}_{\mathbf{i}}^{-}$ & $\mathbf{R}_{\mathbf{i}}$ & $\mathbf{R}_{\mathbf{i}}{ }^{2}$ \\
\hline \multirow[t]{9}{*}{ Initial } & $\mathrm{X} 1$ & -83.22 & 7.91 & -83.22 & 7.91 & 45.57 & 2076.26 \\
\hline & Y1 & 7.07 & -57.81 & 7.07 & -57.81 & 32.44 & 1052.18 \\
\hline & Z1 & 4.59 & -1.66 & 4.59 & -1.66 & 3.12 & 9.76 \\
\hline & $\mathrm{Z} 2$ & 7.13 & -77.93 & 7.13 & -77.93 & 42.53 & 1808.63 \\
\hline & Y2 & -57.79 & 7.06 & -57.79 & 7.06 & 32.43 & 1051.40 \\
\hline & $\mathrm{Z} 2$ & 0.53 & 2.41 & 0.53 & 2.41 & 1.47 & 2.16 \\
\hline & X3 & 1.46 & 1.46 & 1.46 & 1.46 & 1.46 & 2.14 \\
\hline & Y3 & 1.46 & 1.46 & 1.46 & 1.46 & 1.46 & 2.14 \\
\hline & $\mathrm{Z3}$ & -0.72 & 3.64 & -0.72 & 3.64 & 2.18 & 4.76 \\
\hline \multirow[t]{9}{*}{ Final } & $\mathrm{X} 1$ & 7.96 & -123.15 & 7.96 & -123.15 & 65.56 & 4297.52 \\
\hline & $\mathrm{Y} 1$ & -120.98 & 6.99 & -120.98 & 6.99 & 63.98 & 4094.05 \\
\hline & $\mathrm{Z1}$ & -1.67 & 4.58 & -1.67 & 4.58 & 3.12 & 9.76 \\
\hline & $\mathrm{Z} 2$ & -115.73 & 7.18 & -115.73 & 7.18 & 61.45 & 3776.51 \\
\hline & $\mathrm{Y} 2$ & 7.00 & -121.06 & 7.00 & -121.06 & 64.03 & 4099.93 \\
\hline & $\mathrm{Z} 2$ & 2.41 & 0.52 & 2.41 & 0.52 & 1.47 & 2.15 \\
\hline & X3 & 1.46 & 1.46 & 1.46 & 1.46 & 1.46 & 2.14 \\
\hline & Y3 & 1.46 & 1.46 & 1.46 & 1.46 & 1.46 & 2.14 \\
\hline & $\mathrm{Z3}$ & 3.64 & -0.74 & 3.64 & -0.74 & 2.19 & 4.81 \\
\hline \multicolumn{7}{|c|}{ sum } & 22298.44 \\
\hline
\end{tabular}




\section{Tables A.10-A.18: Two Degree Sequential Perturbation Results}

Table A.10: Two degree initial coordinate values.

\begin{tabular}{c|c|c|c|}
\cline { 2 - 4 } & $\mathbf{X}$ & $\mathbf{Y}$ & $\mathbf{Z}$ \\
\cline { 2 - 4 } Target 1 & -31.92 & 19.67 & 200.00 \\
\cline { 2 - 4 } Target 2 & 28.05 & -37.05 & 200.00 \\
\cline { 2 - 4 } Target 3 & 47.21 & 43.28 & 200.00 \\
\cline { 2 - 4 } & &
\end{tabular}

Table A.11: Two degree final coordinate values.

\begin{tabular}{c|c|c|c|}
\cline { 2 - 4 } & $\mathbf{X}$ & $\mathbf{Y}$ & $\mathbf{Z}$ \\
\cline { 2 - 4 } Target 1 & -32.49 & 18.54 & 200.00 \\
\cline { 2 - 4 } Target 2 & 29.43 & -36.05 & 200.00 \\
\cline { 2 - 4 } Target 3 & 45.77 & 44.90 & 200.00 \\
\cline { 2 - 4 } & \multicolumn{3}{|c}{}
\end{tabular}

Table A.12: Two degree original parameter results.

\begin{tabular}{|c|c|}
\hline $\mathrm{kx}$ & 0.00 \\
\hline $\mathrm{x} 0$ & 0.05 \\
\hline $\mathrm{ky}$ & 0.00 \\
\hline $\mathrm{y} 0$ & 2.93 \\
\hline
\end{tabular}


Table A.13: Two degree parameter values after addition.

Initial Coordinates

\begin{tabular}{|c|c|c|c|c|c|c|c|c|c|}
\cline { 2 - 10 } \multicolumn{1}{c|}{} & $\mathrm{X} 1$ & $\mathrm{Y} 1$ & $\mathrm{Z} 1$ & $\mathrm{Z} 2$ & $\mathrm{Y} 2$ & $\mathrm{Z} 2$ & $\mathrm{X} 3$ & $\mathrm{Y} 3$ & $\mathrm{Z} 3$ \\
\hline $\mathrm{Kx}$ & 0.00 & 0.00 & 0.00 & 0.00 & 0.00 & 0.01 & 0.00 & 0.00 & -0.01 \\
\hline $\mathrm{Xo}$ & 5.80 & -3.23 & 0.40 & -3.69 & 5.90 & -1.48 & 0.05 & 0.05 & 1.23 \\
\hline $\mathrm{Ky}$ & 0.00 & 0.00 & -0.01 & 0.00 & 0.00 & 0.00 & 0.00 & 0.00 & 0.01 \\
\hline $\mathrm{Yo}$ & -0.63 & 4.83 & 4.49 & 4.80 & -0.01 & 2.44 & 2.93 & 2.93 & 1.84 \\
\hline
\end{tabular}

Final Coordinates

\begin{tabular}{|c|c|c|c|c|c|c|c|c|c|}
\cline { 2 - 10 } \multicolumn{1}{c|}{} & $\mathrm{X} 1$ & $\mathrm{Y} 1$ & $\mathrm{Z} 1$ & $\mathrm{Z} 2$ & $\mathrm{Y} 2$ & $\mathrm{Z} 2$ & $\mathrm{X} 3$ & $\mathrm{Y} 3$ & $\mathrm{Z} 3$ \\
\hline $\mathrm{Kx}$ & 0.00 & 0.00 & 0.00 & 0.00 & 0.00 & -0.01 & 0.00 & 0.00 & 0.01 \\
\hline $\mathrm{Xo}$ & -3.79 & 4.96 & -0.29 & 6.05 & -3.62 & 1.58 & 0.05 & 0.05 & -1.13 \\
\hline $\mathrm{Ky}$ & 0.00 & 0.00 & 0.01 & 0.00 & 0.00 & 0.00 & 0.00 & 0.00 & -0.01 \\
\hline $\mathrm{Yo}$ & 5.36 & 0.13 & 1.36 & -0.08 & 4.77 & 3.41 & 2.93 & 2.93 & 4.01 \\
\hline
\end{tabular}

Table A.14: Two degree parameter values after subtraction.

Initial Coordinates

\begin{tabular}{|c|c|c|c|c|c|c|c|c|c|}
\cline { 2 - 10 } \multicolumn{1}{c|}{} & $\mathrm{X} 1$ & $\mathrm{Y} 1$ & $\mathrm{Z} 1$ & $\mathrm{Z} 2$ & $\mathrm{Y} 2$ & $\mathrm{Z} 2$ & $\mathrm{X} 3$ & $\mathrm{Y} 3$ & $\mathrm{Z} 3$ \\
\hline $\mathrm{Kx}$ & 0.00 & 0.00 & 0.00 & 0.00 & 0.00 & -0.01 & 0.00 & 0.00 & 0.01 \\
\hline $\mathrm{Xo}$ & -3.70 & 5.22 & -0.29 & 5.79 & -3.37 & 1.58 & 0.05 & 0.05 & -1.13 \\
\hline $\mathrm{Ky}$ & 0.00 & 0.00 & 0.01 & 0.00 & 0.00 & 0.00 & 0.00 & 0.00 & -0.01 \\
\hline $\mathrm{Yo}$ & 5.31 & -0.02 & 1.36 & 0.05 & 4.82 & 3.41 & 2.93 & 2.93 & 4.01 \\
\hline
\end{tabular}

Final Coordinates

\begin{tabular}{|c|c|c|c|c|c|c|c|c|c|}
\cline { 2 - 10 } \multicolumn{1}{c|}{} & $\mathrm{X} 1$ & $\mathrm{Y} 1$ & $\mathrm{Z} 1$ & $\mathrm{Z} 2$ & $\mathrm{Y} 2$ & $\mathrm{Z} 2$ & $\mathrm{X} 3$ & $\mathrm{Y} 3$ & $\mathrm{Z} 3$ \\
\hline $\mathrm{Kx}$ & 0.00 & 0.00 & 0.00 & 0.00 & 0.00 & 0.01 & 0.00 & 0.00 & -0.01 \\
\hline $\mathrm{Xo}$ & 6.04 & -3.11 & 0.40 & -3.80 & 5.63 & -1.48 & 0.05 & 0.05 & 1.23 \\
\hline $\mathrm{Ky}$ & 0.00 & 0.00 & -0.01 & 0.00 & 0.00 & 0.00 & 0.00 & 0.00 & 0.01 \\
\hline $\mathrm{Yo}$ & -0.76 & 4.76 & 4.49 & 4.86 & 0.12 & 2.44 & 2.93 & 2.93 & 1.84 \\
\hline
\end{tabular}


Table A.15: Two degree sequential perturbation for $\mathbf{k x}$.

\begin{tabular}{|c|c|c|c|c|c|c|c|}
\hline \multirow{3}{*}{ Initial } & & $\mathbf{R}_{\mathbf{i}}^{+}$ & $\mathbf{R}_{\mathbf{i}}^{-}$ & $\mathbf{R}_{\mathbf{i}}^{+}$ & $\mathbf{R}_{\mathbf{i}}^{-}$ & $\mathbf{R}_{\mathbf{i}}$ & $\mathbf{R}_{i}{ }^{2}$ \\
\hline & $\mathrm{X} 1$ & 0.00 & 0.00 & 0.00 & 0.00 & 0.00 & 0.00 \\
\hline & $\mathrm{Y} 1$ & 0.00 & 0.00 & 0.00 & 0.00 & 0.00 & 0.00 \\
\hline \multirow{16}{*}{ Final } & $\mathrm{Z} 1$ & 0.00 & 0.00 & 0.00 & 0.00 & 0.00 & 0.00 \\
\hline & $\mathrm{Z} 2$ & 0.00 & 0.00 & 0.00 & 0.00 & 0.00 & 0.00 \\
\hline & $\mathrm{Y} 2$ & 0.00 & 0.00 & 0.00 & 0.00 & 0.00 & 0.00 \\
\hline & $\mathrm{Z} 2$ & 0.01 & -0.01 & 0.01 & -0.01 & 0.01 & 0.00 \\
\hline & X3 & 0.00 & 0.00 & 0.00 & 0.00 & 0.00 & 0.00 \\
\hline & $\mathrm{Y} 3$ & 0.00 & 0.00 & 0.00 & 0.00 & 0.00 & 0.00 \\
\hline & $\mathrm{Z3}$ & -0.01 & 0.01 & -0.01 & 0.01 & 0.01 & 0.00 \\
\hline & $\mathrm{X} 1$ & 0.00 & 0.00 & 0.00 & 0.00 & 0.00 & 0.00 \\
\hline & $\mathrm{Y} 1$ & 0.00 & 0.00 & 0.00 & 0.00 & 0.00 & 0.00 \\
\hline & $\mathrm{Z} 1$ & 0.00 & 0.00 & 0.00 & 0.00 & 0.00 & 0.00 \\
\hline & $\mathrm{Z} 2$ & 0.00 & 0.00 & 0.00 & 0.00 & 0.00 & 0.00 \\
\hline & $\mathrm{Y} 2$ & 0.00 & 0.00 & 0.00 & 0.00 & 0.00 & 0.00 \\
\hline & $\mathrm{Z} 2$ & -0.01 & 0.01 & -0.01 & 0.01 & 0.01 & 0.00 \\
\hline & X3 & 0.00 & 0.00 & 0.00 & 0.00 & 0.00 & 0.00 \\
\hline & Y3 & 0.00 & 0.00 & 0.00 & 0.00 & 0.00 & 0.00 \\
\hline & $\mathrm{Z3}$ & 0.01 & $\begin{array}{l}-0.01 \\
\end{array}$ & 0.01 & -0.01 & 0.01 & 0.00 \\
\hline & & & & & $\begin{array}{l}\text { im } \\
\text { ncerta }\end{array}$ & & $\begin{array}{l}0.00 \\
0.01\end{array}$ \\
\hline
\end{tabular}


Table A.16: Two degree sequential perturbation for xo.

\begin{tabular}{|c|c|c|c|c|c|c|c|}
\hline \multirow{3}{*}{ Initial } & & $\mathbf{R}_{\mathbf{i}}^{+}$ & $\mathbf{R}_{\mathbf{i}}^{-}$ & $\mathbf{R}_{\mathbf{i}}^{+}$ & $\mathbf{R}_{\mathbf{i}}^{-}$ & $\mathbf{R}_{\mathbf{i}}$ & $\mathbf{R}_{i}{ }^{2}$ \\
\hline & $\mathrm{X} 1$ & 5.80 & -3.70 & 5.75 & -3.75 & 4.75 & 22.56 \\
\hline & $\mathrm{Y} 1$ & -3.23 & 5.22 & -3.28 & 5.17 & 4.22 & 17.83 \\
\hline \multirow{16}{*}{ Final } & $\mathrm{Z} 1$ & 0.40 & -0.29 & 0.35 & -0.34 & 0.34 & 0.12 \\
\hline & $\mathrm{Z} 2$ & -3.69 & 5.79 & -3.74 & 5.74 & 4.74 & 22.46 \\
\hline & $\mathrm{Y} 2$ & 5.90 & -3.37 & 5.84 & -3.42 & 4.63 & 21.48 \\
\hline & $\mathrm{Z} 2$ & -1.48 & 1.58 & -1.53 & 1.53 & 1.53 & 2.33 \\
\hline & X3 & 0.05 & 0.05 & 0.00 & 0.00 & 0.00 & 0.00 \\
\hline & $\mathrm{Y} 3$ & 0.05 & 0.05 & 0.00 & 0.00 & 0.00 & 0.00 \\
\hline & $\mathrm{Z3}$ & 1.23 & -1.13 & 1.18 & -1.18 & 1.18 & 1.40 \\
\hline & $\mathrm{X} 1$ & -3.79 & 6.04 & -3.84 & 5.99 & 4.91 & 24.13 \\
\hline & $\mathrm{Y} 1$ & 4.96 & -3.11 & 4.91 & -3.16 & 4.04 & 16.30 \\
\hline & $\mathrm{Z} 1$ & -0.29 & 0.40 & -0.34 & 0.35 & 0.34 & 0.12 \\
\hline & $\mathrm{Z} 2$ & 6.05 & -3.80 & 6.00 & -3.85 & 4.92 & 24.23 \\
\hline & $\mathrm{Y} 2$ & -3.62 & 5.63 & -3.67 & 5.58 & 4.63 & 21.41 \\
\hline & $\mathrm{Z} 2$ & 1.58 & -1.48 & 1.53 & -1.53 & 1.53 & 2.33 \\
\hline & X3 & 0.05 & 0.05 & 0.00 & 0.00 & 0.00 & 0.00 \\
\hline & Y3 & 0.05 & 0.05 & 0.00 & 0.00 & 0.00 & 0.00 \\
\hline & $\mathrm{Z3}$ & -1.13 & 1.23 & -1.18 & 1.18 & 1.18 & 1.40 \\
\hline & & & & & um & & $\begin{array}{r}178.1 \\
13.3\end{array}$ \\
\hline
\end{tabular}


Table A.17: Two degree sequential perturbation for ky.

\begin{tabular}{|c|c|c|c|c|c|c|c|}
\hline \multirow{3}{*}{ Initial } & & $\mathbf{R}_{\mathbf{i}}^{+}$ & $\mathbf{R}_{\mathbf{i}}^{-}$ & $\mathbf{R}_{\mathbf{i}}^{+}$ & $\mathbf{R}_{\mathbf{i}}^{-}$ & $\mathbf{R}_{\mathbf{i}}$ & $\mathbf{R}_{i}{ }^{2}$ \\
\hline & $\mathrm{X} 1$ & 0.00 & 0.00 & 0.00 & 0.00 & 0.00 & 0.00 \\
\hline & Y1 & 0.00 & 0.00 & 0.00 & 0.00 & 0.00 & 0.00 \\
\hline \multirow{16}{*}{ Final } & $\mathrm{Z} 1$ & -0.01 & 0.01 & -0.01 & 0.01 & 0.01 & 0.00 \\
\hline & Z2 & 0.00 & 0.00 & 0.00 & 0.00 & 0.00 & 0.00 \\
\hline & Y2 & 0.00 & 0.00 & 0.00 & 0.00 & 0.00 & 0.00 \\
\hline & Z2 & 0.00 & 0.00 & 0.00 & 0.00 & 0.00 & 0.00 \\
\hline & X3 & 0.00 & 0.00 & 0.00 & 0.00 & 0.00 & 0.00 \\
\hline & Y3 & 0.00 & 0.00 & 0.00 & 0.00 & 0.00 & 0.00 \\
\hline & Z3 & 0.01 & -0.01 & 0.01 & -0.01 & 0.01 & 0.00 \\
\hline & $\mathrm{X} 1$ & 0.00 & 0.00 & 0.00 & 0.00 & 0.00 & 0.00 \\
\hline & Y1 & 0.00 & 0.00 & 0.00 & 0.00 & 0.00 & 0.00 \\
\hline & $\mathrm{Z} 1$ & 0.01 & -0.01 & 0.01 & -0.01 & 0.01 & 0.00 \\
\hline & $\mathrm{Z} 2$ & 0.00 & 0.00 & 0.00 & 0.00 & 0.00 & 0.00 \\
\hline & $\mathrm{Y} 2$ & 0.00 & 0.00 & 0.00 & 0.00 & 0.00 & 0.00 \\
\hline & $\mathrm{Z2}$ & 0.00 & 0.00 & 0.00 & 0.00 & 0.00 & 0.00 \\
\hline & X3 & 0.00 & 0.00 & 0.00 & 0.00 & 0.00 & 0.00 \\
\hline & Y3 & 0.00 & 0.00 & 0.00 & 0.00 & 0.00 & 0.00 \\
\hline & Z3 & -0.01 & 0.01 & -0.01 & 0.01 & 0.01 & 0.00 \\
\hline & & & & & $\begin{array}{l}\text { m } \\
\text { cer }\end{array}$ & & $\begin{array}{l}0.0 \\
0.01\end{array}$ \\
\hline
\end{tabular}


Table A.18: Two degree sequential perturbation for yo.

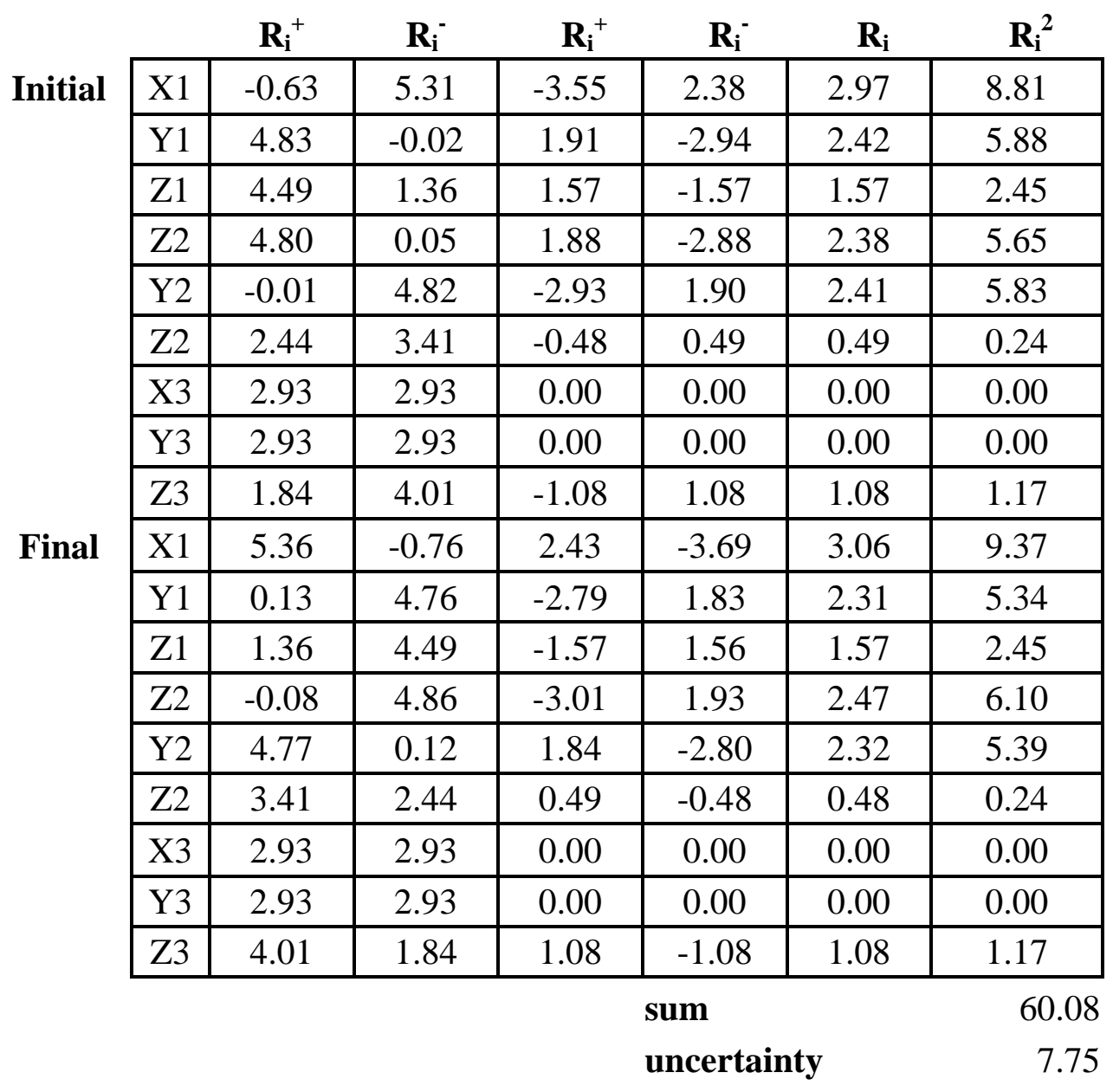




\section{Tables A.19-A.27: Three Degree Sequential Perturbation Results}

Table A.19: Three degree initial coordinate values.

\begin{tabular}{l|c|c|c|}
\cline { 2 - 4 } & $\mathbf{X}$ & $\mathbf{Y}$ & $\mathbf{Z}$ \\
\cline { 2 - 4 } Target 1 & -31.92 & 19.67 & 200.00 \\
\cline { 2 - 4 } Target 2 & 28.05 & -37.05 & 200.00 \\
\cline { 2 - 4 } Target 3 & 47.21 & 43.28 & 200.00 \\
\cline { 2 - 4 } & &
\end{tabular}

Table A.20: Three degree final coordinate values.

\begin{tabular}{l|c|c|c|}
\cline { 2 - 4 } & $\mathbf{X}$ & $\mathbf{Y}$ & $\mathbf{Z}$ \\
\cline { 2 - 4 } Target 1 & -32.68 & 17.98 & 200.00 \\
\cline { 2 - 4 } Target 2 & 30.18 & -35.53 & 200.00 \\
\cline { 2 - 4 } Target 3 & 45.11 & 45.69 & 200.00 \\
\cline { 2 - 4 } & & \multicolumn{3}{|c}{}
\end{tabular}

Table A.21: Three degree original parameter results.

\begin{tabular}{|c|c|}
\hline $\mathrm{kx}$ & 0.00 \\
\hline $\mathrm{x} 0$ & 0.04 \\
\hline $\mathrm{ky}$ & 0.00 \\
\hline $\mathrm{y} 0$ & 4.39 \\
\hline
\end{tabular}


Table A.22: Three degree parameter values after addition.

\begin{tabular}{|c|c|c|c|c|c|c|c|c|c|}
\hline \multicolumn{10}{|c|}{ Initial Coordinates } \\
\hline & $\mathrm{X} 1$ & $\mathrm{Y} 1$ & Z1 & $\mathrm{Z} 2$ & $\mathrm{Y} 2$ & $\mathrm{Z} 2$ & X3 & Y3 & $\mathrm{Z3}$ \\
\hline $\mathrm{Kx}$ & 0.00 & 0.00 & 0.00 & 0.00 & 0.00 & 0.01 & 0.00 & 0.00 & 0.00 \\
\hline Xo & 2.23 & -1.49 & 0.26 & -1.77 & 2.34 & -0.97 & 0.04 & 0.04 & 0.84 \\
\hline Ky & 0.00 & 0.00 & -0.01 & 0.00 & 0.00 & 0.00 & 0.00 & 0.00 & 0.00 \\
\hline Yo & 3.02 & 5.25 & 5.44 & 5.20 & 3.37 & 4.06 & 4.39 & 4.39 & 3.68 \\
\hline
\end{tabular}

Final Coordinates

\begin{tabular}{|c|c|c|c|c|c|c|c|c|c|}
\cline { 2 - 10 } \multicolumn{1}{c|}{} & $\mathrm{X} 1$ & $\mathrm{Y} 1$ & $\mathrm{Z} 1$ & $\mathrm{Z} 2$ & $\mathrm{Y} 2$ & $\mathrm{Z} 2$ & $\mathrm{X} 3$ & $\mathrm{Y} 3$ & $\mathrm{Z} 3$ \\
\hline $\mathrm{Kx}$ & 0.00 & 0.00 & 0.00 & 0.00 & 0.00 & -0.01 & 0.00 & 0.00 & 0.00 \\
\hline $\mathrm{Xo}$ & -1.85 & 1.80 & -0.18 & 2.35 & -1.76 & 1.06 & 0.04 & 0.04 & -0.75 \\
\hline $\mathrm{Ky}$ & 0.00 & 0.00 & 0.01 & 0.00 & 0.00 & 0.00 & 0.00 & 0.00 & 0.00 \\
\hline $\mathrm{Yo}$ & 5.60 & 3.44 & 3.35 & 3.37 & 5.20 & 4.73 & 4.39 & 4.39 & 5.11 \\
\hline
\end{tabular}

Table A.23: Three degree parameter values after subtraction.

\begin{tabular}{|c|c|c|c|c|c|c|c|c|c|}
\hline & $\mathrm{X} 1$ & Y1 & $\mathrm{Z} 1$ & $\mathrm{Z} 2$ & Y2 & $\mathrm{Z} 2$ & X3 & Y3 & Z3 \\
\hline $\mathrm{Kx}$ & 0.00 & 0.00 & 0.00 & 0.00 & 0.00 & -0.01 & 0.00 & 0.00 & 0.00 \\
\hline Xo & -1.78 & 1.93 & -0.18 & 2.22 & -1.85 & 1.06 & 0.04 & 0.04 & -0.75 \\
\hline $\mathrm{Ky}$ & 0.00 & 0.00 & 0.01 & 0.00 & 0.00 & 0.00 & 0.00 & 0.00 & 0.00 \\
\hline Yo & 5.56 & 3.36 & 3.35 & 3.42 & 5.24 & 4.73 & 4.39 & 4.39 & 5.11 \\
\hline
\end{tabular}

\section{Final Coordinates}

\begin{tabular}{|c|c|c|c|c|c|c|c|c|c|}
\cline { 2 - 10 } \multicolumn{1}{c|}{} & $\mathrm{X} 1$ & $\mathrm{Y} 1$ & $\mathrm{Z} 1$ & $\mathrm{Z} 2$ & $\mathrm{Y} 2$ & $\mathrm{Z} 2$ & $\mathrm{X} 3$ & $\mathrm{Y} 3$ & $\mathrm{Z} 3$ \\
\hline $\mathrm{Kx}$ & 0.00 & 0.00 & 0.00 & 0.00 & 0.00 & 0.01 & 0.00 & 0.00 & 0.00 \\
\hline $\mathrm{Xo}$ & 2.34 & -1.40 & 0.26 & -1.86 & 2.21 & -0.97 & 0.04 & 0.04 & 0.84 \\
\hline $\mathrm{Ky}$ & 0.00 & 0.00 & -0.01 & 0.00 & 0.00 & 0.00 & 0.00 & 0.00 & 0.00 \\
\hline $\mathrm{Yo}$ & 2.96 & 5.19 & 5.44 & 5.24 & 3.43 & 4.06 & 4.39 & 4.39 & 3.68 \\
\hline
\end{tabular}


Table A.24: Three degree sequential perturbation for $\mathbf{k x}$.

\begin{tabular}{|c|c|c|c|c|c|c|c|}
\hline \multirow{3}{*}{ Initial } & \multicolumn{2}{|c|}{$\mathbf{R}_{\mathbf{i}}^{+}$} & $\mathbf{R}_{\mathbf{i}}^{-}$ & $\mathbf{R}_{\mathbf{i}}^{+}$ & $\mathbf{R}_{\mathbf{i}}^{-}$ & $\mathbf{R}_{\mathbf{i}}$ & $\mathbf{R}_{\mathbf{i}}{ }^{2}$ \\
\hline & $\mathrm{X} 1$ & 0.00 & 0.00 & 0.00 & 0.00 & 0.00 & 0.00 \\
\hline & Y1 & 0.00 & 0.00 & 0.00 & 0.00 & 0.00 & 0.00 \\
\hline \multirow{16}{*}{ Final } & $\mathrm{Z} 1$ & 0.00 & 0.00 & 0.00 & 0.00 & 0.00 & 0.00 \\
\hline & $\mathrm{Z} 2$ & 0.00 & 0.00 & 0.00 & 0.00 & 0.00 & 0.00 \\
\hline & Y2 & 0.00 & 0.00 & 0.00 & 0.00 & 0.00 & 0.00 \\
\hline & $\mathrm{Z} 2$ & 0.01 & -0.01 & 0.01 & -0.01 & 0.01 & 0.00 \\
\hline & X3 & 0.00 & 0.00 & 0.00 & 0.00 & 0.00 & 0.00 \\
\hline & $\mathrm{Y} 3$ & 0.00 & 0.00 & 0.00 & 0.00 & 0.00 & 0.00 \\
\hline & $\mathrm{Z3}$ & 0.00 & 0.00 & 0.00 & 0.00 & 0.00 & 0.00 \\
\hline & $\mathrm{X} 1$ & 0.00 & 0.00 & 0.00 & 0.00 & 0.00 & 0.00 \\
\hline & $\mathrm{Y} 1$ & 0.00 & 0.00 & 0.00 & 0.00 & 0.00 & 0.00 \\
\hline & $\mathrm{Z} 1$ & 0.00 & 0.00 & 0.00 & 0.00 & 0.00 & 0.00 \\
\hline & $\mathrm{Z} 2$ & 0.00 & 0.00 & 0.00 & 0.00 & 0.00 & 0.00 \\
\hline & $\mathrm{Y} 2$ & 0.00 & 0.00 & 0.00 & 0.00 & 0.00 & 0.00 \\
\hline & $\mathrm{Z} 2$ & -0.01 & 0.01 & -0.01 & 0.01 & 0.01 & 0.00 \\
\hline & $\mathrm{X} 3$ & 0.00 & 0.00 & 0.00 & 0.00 & 0.00 & 0.00 \\
\hline & $\mathrm{Y3}$ & 0.00 & 0.00 & 0.00 & 0.00 & 0.00 & 0.00 \\
\hline & $\mathrm{Z3}$ & 0.00 & 0.00 & 0.00 & 0.00 & 0.00 & 0.00 \\
\hline
\end{tabular}


Table A.25: Three degree sequential perturbation for xo.

\begin{tabular}{|c|c|c|c|c|c|c|c|}
\hline \multirow{3}{*}{ Initial } & \multicolumn{2}{|c|}{$\mathbf{R}_{\mathbf{i}}^{+}$} & $\mathbf{R}_{\mathbf{i}}^{-}$ & $\mathbf{R}_{\mathbf{i}}^{+}$ & $\mathbf{R}_{\mathbf{i}}^{-}$ & $\mathbf{R}_{\mathbf{i}}$ & \multirow{2}{*}{$\frac{\mathbf{R}_{\mathbf{i}}{ }^{2}}{4.01}$} \\
\hline & $\mathrm{X} 1$ & 2.23 & -1.78 & 2.18 & -1.82 & 2.00 & \\
\hline & $\mathrm{Y} 1$ & -1.49 & 1.93 & -1.53 & 1.89 & 1.71 & 2.92 \\
\hline \multirow{16}{*}{ Final } & $\mathrm{Z} 1$ & 0.26 & -0.18 & 0.22 & -0.22 & 0.22 & 0.05 \\
\hline & $\mathrm{Z} 2$ & -1.77 & 2.22 & -1.81 & 2.17 & 1.99 & 3.97 \\
\hline & Y2 & 2.34 & -1.85 & 2.29 & -1.89 & 2.09 & 4.38 \\
\hline & $\mathrm{Z} 2$ & -0.97 & 1.06 & -1.02 & 1.02 & 1.02 & 1.03 \\
\hline & X3 & 0.04 & 0.04 & 0.00 & 0.00 & 0.00 & 0.00 \\
\hline & $\mathrm{Y} 3$ & 0.04 & 0.04 & 0.00 & 0.00 & 0.00 & 0.00 \\
\hline & $\mathrm{Z3}$ & 0.84 & -0.75 & 0.79 & -0.80 & 0.80 & 0.63 \\
\hline & $\mathrm{X} 1$ & -1.85 & 2.34 & -1.89 & 2.29 & 2.09 & 4.37 \\
\hline & $\mathrm{Y} 1$ & 1.80 & -1.40 & 1.76 & -1.44 & 1.60 & 2.56 \\
\hline & $\mathrm{Z} 1$ & -0.18 & 0.26 & -0.22 & 0.22 & 0.22 & 0.05 \\
\hline & $\mathrm{Z} 2$ & 2.35 & -1.86 & 2.30 & -1.90 & 2.10 & 4.41 \\
\hline & $\mathrm{Y} 2$ & -1.76 & 2.21 & -1.80 & 2.17 & 1.98 & 3.94 \\
\hline & $\mathrm{Z} 2$ & 1.06 & -0.97 & 1.02 & -1.02 & 1.02 & 1.03 \\
\hline & $\mathrm{X} 3$ & 0.04 & 0.04 & 0.00 & 0.00 & 0.00 & 0.00 \\
\hline & $\mathrm{Y3}$ & 0.04 & 0.04 & 0.00 & 0.00 & 0.00 & 0.00 \\
\hline & $\mathrm{Z3}$ & -0.75 & 0.84 & -0.80 & 0.79 & 0.80 & 0.63 \\
\hline
\end{tabular}


Table A.26: Three degree sequential perturbation for ky.

\begin{tabular}{|c|c|c|c|c|c|c|c|}
\hline \multirow{3}{*}{ Initial } & \multicolumn{2}{|c|}{$\mathbf{R}_{\mathbf{i}}^{+}$} & \multirow{2}{*}{$\begin{array}{r}\mathbf{R}_{\mathbf{i}}^{-} \\
0.00 \\
\end{array}$} & \multirow{2}{*}{$\begin{array}{l}\mathbf{R}_{\mathbf{i}}^{+} \\
0.00 \\
\end{array}$} & \multirow{2}{*}{$\begin{array}{r}\mathbf{R}_{\mathbf{i}}^{-} \\
0.00 \\
\end{array}$} & \multirow{2}{*}{$\begin{array}{l}\mathbf{R}_{\mathbf{i}} \\
0.00 \\
\end{array}$} & \multirow{2}{*}{$\begin{array}{r}\mathbf{R}_{\mathbf{i}}^{2} \\
0.00 \\
\end{array}$} \\
\hline & $\mathrm{X} 1$ & 0.00 & & & & & \\
\hline & $\mathrm{Y} 1$ & 0.00 & 0.00 & 0.00 & 0.00 & 0.00 & 0.00 \\
\hline \multirow{16}{*}{ Final } & $\mathrm{Z} 1$ & -0.01 & 0.01 & -0.01 & 0.01 & 0.01 & 0.00 \\
\hline & $\mathrm{Z} 2$ & 0.00 & 0.00 & 0.00 & 0.00 & 0.00 & 0.00 \\
\hline & Y2 & 0.00 & 0.00 & 0.00 & 0.00 & 0.00 & 0.00 \\
\hline & $\mathrm{Z} 2$ & 0.00 & 0.00 & 0.00 & 0.00 & 0.00 & 0.00 \\
\hline & $\mathrm{X} 3$ & 0.00 & 0.00 & 0.00 & 0.00 & 0.00 & 0.00 \\
\hline & $\mathrm{Y3}$ & 0.00 & 0.00 & 0.00 & 0.00 & 0.00 & 0.00 \\
\hline & $\mathrm{Z3}$ & 0.00 & 0.00 & 0.00 & 0.00 & 0.00 & 0.00 \\
\hline & $\mathrm{X} 1$ & 0.00 & 0.00 & 0.00 & 0.00 & 0.00 & 0.00 \\
\hline & $\mathrm{Y} 1$ & 0.00 & 0.00 & 0.00 & 0.00 & 0.00 & 0.00 \\
\hline & $\mathrm{Z} 1$ & 0.01 & -0.01 & 0.01 & -0.01 & 0.01 & 0.00 \\
\hline & $\mathrm{Z} 2$ & 0.00 & 0.00 & 0.00 & 0.00 & 0.00 & 0.00 \\
\hline & $\mathrm{Y} 2$ & 0.00 & 0.00 & 0.00 & 0.00 & 0.00 & 0.00 \\
\hline & $\mathrm{Z} 2$ & 0.00 & 0.00 & 0.00 & 0.00 & 0.00 & 0.00 \\
\hline & $\mathrm{X} 3$ & 0.00 & 0.00 & 0.00 & 0.00 & 0.00 & 0.00 \\
\hline & $\mathrm{Y} 3$ & 0.00 & 0.00 & 0.00 & 0.00 & 0.00 & 0.00 \\
\hline & $\mathrm{Z3}$ & 0.00 & 0.00 & 0.00 & 0.00 & 0.00 & 0.00 \\
\hline & & & & & Im & & $\begin{array}{l}0.00 \\
0.01\end{array}$ \\
\hline
\end{tabular}


Table A.27: Three degree sequential perturbation for yo.

\begin{tabular}{|c|c|c|c|c|c|c|c|}
\hline \multirow{3}{*}{ Initial } & & $i^{+}$ & $\mathbf{R}_{\mathbf{i}}^{-}$ & $\mathbf{R}_{i}^{+}$ & $\mathbf{R}_{\mathbf{i}}^{-}$ & $\mathbf{R}_{\mathbf{i}}$ & $\mathbf{R}_{i}{ }^{2}$ \\
\hline & $\mathrm{X} 1$ & 3.02 & 5.56 & -1.38 & 1.17 & 1.27 & 1.62 \\
\hline & $\mathrm{Y} 1$ & 5.25 & 3.36 & 0.85 & -1.03 & 0.94 & 0.89 \\
\hline \multirow{16}{*}{ Final } & $\mathrm{Z} 1$ & 5.44 & 3.35 & 1.05 & -1.05 & 1.05 & 1.09 \\
\hline & $\mathrm{Z} 2$ & 5.20 & 3.42 & 0.81 & -0.97 & 0.89 & 0.79 \\
\hline & $\mathrm{Y} 2$ & 3.37 & 5.24 & -1.02 & 0.84 & 0.93 & 0.87 \\
\hline & $\mathrm{Z} 2$ & 4.06 & 4.73 & -0.33 & 0.33 & 0.33 & 0.11 \\
\hline & X3 & 4.39 & 4.39 & 0.00 & 0.00 & 0.00 & 0.00 \\
\hline & $\mathrm{Y} 3$ & 4.39 & 4.39 & 0.00 & 0.00 & 0.00 & 0.00 \\
\hline & $\mathrm{Z3}$ & 3.68 & 5.11 & -0.71 & 0.71 & 0.71 & 0.51 \\
\hline & $\mathrm{X} 1$ & 5.60 & 2.96 & 1.21 & -1.44 & 1.32 & 1.75 \\
\hline & $\mathrm{Y} 1$ & 3.44 & 5.19 & -0.96 & 0.79 & 0.88 & 0.77 \\
\hline & $\mathrm{Z} 1$ & 3.35 & 5.44 & -1.05 & 1.05 & 1.05 & 1.09 \\
\hline & $\mathrm{Z} 2$ & 3.37 & 5.24 & -1.03 & 0.85 & 0.94 & 0.88 \\
\hline & $\mathrm{Y} 2$ & 5.20 & 3.43 & 0.80 & -0.97 & 0.89 & 0.78 \\
\hline & $\mathrm{Z} 2$ & 4.73 & 4.06 & 0.33 & -0.33 & 0.33 & 0.11 \\
\hline & $\mathrm{X} 3$ & 4.39 & 4.39 & 0.00 & 0.00 & 0.00 & 0.00 \\
\hline & Y3 & 4.39 & 4.39 & 0.00 & 0.00 & 0.00 & 0.00 \\
\hline & $\mathrm{Z3}$ & 5.11 & 3.68 & 0.71 & -0.71 & 0.71 & 0.51 \\
\hline & & & & & um & & 11.77 \\
\hline & & & & & incer & & 3.43 \\
\hline
\end{tabular}




\section{Tables A.28-A.36: Four Degree Sequential Perturbation Results}

Table A.28: Four degree initial coordinate values.

\begin{tabular}{c|c|c|c|}
\cline { 2 - 4 } & $\mathbf{X}$ & $\mathbf{Y}$ & $\mathbf{Z}$ \\
\cline { 2 - 4 } Target 1 & -31.92 & 19.67 & 200.00 \\
\cline { 2 - 4 } Target 2 & 28.05 & -37.05 & 200.00 \\
\cline { 2 - 4 } Target 3 & 47.21 & 43.28 & 200.00 \\
\cline { 2 - 4 } & &
\end{tabular}

Table A.29: Four degree final coordinate values.

\begin{tabular}{c|c|c|c|}
\cline { 2 - 4 } & $\mathbf{X}$ & $\mathbf{Y}$ & $\mathbf{Z}$ \\
\cline { 2 - 4 } Target 1 & -32.81 & 17.41 & 200.00 \\
\cline { 2 - 4 } Target 2 & 30.98 & -34.99 & 200.00 \\
\cline { 2 - 4 } Target 3 & 44.49 & 46.48 & 200.00 \\
\cline { 2 - 4 } & & \multicolumn{3}{|c|}{}
\end{tabular}

Table A.30: Four degree original parameter results.

\begin{tabular}{|c|c|}
\hline $\mathrm{kx}$ & 0.00 \\
\hline $\mathrm{x} 0$ & 0.01 \\
\hline $\mathrm{ky}$ & 0.00 \\
\hline $\mathrm{y} 0$ & 5.87 \\
\hline
\end{tabular}


Table A.31: Four degree parameter values after addition.

\begin{tabular}{|c|c|c|c|c|c|c|c|c|c|}
\hline & X1 & Y1 & Z1 & $\mathrm{Z2}$ & Y2 & $\mathrm{Z2}$ & X3 & Y3 & Z3 \\
\hline $\mathrm{Kx}$ & 0.00 & 0.00 & 0.00 & 0.00 & 0.00 & 0.00 & 0.00 & 0.00 & 0.00 \\
\hline Xo & 1.17 & -0.84 & 0.17 & -1.03 & 1.27 & -0.75 & 0.01 & 0.01 & 0.61 \\
\hline $\mathrm{Ky}$ & 0.00 & 0.00 & 0.00 & 0.00 & 0.00 & 0.00 & 0.00 & 0.00 & 0.00 \\
\hline Yo & 5.13 & 6.32 & 6.66 & 6.28 & 5.38 & 5.62 & 5.87 & 5.87 & 5.34 \\
\hline
\end{tabular}

Final Coordinates

\begin{tabular}{|c|c|c|c|c|c|c|c|c|c|}
\cline { 2 - 10 } \multicolumn{1}{c|}{} & $\mathrm{X} 1$ & $\mathrm{Y} 1$ & $\mathrm{Z} 1$ & $\mathrm{Z} 2$ & $\mathrm{Y} 2$ & $\mathrm{Z} 2$ & $\mathrm{X} 3$ & $\mathrm{Y} 3$ & $\mathrm{Z} 3$ \\
\hline $\mathrm{Kx}$ & 0.00 & 0.00 & 0.00 & 0.00 & 0.00 & 0.00 & 0.00 & 0.00 & 0.00 \\
\hline $\mathrm{Xo}$ & -1.09 & 0.88 & -0.15 & 1.25 & -1.04 & 0.77 & 0.01 & 0.01 & -0.59 \\
\hline $\mathrm{Ky}$ & 0.00 & 0.00 & 0.00 & 0.00 & 0.00 & 0.00 & 0.00 & 0.00 & 0.00 \\
\hline $\mathrm{Yo}$ & 6.58 & 0.07 & 5.09 & 5.39 & 6.28 & 6.13 & 5.87 & 5.87 & 6.40 \\
\hline
\end{tabular}

Table A.32: Four degree parameter values after subtraction.

Initial Coordinates
\begin{tabular}{|c|c|c|c|c|c|c|c|c|c|}
\multicolumn{1}{|c|}{} & $\mathrm{X} 1$ & $\mathrm{Y} 1$ & $\mathrm{Z} 1$ & $\mathrm{Z} 2$ & $\mathrm{Y} 2$ & $\mathrm{Z} 2$ & $\mathrm{X} 3$ & $\mathrm{Y} 3$ & $\mathrm{Z} 3$ \\
\hline $\mathrm{Kx}$ & 0.00 & 0.00 & 0.00 & 0.00 & 0.00 & 0.00 & 0.00 & 0.00 & 0.00 \\
\hline $\mathrm{Xo}$ & -1.04 & 0.97 & -0.15 & 1.16 & -1.11 & 0.77 & 0.01 & 0.01 & -0.59 \\
\hline $\mathrm{Ky}$ & 0.00 & 0.00 & 0.00 & 0.00 & 0.00 & 0.00 & 0.00 & 0.00 & 0.00 \\
\hline $\mathrm{Yo}$ & 6.56 & 5.37 & 5.09 & 5.42 & 6.31 & 6.13 & 5.87 & 5.87 & 6.40 \\
\hline
\end{tabular}

\section{Final Coordinates}

\begin{tabular}{|c|c|c|c|c|c|c|c|c|c|}
\cline { 2 - 10 } \multicolumn{1}{c|}{} & $\mathrm{X} 1$ & $\mathrm{Y} 1$ & $\mathrm{Z} 1$ & $\mathrm{Z} 2$ & $\mathrm{Y} 2$ & $\mathrm{Z} 2$ & $\mathrm{X} 3$ & $\mathrm{Y} 3$ & $\mathrm{Z} 3$ \\
\hline $\mathrm{Kx}$ & 0.00 & 0.00 & 0.00 & 0.00 & 0.00 & 0.00 & 0.00 & 0.00 & 0.00 \\
\hline $\mathrm{Xo}$ & 1.24 & -0.76 & 0.17 & -1.10 & 1.18 & -0.75 & 0.01 & 0.01 & 0.61 \\
\hline $\mathrm{Ky}$ & 0.00 & 0.00 & 0.00 & 0.00 & 0.00 & 0.00 & 0.00 & 0.00 & 0.00 \\
\hline $\mathrm{Yo}$ & 5.09 & 6.27 & 6.66 & 6.31 & 5.41 & 5.62 & 5.87 & 5.87 & 5.34 \\
\hline
\end{tabular}


Table A.33: Four degree sequential perturbation for kx.

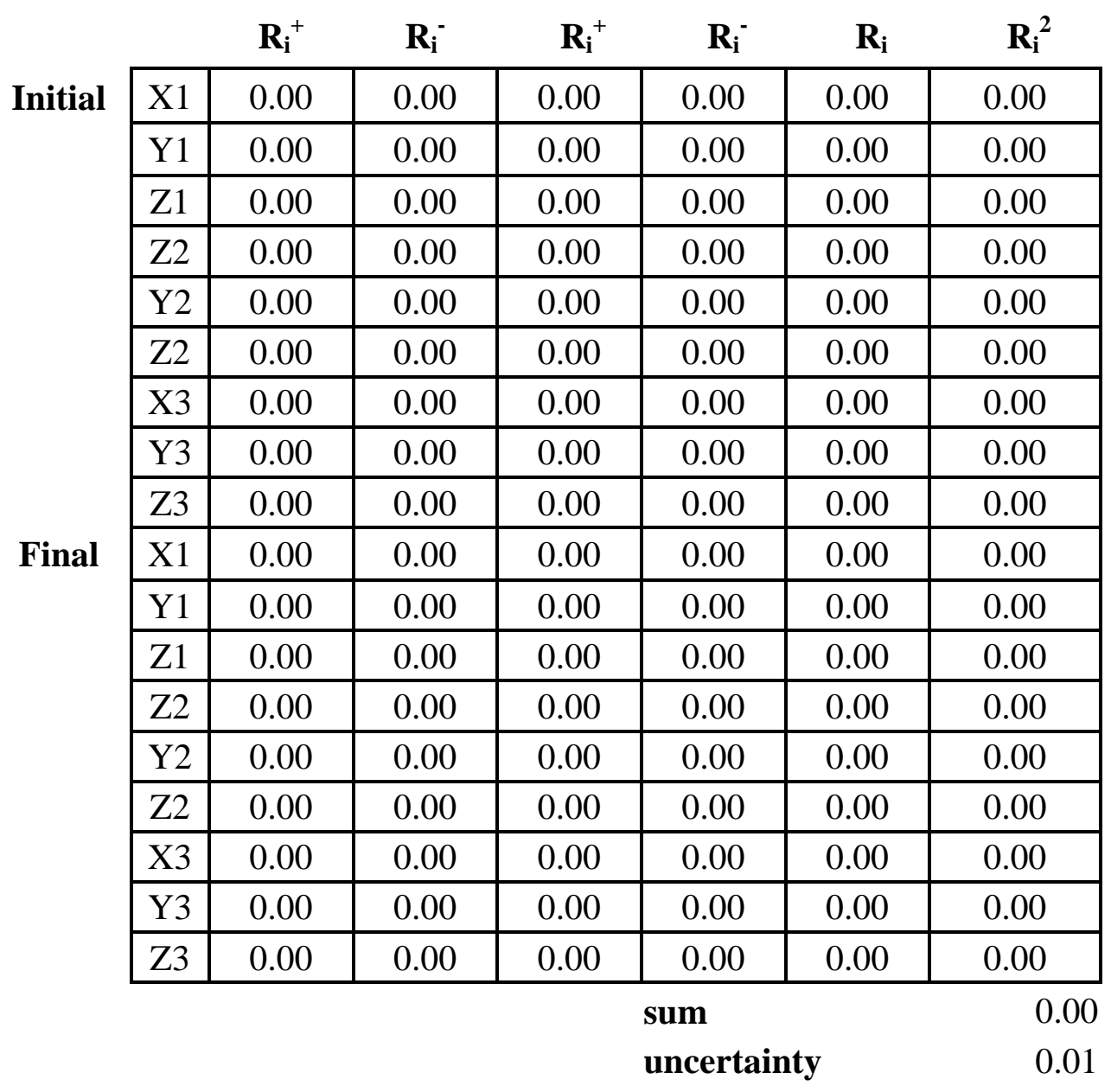


Table A.34: Four degree sequential perturbation for xo.

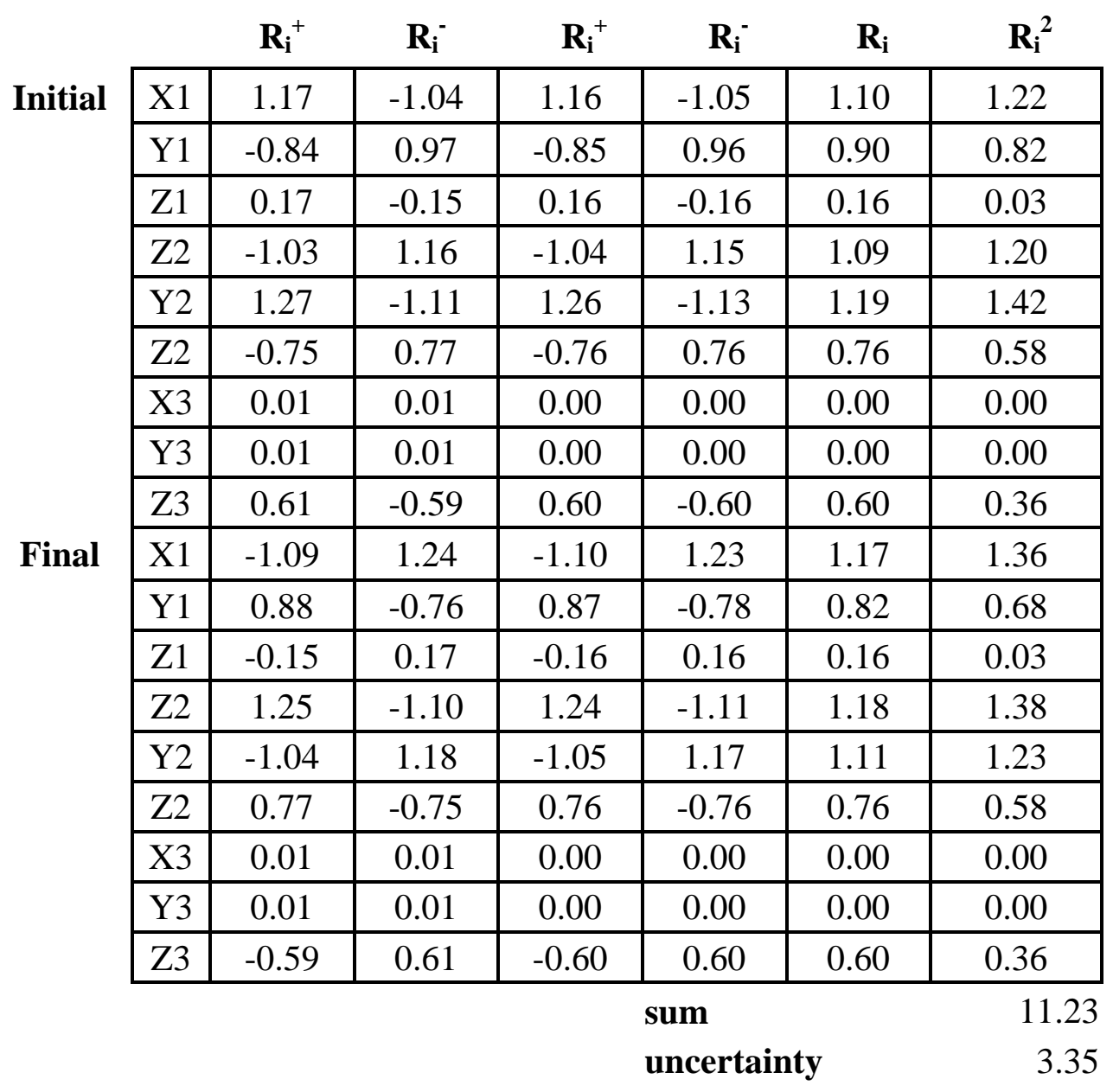


Table A.35: Four degree sequential perturbation for ky.

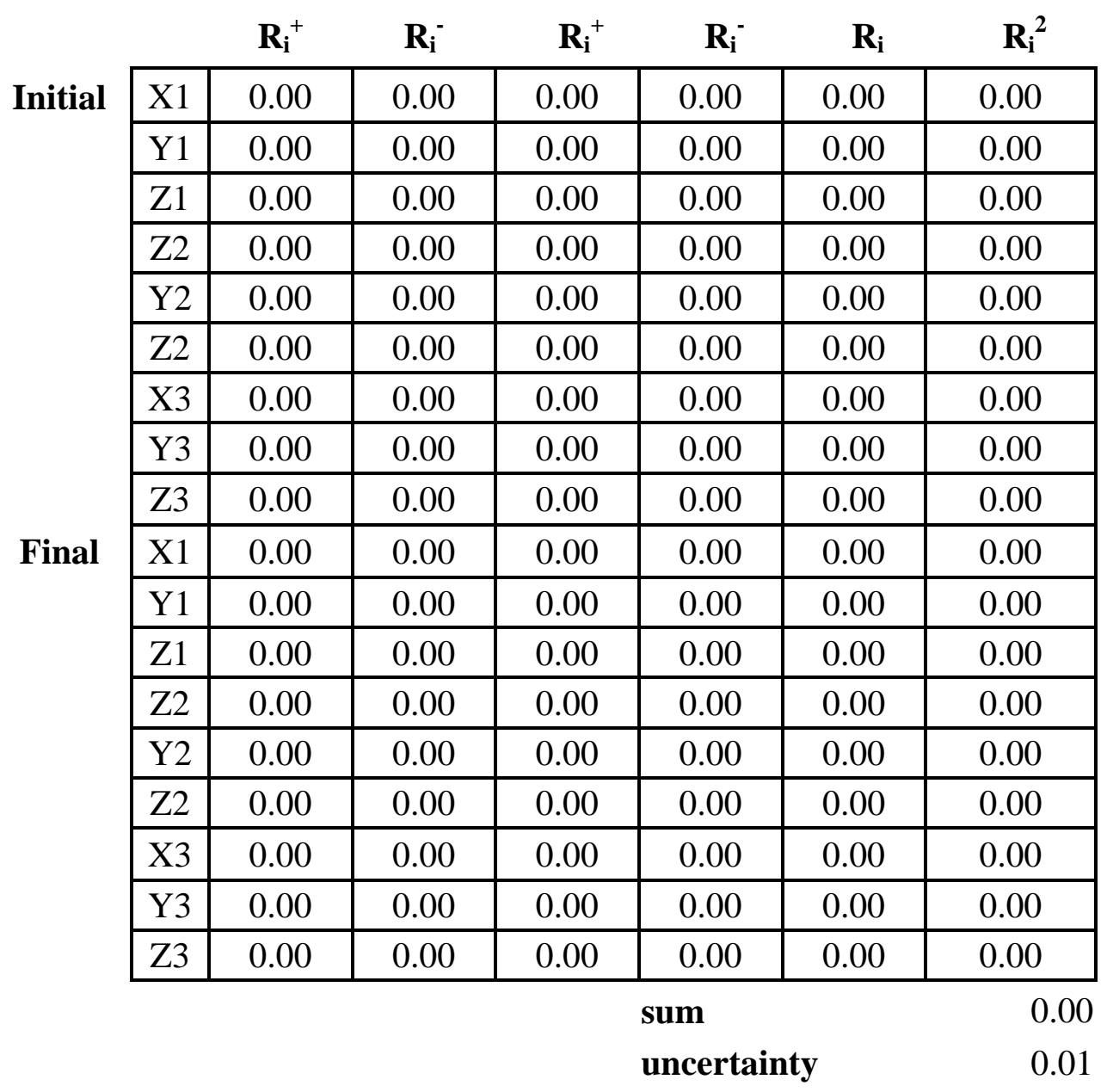


Table A.36: Four degree sequential perturbation for yo.

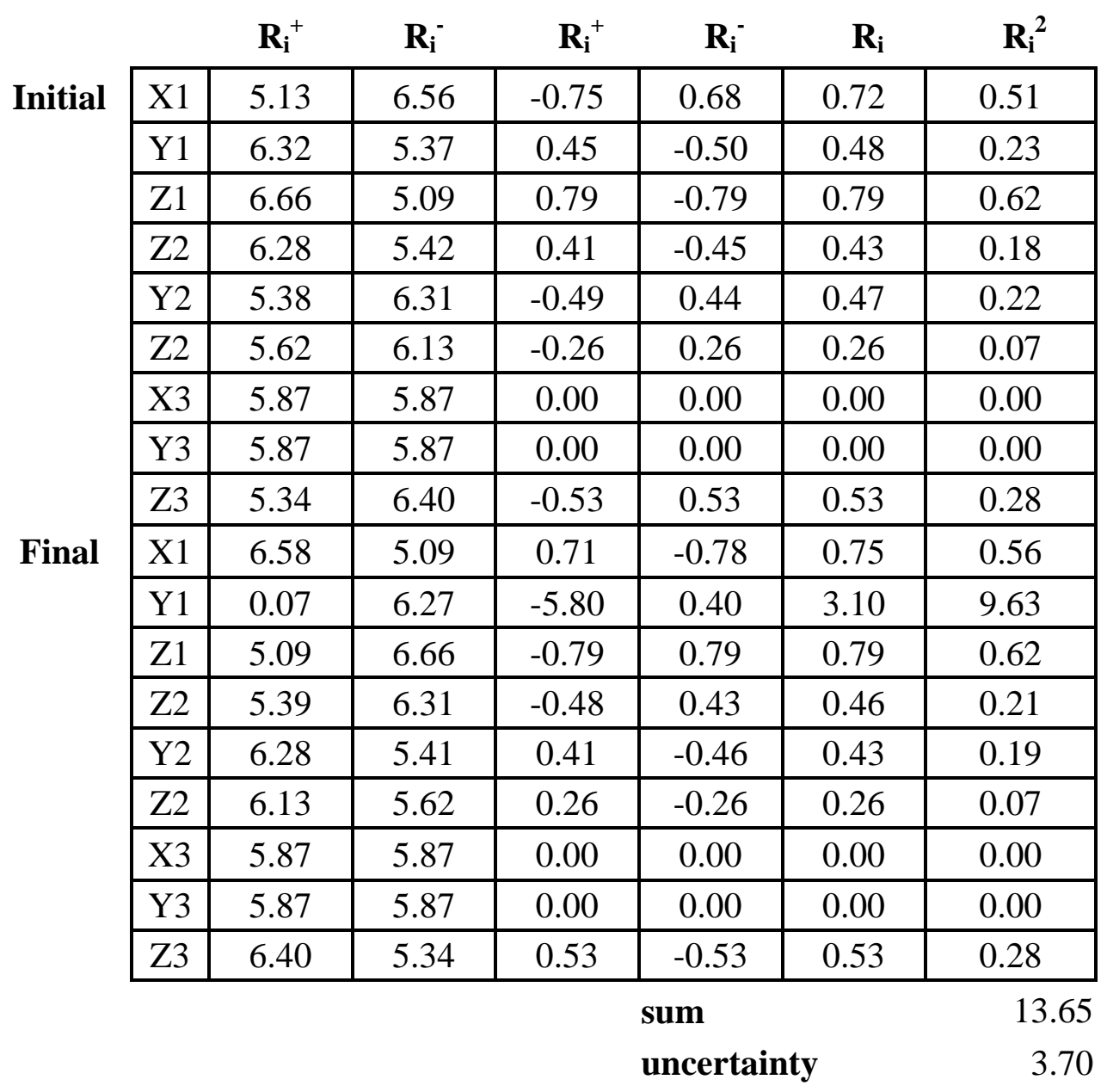


Tables A.37-A.45: Five Degree Sequential Perturbation Results

Table A.37: Five degree initial coordinate values.

\begin{tabular}{l|c|c|c|}
\cline { 2 - 4 } & $\mathbf{X}$ & $\mathbf{Y}$ & $\mathbf{Z}$ \\
\cline { 2 - 4 } Target 1 & -31.92 & 19.67 & 200.00 \\
\cline { 2 - 4 } Target 2 & 28.05 & -37.05 & 200.00 \\
\cline { 2 - 4 } Target 3 & 47.21 & 43.28 & 200.00 \\
\cline { 2 - 4 } & &
\end{tabular}

Table A.38: Five degree final coordinate values.

\begin{tabular}{c|c|c|c|}
\cline { 2 - 4 } & $\mathbf{X}$ & $\mathbf{Y}$ & $\mathbf{Z}$ \\
\cline { 2 - 4 } Target 1 & -32.88 & 16.84 & 200.00 \\
\cline { 2 - 4 } Target 2 & 31.82 & -34.43 & 200.00 \\
\cline { 2 - 4 } Target 3 & 43.90 & 47.26 & 200.00 \\
\cline { 2 - 4 } & &
\end{tabular}

Table A.39: Five degree original parameter results.

\begin{tabular}{|c|c|}
\hline $\mathrm{kx}$ & 0.00 \\
\hline $\mathrm{x} 0$ & -0.04 \\
\hline $\mathrm{ky}$ & 0.00 \\
\hline $\mathrm{y} 0$ & 7.36 \\
\hline
\end{tabular}


Table A.40: Five degree parameter values after addition.

\begin{tabular}{|c|c|c|c|c|c|c|c|c|c|}
\hline & X1 & Y1 & Z1 & $\mathrm{Z2}$ & Y2 & $\mathrm{Z2}$ & X3 & Y3 & Z3 \\
\hline $\mathrm{Kx}$ & 0.00 & 0.00 & 0.00 & 0.00 & 0.00 & 0.00 & 0.00 & 0.00 & 0.00 \\
\hline Xo & 0.68 & -0.56 & 0.09 & -0.70 & 0.76 & -0.64 & -0.04 & -0.04 & 0.45 \\
\hline $\mathrm{Ky}$ & 0.00 & 0.00 & 0.00 & 0.00 & 0.00 & 0.00 & 0.00 & 0.00 & 0.00 \\
\hline Yo & 6.89 & 7.62 & 7.99 & 7.59 & 7.09 & 7.15 & 7.36 & 7.36 & 6.94 \\
\hline
\end{tabular}

Final Coordinates

\begin{tabular}{|c|c|c|c|c|c|c|c|c|c|}
\cline { 2 - 10 } \multicolumn{1}{c|}{} & $\mathrm{X} 1$ & $\mathrm{Y} 1$ & $\mathrm{Z} 1$ & $\mathrm{Z} 2$ & $\mathrm{Y} 2$ & $\mathrm{Z} 2$ & $\mathrm{X} 3$ & $\mathrm{Y} 3$ & $\mathrm{Z} 3$ \\
\hline $\mathrm{Kx}$ & 0.00 & 0.00 & 0.00 & 0.00 & 0.00 & 0.00 & 0.00 & 0.00 & 0.00 \\
\hline $\mathrm{Xo}$ & -0.75 & 0.46 & -0.16 & 0.74 & -0.72 & 0.57 & -0.04 & -0.04 & -0.52 \\
\hline $\mathrm{Ky}$ & 0.00 & 0.00 & 0.00 & 0.00 & 0.00 & 0.00 & 0.00 & 0.00 & 0.00 \\
\hline $\mathrm{Yo}$ & 7.83 & 7.13 & 6.73 & 7.10 & 7.59 & 7.57 & 7.36 & 7.36 & 7.78 \\
\hline
\end{tabular}

Table A.41: Five degree parameter values after subtraction.

Initial Coordinates
\begin{tabular}{|c|c|c|c|c|c|c|c|c|c|}
\multicolumn{1}{c|}{} & $\mathrm{X} 1$ & $\mathrm{Y} 1$ & $\mathrm{Z} 1$ & $\mathrm{Z} 2$ & $\mathrm{Y} 2$ & $\mathrm{Z} 2$ & $\mathrm{X} 3$ & $\mathrm{Y} 3$ & $\mathrm{Z} 3$ \\
\hline $\mathrm{Kx}$ & 0.00 & 0.00 & 0.00 & 0.00 & 0.00 & 0.00 & 0.00 & 0.00 & 0.00 \\
\hline $\mathrm{Xo}$ & -0.71 & 0.53 & -0.16 & 0.67 & -0.78 & 0.57 & -0.04 & -0.04 & -0.52 \\
\hline $\mathrm{Ky}$ & 0.00 & 0.00 & 0.00 & 0.00 & 0.00 & 0.00 & 0.00 & 0.00 & 0.00 \\
\hline $\mathrm{Yo}$ & 7.81 & 7.08 & 6.73 & 7.12 & 7.61 & 7.57 & 7.36 & 7.36 & 7.78 \\
\hline
\end{tabular}

\section{Final Coordinates}

\begin{tabular}{|c|c|c|c|c|c|c|c|c|c|}
\cline { 2 - 10 } \multicolumn{1}{c|}{} & $\mathrm{X} 1$ & $\mathrm{Y} 1$ & $\mathrm{Z} 1$ & $\mathrm{Z} 2$ & $\mathrm{Y} 2$ & $\mathrm{Z} 2$ & $\mathrm{X} 3$ & $\mathrm{Y} 3$ & $\mathrm{Z} 3$ \\
\hline $\mathrm{Kx}$ & 0.00 & 0.00 & 0.00 & 0.00 & 0.00 & 0.00 & 0.00 & 0.00 & 0.00 \\
\hline $\mathrm{Xo}$ & 0.73 & -0.50 & 0.09 & -0.76 & 0.70 & -0.64 & -0.04 & -0.04 & 0.45 \\
\hline $\mathrm{Ky}$ & 0.00 & 0.00 & 0.00 & 0.00 & 0.00 & 0.00 & 0.00 & 0.00 & 0.00 \\
\hline $\mathrm{Yo}$ & 6.87 & 7.58 & 7.99 & 7.61 & 7.12 & 7.15 & 7.36 & 7.36 & 6.94 \\
\hline
\end{tabular}


Table A.42: Five degree sequential perturbation for $\mathbf{k x}$.

\begin{tabular}{|c|c|c|c|c|c|c|c|}
\hline \multirow{3}{*}{ Initial } & & $\mathbf{R}_{\mathrm{i}}^{+}$ & $\mathbf{R}_{\mathbf{i}}^{-}$ & $\mathbf{R}_{\mathbf{i}}^{+}$ & $\mathbf{R}_{\mathbf{i}}^{-}$ & $\mathbf{R}_{\mathbf{i}}$ & $\mathbf{R}_{i}{ }^{2}$ \\
\hline & $\mathrm{X} 1$ & 0.00 & 0.00 & 0.00 & 0.00 & 0.00 & 0.00 \\
\hline & $\mathrm{Y} 1$ & 0.00 & 0.00 & 0.00 & 0.00 & 0.00 & 0.00 \\
\hline \multirow{16}{*}{ Final } & $\mathrm{Z} 1$ & 0.00 & 0.00 & 0.00 & 0.00 & 0.00 & 0.00 \\
\hline & $\mathrm{Z} 2$ & 0.00 & 0.00 & 0.00 & 0.00 & 0.00 & 0.00 \\
\hline & $\mathrm{Y} 2$ & 0.00 & 0.00 & 0.00 & 0.00 & 0.00 & 0.00 \\
\hline & $\mathrm{Z2}$ & 0.00 & 0.00 & 0.00 & 0.00 & 0.00 & 0.00 \\
\hline & X3 & 0.00 & 0.00 & 0.00 & 0.00 & 0.00 & 0.00 \\
\hline & $\mathrm{Y} 3$ & 0.00 & 0.00 & 0.00 & 0.00 & 0.00 & 0.00 \\
\hline & $\mathrm{Z3}$ & 0.00 & 0.00 & 0.00 & 0.00 & 0.00 & 0.00 \\
\hline & $\mathrm{X} 1$ & 0.00 & 0.00 & 0.00 & 0.00 & 0.00 & 0.00 \\
\hline & $\mathrm{Y} 1$ & 0.00 & 0.00 & 0.00 & 0.00 & 0.00 & 0.00 \\
\hline & $\mathrm{Z} 1$ & 0.00 & 0.00 & 0.00 & 0.00 & 0.00 & 0.00 \\
\hline & $\mathrm{Z} 2$ & 0.00 & 0.00 & 0.00 & 0.00 & 0.00 & 0.00 \\
\hline & $\mathrm{Y} 2$ & 0.00 & 0.00 & 0.00 & 0.00 & 0.00 & 0.00 \\
\hline & $\mathrm{Z} 2$ & 0.00 & 0.00 & 0.00 & 0.00 & 0.00 & 0.00 \\
\hline & $\mathrm{X} 3$ & 0.00 & 0.00 & 0.00 & 0.00 & 0.00 & 0.00 \\
\hline & $\mathrm{Y} 3$ & 0.00 & 0.00 & 0.00 & 0.00 & 0.00 & 0.00 \\
\hline & $\mathrm{Z3}$ & 0.00 & 0.00 & 0.00 & 0.00 & 0.00 & 0.00 \\
\hline & & & & & $\begin{array}{l}\text { Im } \\
\text { ncert }\end{array}$ & & $\begin{array}{l}0.00 \\
0.01\end{array}$ \\
\hline
\end{tabular}


Table A.43: Five degree sequential perturbation for xo.

\begin{tabular}{|c|c|c|c|c|c|c|c|}
\hline \multirow{3}{*}{ Initial } & & $\mathbf{R}_{\mathbf{i}}^{+}$ & $\mathbf{R}_{\mathbf{i}}^{-}$ & $\mathbf{R}_{\mathbf{i}}^{+}$ & $\mathbf{R}_{\mathbf{i}}^{-}$ & $\mathbf{R}_{\mathbf{i}}$ & $\mathbf{R}_{i}{ }^{2}$ \\
\hline & $\mathrm{X} 1$ & 0.68 & -0.71 & 0.72 & -0.67 & 0.70 & 0.48 \\
\hline & $\mathrm{Y} 1$ & -0.56 & 0.53 & -0.52 & 0.57 & 0.54 & 0.30 \\
\hline \multirow{16}{*}{ Final } & $\mathrm{Z} 1$ & 0.09 & -0.16 & 0.12 & -0.12 & 0.12 & 0.01 \\
\hline & $\mathrm{Z} 2$ & -0.70 & 0.67 & -0.66 & 0.71 & 0.69 & 0.47 \\
\hline & $\mathrm{Y} 2$ & 0.76 & -0.78 & 0.80 & -0.75 & 0.77 & 0.60 \\
\hline & $\mathrm{Z} 2$ & -0.64 & 0.57 & -0.61 & 0.61 & 0.61 & 0.37 \\
\hline & X3 & -0.04 & -0.04 & 0.00 & 0.00 & 0.00 & 0.00 \\
\hline & $\mathrm{Y} 3$ & -0.04 & -0.04 & 0.00 & 0.00 & 0.00 & 0.00 \\
\hline & $\mathrm{Z3}$ & 0.45 & $\begin{array}{l}-0.52 \\
\end{array}$ & 0.48 & $\begin{array}{l}-0.48 \\
\end{array}$ & 0.48 & 0.23 \\
\hline & $\mathrm{X} 1$ & -0.75 & 0.73 & -0.71 & 0.77 & 0.74 & 0.55 \\
\hline & $\mathrm{Y} 1$ & 0.46 & -0.50 & 0.50 & -0.46 & 0.48 & 0.23 \\
\hline & $\mathrm{Z} 1$ & -0.16 & 0.09 & -0.12 & 0.12 & 0.12 & 0.01 \\
\hline & $\mathrm{Z} 2$ & 0.74 & -0.76 & 0.78 & -0.72 & 0.75 & 0.57 \\
\hline & $\mathrm{Y} 2$ & -0.72 & 0.70 & -0.69 & 0.73 & 0.71 & 0.50 \\
\hline & $\mathrm{Z} 2$ & 0.57 & -0.64 & 0.61 & -0.61 & 0.61 & 0.37 \\
\hline & $\mathrm{X} 3$ & -0.04 & -0.04 & 0.00 & 0.00 & 0.00 & 0.00 \\
\hline & $\mathrm{Y3}$ & -0.04 & -0.04 & 0.00 & 0.00 & 0.00 & 0.00 \\
\hline & $\mathrm{Z3}$ & -0.52 & 0.45 & -0.48 & 0.48 & 0.48 & 0.23 \\
\hline & & & & & $\begin{array}{l}\text { um } \\
\text { incert }\end{array}$ & & $\begin{array}{l}4.93 \\
2.22\end{array}$ \\
\hline
\end{tabular}


Table A.44: Five degree sequential perturbation for ky.

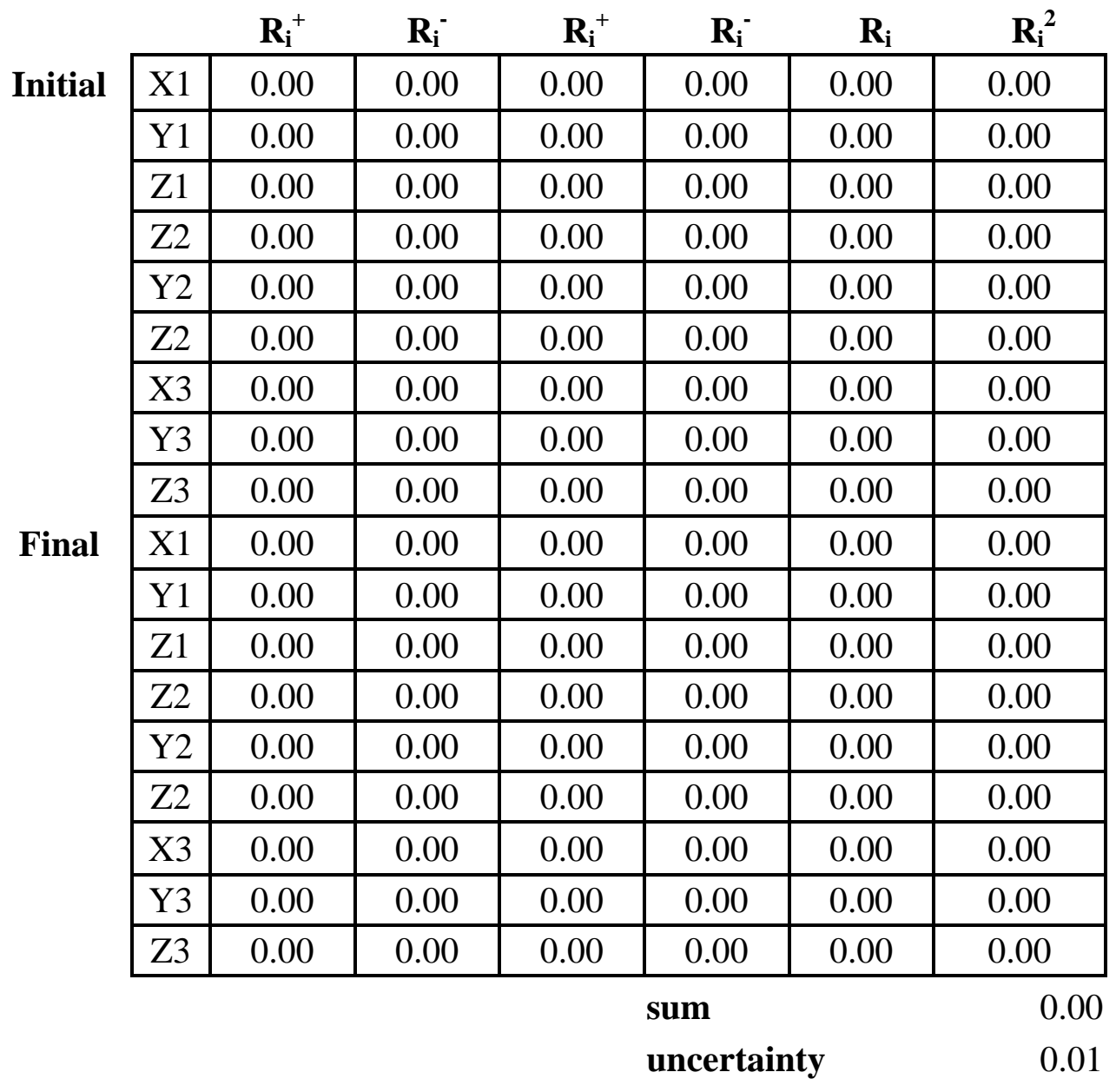


Table A.45: Five degree sequential perturbation for yo.

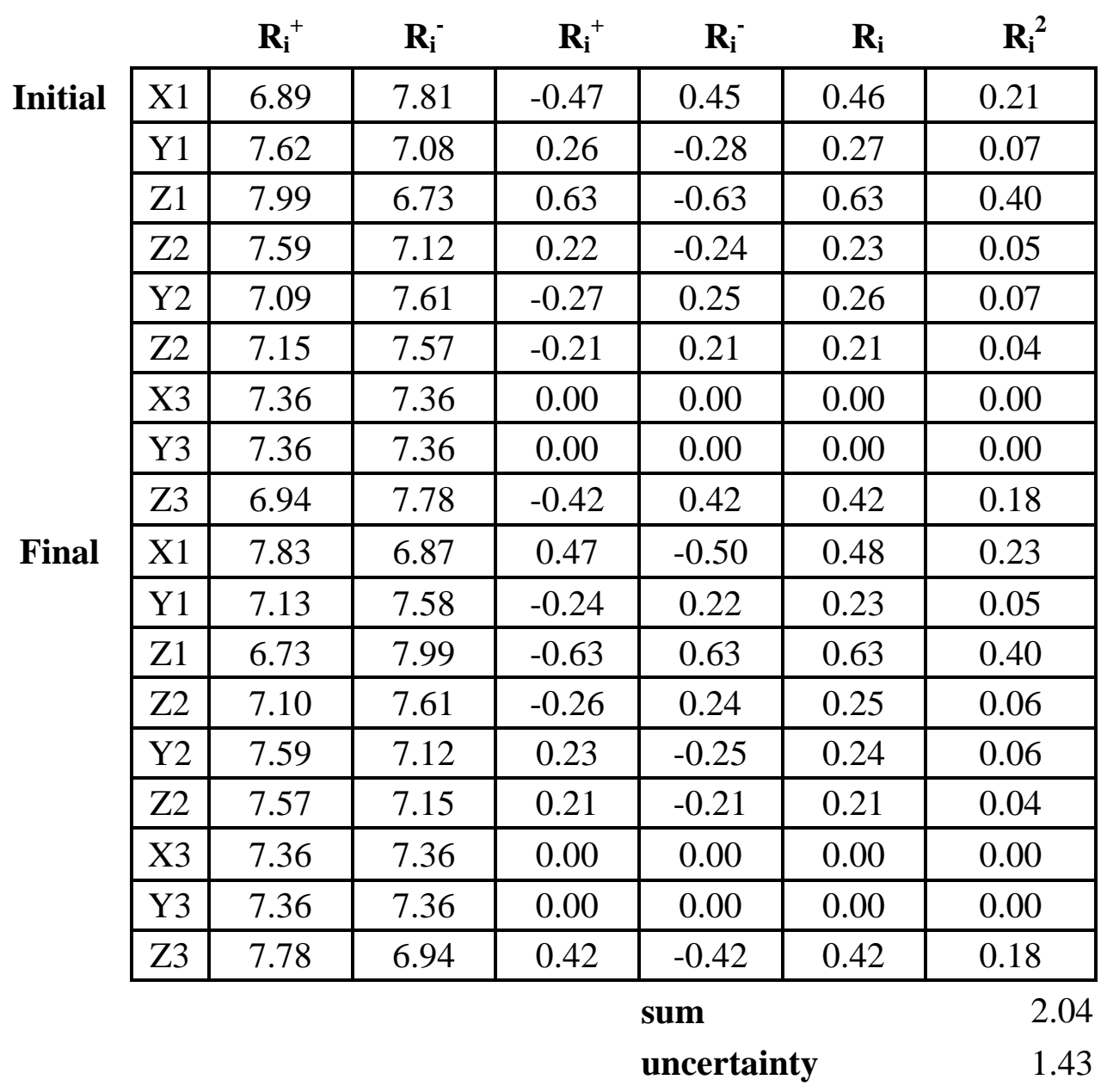


Appendix B:

Mean Peak to Valley Values and Extended Tukey Results 


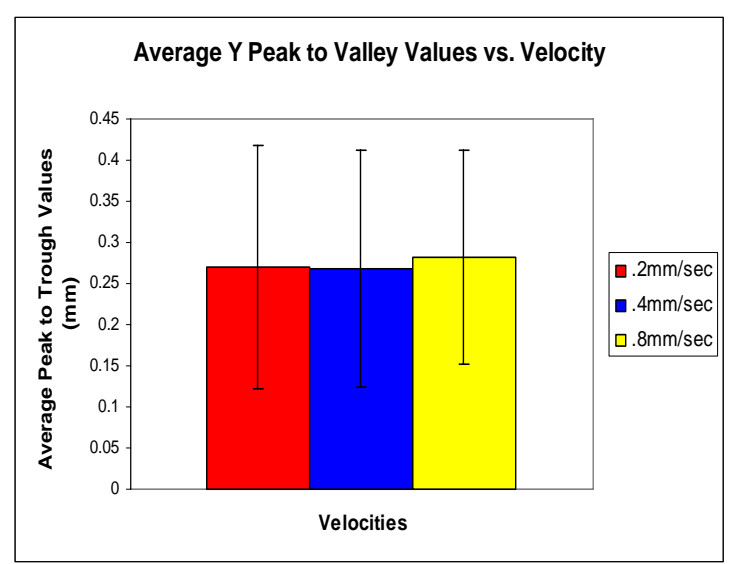

A

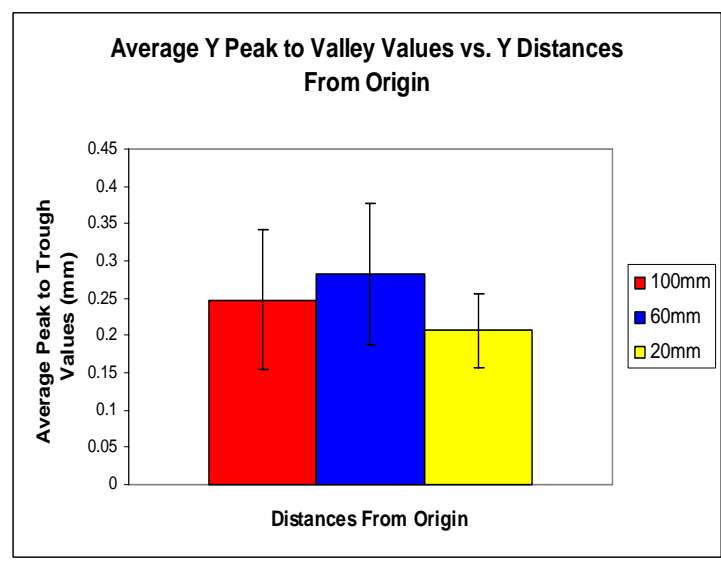

$\mathrm{C}$

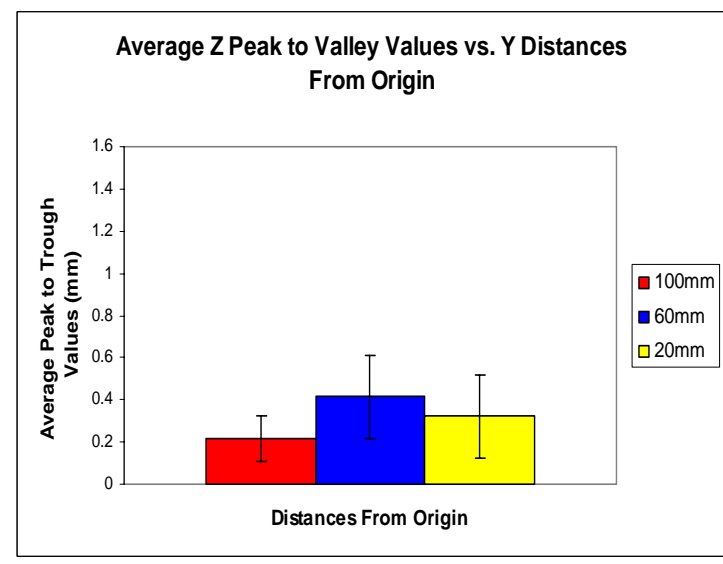

E

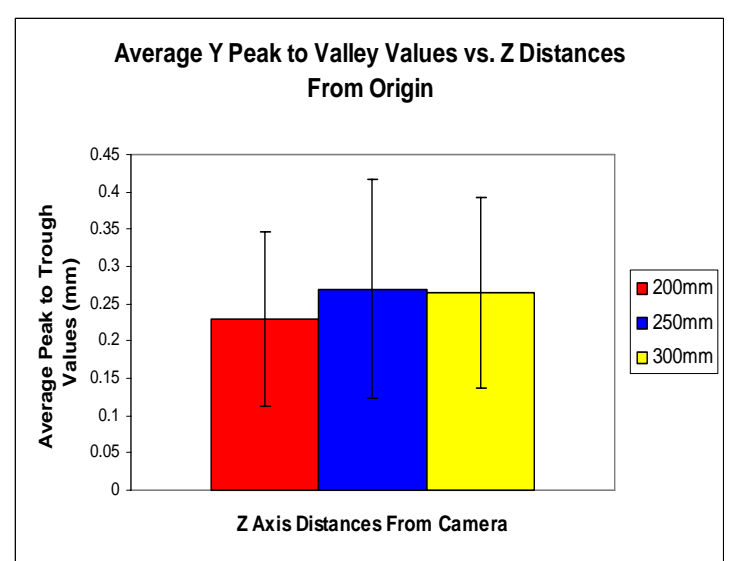

B

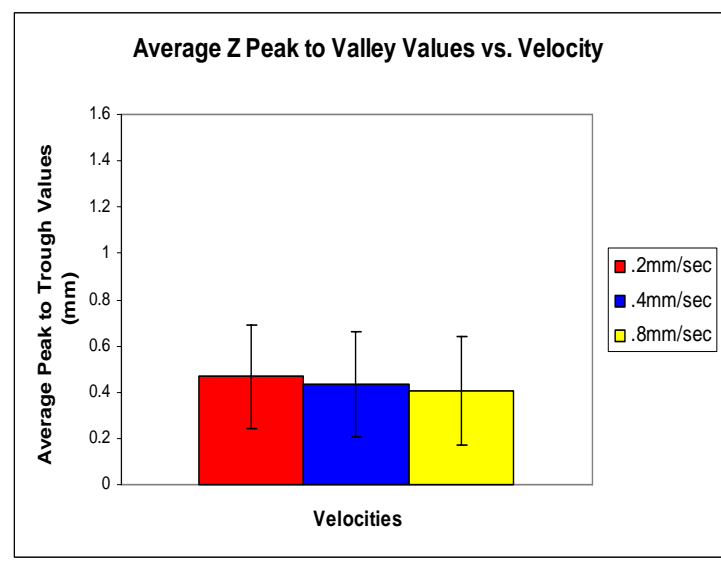

$\mathrm{D}$

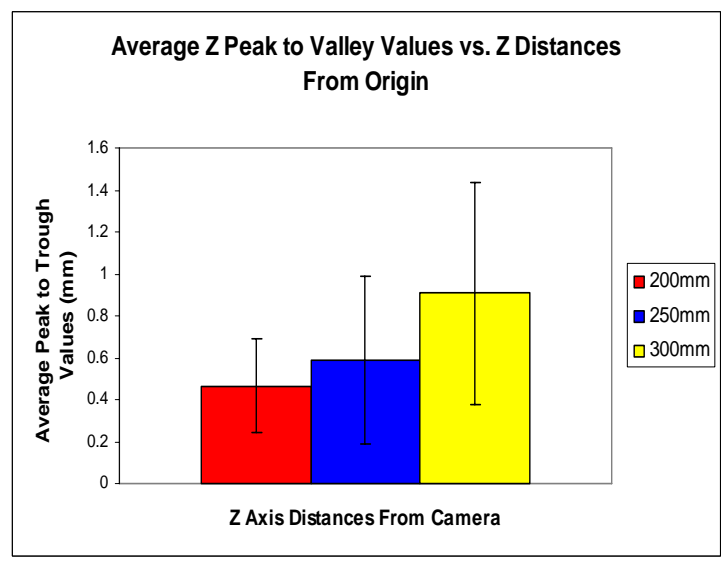

F

Figure B.1 Average peak to valley values for targets undergoing motion along the $x$ axis. A-C show average values for $Y$ coordinate data while D-F show the average values for $\mathrm{Z}$ coordinate data. Error bars denote one standard deviation from the mean value. 


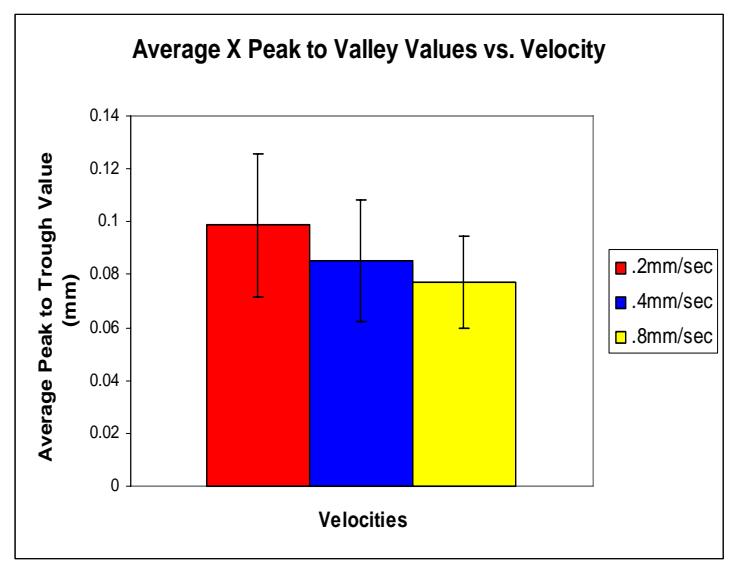

A

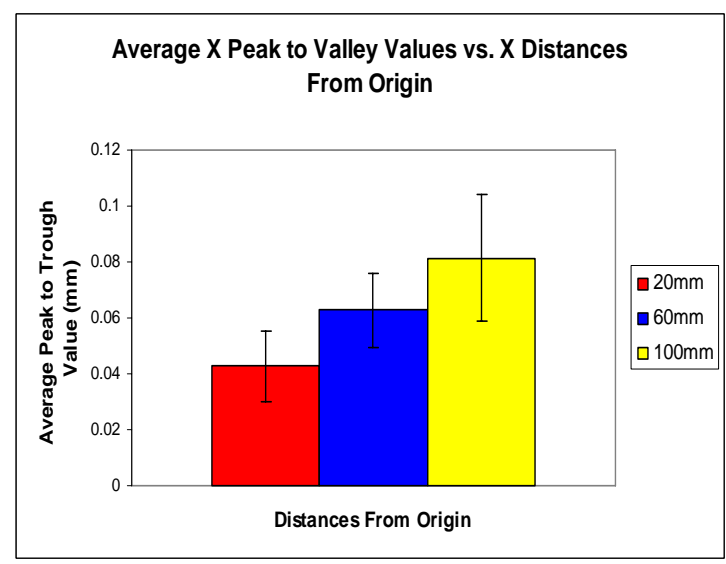

C

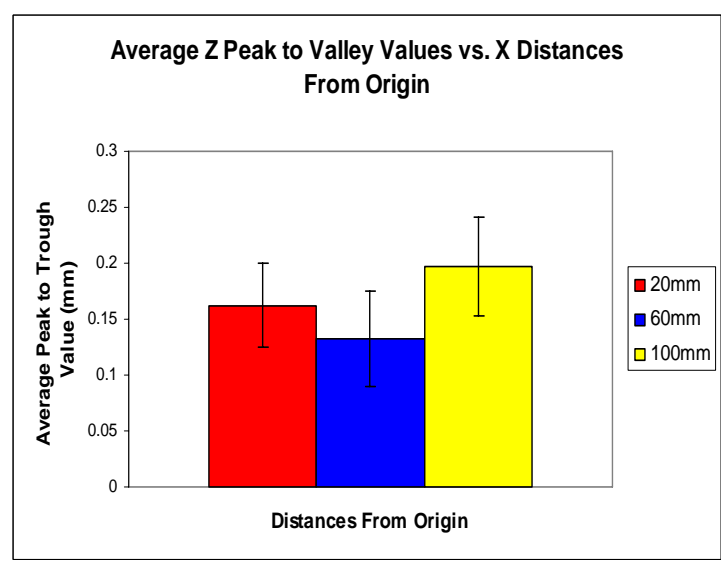

$\mathrm{E}$

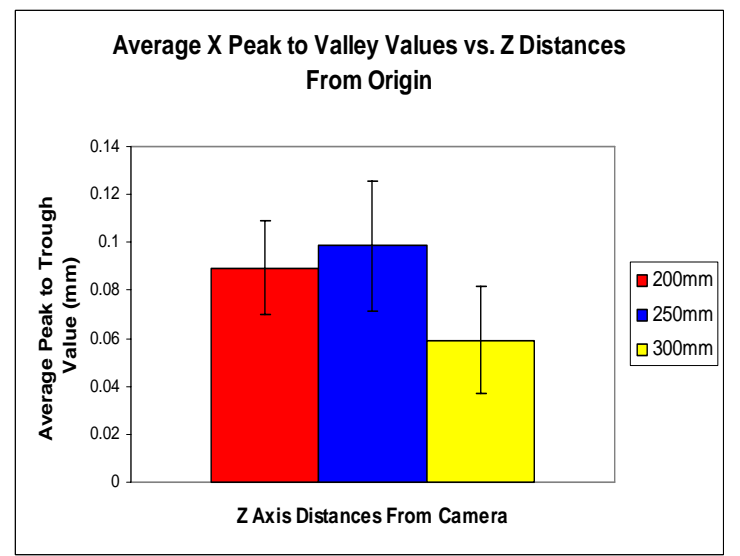

B

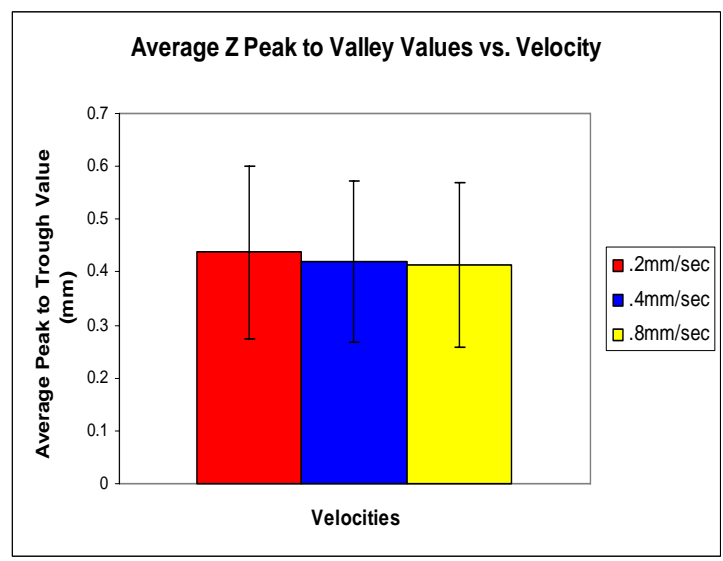

$\mathrm{D}$

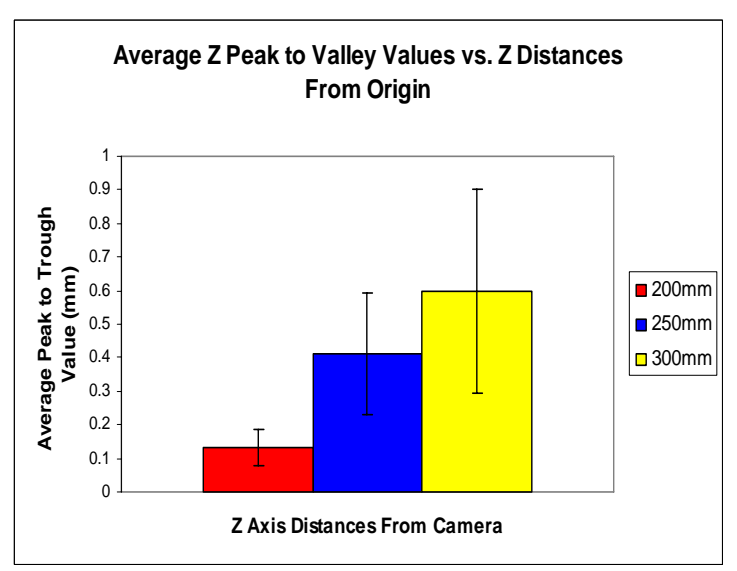

$\mathrm{F}$

Figure B.2 Average peak to valley values for targets undergoing motion along the $y$ axis. A-C show average values for $X$ coordinate data while $D-F$ show the average values for $\mathrm{Z}$ coordinate data. Error bars denote one standard deviation from the mean value. 
Table B.1: X motion tukey results.

$\mathrm{Z}$ peak to trough varied $\mathrm{Y}$ dist.

Tukey Results:

$60 \mathrm{~mm}$ vs $100 \mathrm{~mm}$ :

$60 \mathrm{~mm}$ vs $20 \mathrm{~mm}$ :

\begin{tabular}{|lccc}
\multicolumn{1}{l}{ q } & HSD & xbar difference & Significance \\
\hline 3.41 & 0.02 & 0.20 & Significant \\
3.41 & 0.02 & 0.09 & Significant \\
3.41 & 0.02 & 0.10 & Significant
\end{tabular}

$20 \mathrm{~mm}$ vs $100 \mathrm{~mm}$ :

$\mathrm{Z}$ peak to valley varied $\mathrm{Z}$ dist.

Tukey Results:

$300 \mathrm{~mm}$ vs $200 \mathrm{~mm}$ :

\begin{tabular}{|cccc}
\multicolumn{1}{c}{$\mathrm{q}$} & HSD & xbar difference & Significance \\
\hline 3.44 & 0.15 & 0.44 & Significant \\
3.44 & 0.15 & 0.32 & Significant \\
3.44 & 0.15 & 0.12 & Not Significant
\end{tabular}

$250 \mathrm{~mm}$ vs $200 \mathrm{~mm}$ : 


\section{Table B.2: Y motion tukey results.}

$\mathrm{Z}$ peak to valley varied $\mathrm{Y}$ dist.

Tukey Results:

$60 \mathrm{~mm}$ vs $100 \mathrm{~mm}:$

$60 \mathrm{~mm}$ vs $20 \mathrm{~mm}$ :

$20 \mathrm{~mm}$ vs $100 \mathrm{~mm}$ :

\begin{tabular}{|cccc}
\multicolumn{1}{c}{ q } & HSD & xbar difference & Significance \\
\hline 3.41 & 0.02 & 0.20 & Significant \\
3.41 & 0.02 & 0.09 & Significant \\
3.41 & 0.02 & 0.10 & Significant
\end{tabular}

$\mathrm{Z}$ peak to valley varied $\mathrm{Z}$ dist.

Tukey Results:

$300 \mathrm{~mm}$ vs $200 \mathrm{~mm}:$

$300 \mathrm{~mm}$ vs $250 \mathrm{~mm}$ :

$250 \mathrm{~mm}$ vs $200 \mathrm{~mm}$ :

\begin{tabular}{|cccc}
\multicolumn{1}{c}{$\mathrm{q}$} & HSD & xbar difference & Significance \\
\hline 3.44 & 0.15 & 0.44 & Significant \\
3.44 & 0.15 & 0.32 & Significant \\
3.44 & 0.15 & 0.12 & Not Significant
\end{tabular}

$\mathrm{X}$ peak to valley varied velocity

Tukey Results:

$.2 \mathrm{~mm} / \mathrm{sec}$ vs $.8 \mathrm{~mm} / \mathrm{sec}$ :

$.2 \mathrm{~mm} / \mathrm{sec}$ vs $.4 \mathrm{~mm} / \mathrm{sec}$ :

\begin{tabular}{|cccc}
\multicolumn{1}{c}{$\mathrm{q}$} & HSD & xbar difference & Significance \\
\hline 3.44 & 0.00 & -0.02 & Significant \\
3.44 & 0.00 & -0.01 & Significant \\
3.44 & 0.00 & 0.01 & Significant
\end{tabular}

$.4 \mathrm{~mm} / \mathrm{sec}$ vs $.8 \mathrm{~mm} / \mathrm{sec}$ :

$\mathrm{X}$ peak to valley varied $\mathrm{X}$ dist.

Tukey Results:

$60 \mathrm{~mm}$ vs $100 \mathrm{~mm}:$

$60 \mathrm{~mm}$ vs $20 \mathrm{~mm}$ :

$20 \mathrm{~mm}$ vs $100 \mathrm{~mm}$ :

\begin{tabular}{|cccc}
\multicolumn{1}{c}{$\mathrm{q}$} & HSD & xbar difference & Significance \\
\hline 3.44 & 0.00 & 0.02 & Significant \\
3.44 & 0.00 & 0.02 & Significant \\
3.44 & 0.00 & 0.04 & Significant
\end{tabular}

$\mathrm{X}$ peak to valley varied $\mathrm{Z}$ dist.

Tukey Results:

$250 \mathrm{~mm}$ vs $300 \mathrm{~mm}$

\begin{tabular}{|cccc}
\multicolumn{1}{c}{$\mathrm{q}$} & HSD & xbar difference & Significance \\
\hline 3.44 & 0.00 & 0.04 & Significant \\
3.44 & 0.00 & 0.01 & Significant \\
3.44 & 0.00 & 0.03 & Significant
\end{tabular}




\section{Table B.2 continued.}

$\mathrm{Z}$ peak to valley varied $\mathrm{X}$ dist.

Tukey Results:

$100 \mathrm{~mm}$ vs $60 \mathrm{~mm}$ :

$100 \mathrm{~mm}$ vs $20 \mathrm{~mm}$ :

$20 \mathrm{~mm}$ vs $60 \mathrm{~mm}$ :

\begin{tabular}{|cccc}
\multicolumn{1}{c}{$\mathrm{q}$} & HSD & xbar difference & Significance \\
\hline 3.44 & 0.00 & 0.06 & Significant \\
3.44 & 0.00 & 0.03 & Significant \\
3.44 & 0.00 & 0.03 & Significant
\end{tabular}

$\mathrm{Z}$ peak to valley varied $\mathrm{Z}$ dist.

Tukey Results:

$300 \mathrm{~mm}$ vs $200 \mathrm{~mm}:$

\begin{tabular}{|cccc}
\multicolumn{1}{c}{$\mathrm{q}$} & HSD & xbar difference & Significance \\
\hline 3.44 & 0.04 & 0.47 & Significant \\
3.44 & 0.04 & 0.19 & Significant \\
3.44 & 0.04 & 0.28 & Significant
\end{tabular}


Appendix C:

Condylar Path Plots 


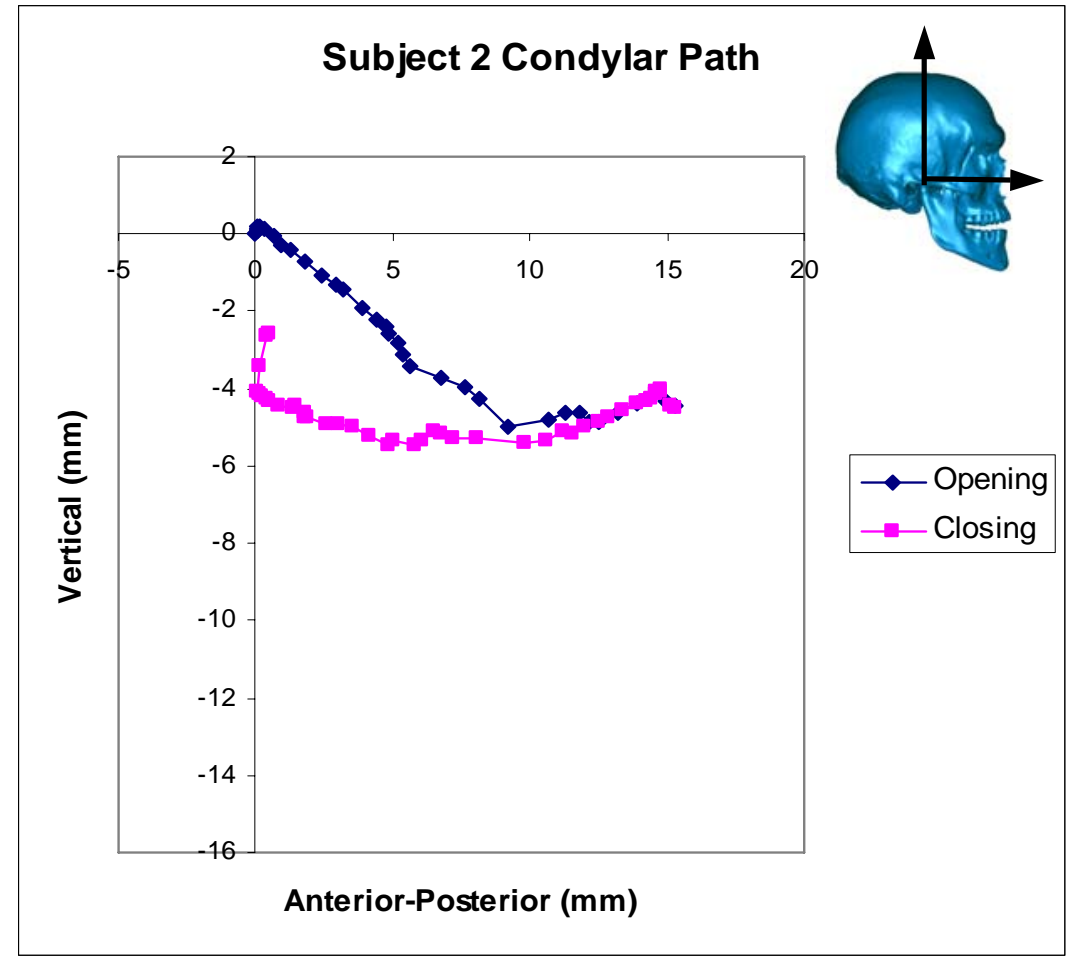

Figure C.1 Condylar path plot for subject two.

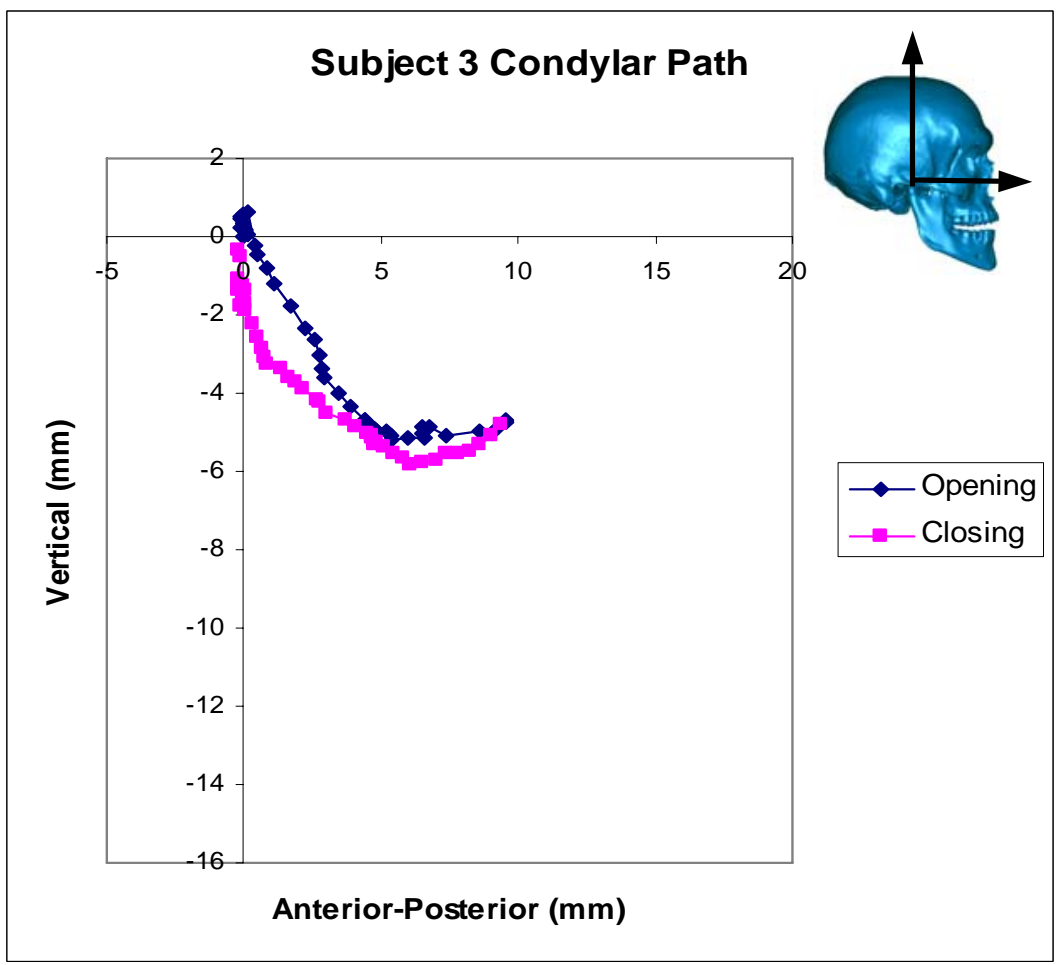

Figure C.2 Condylar path plot for subject three. 


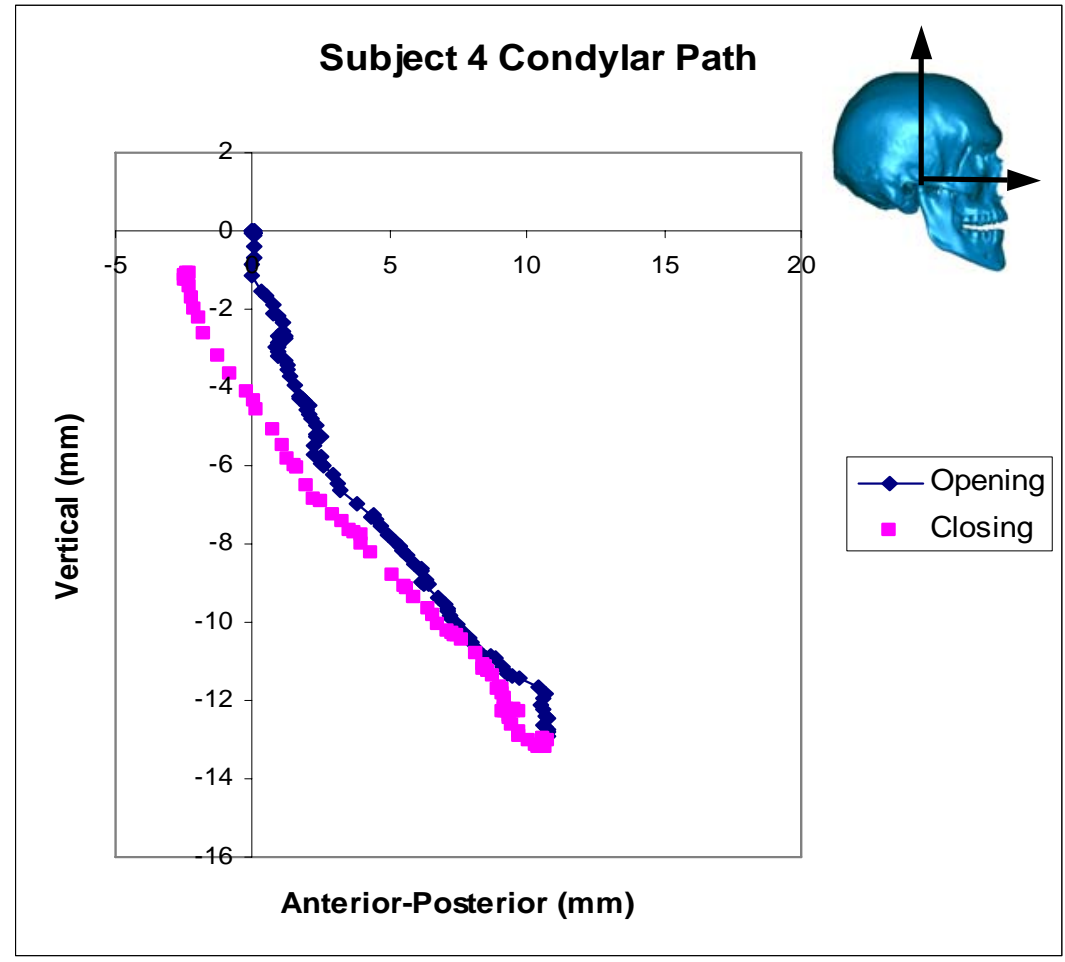

Figure C.3 Condylar path plot for subject four.

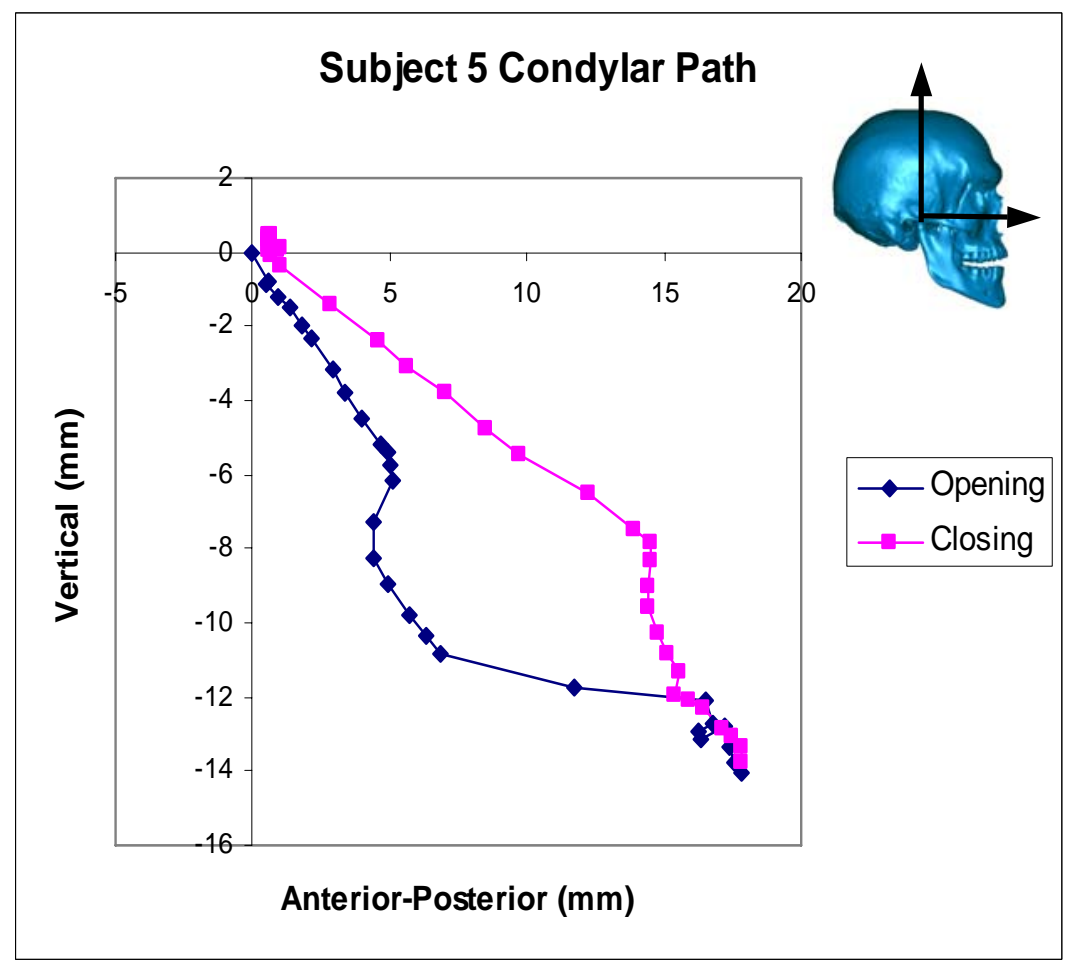

Figure C.4 Condylar path plot for subject five. 
Appendix D:

Rotation and Translation Plots 


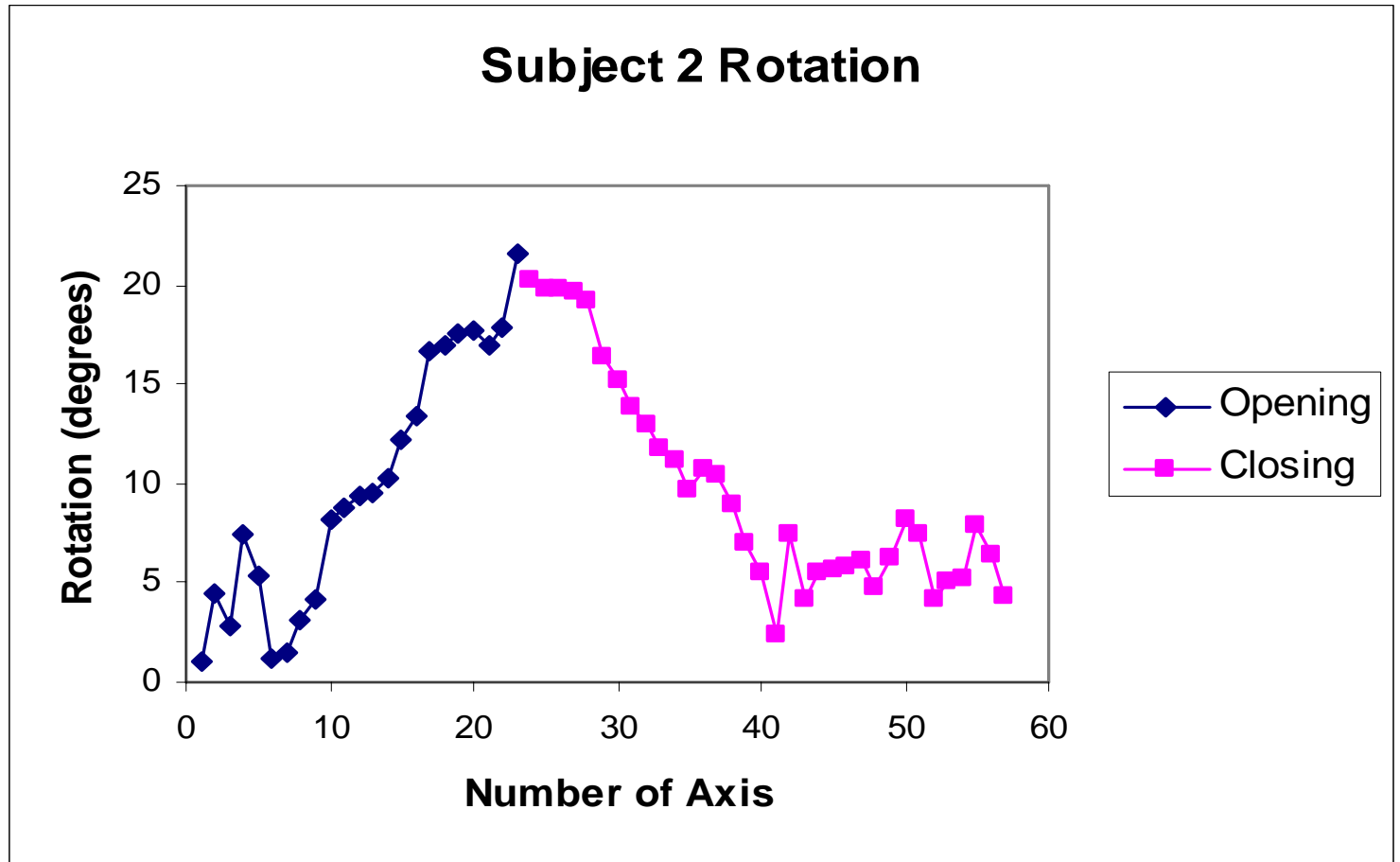

Figure D.1: Rotation about the SDAs for subject two.

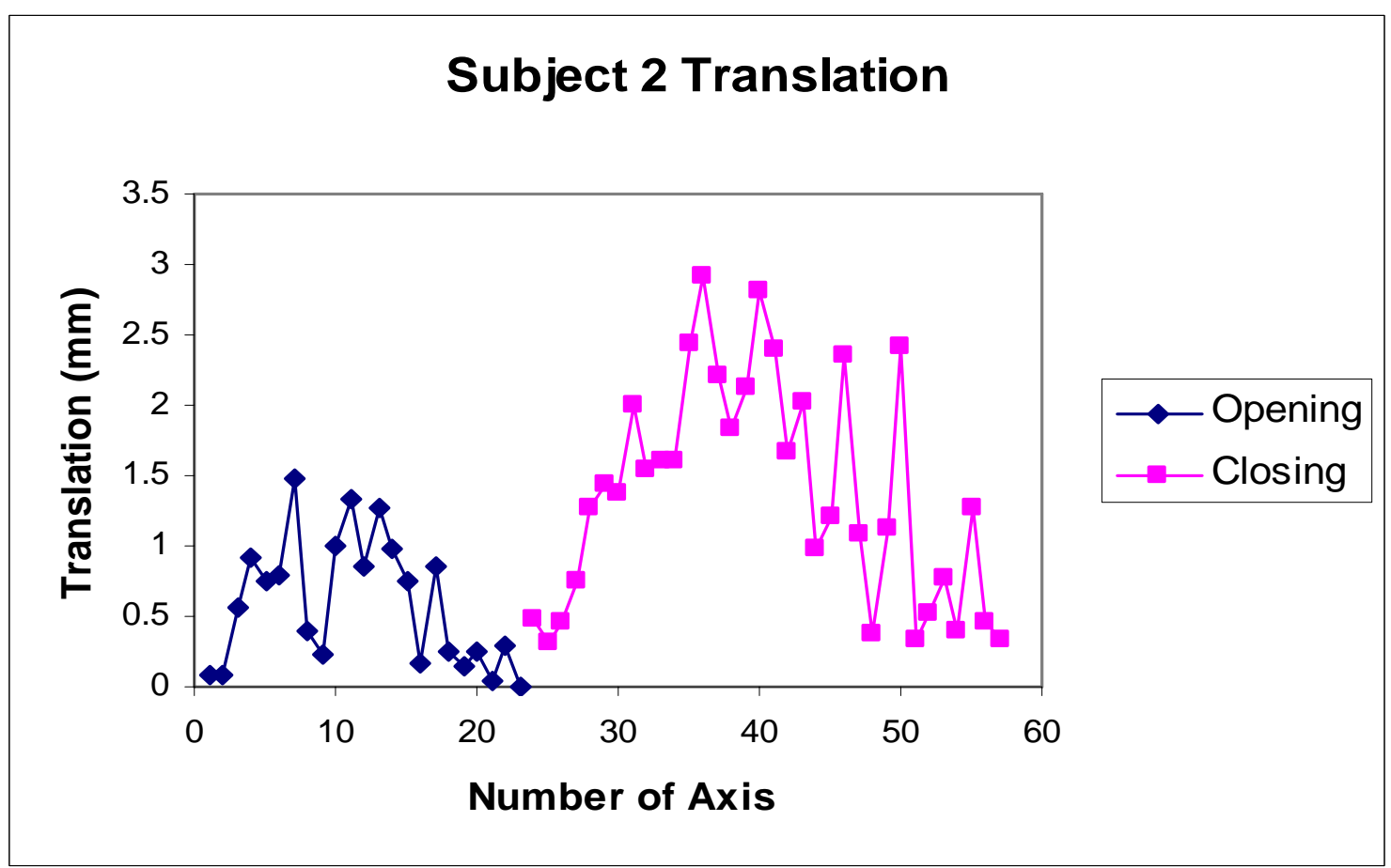

Figure D.2: Translation along the SDAs for subject two. 


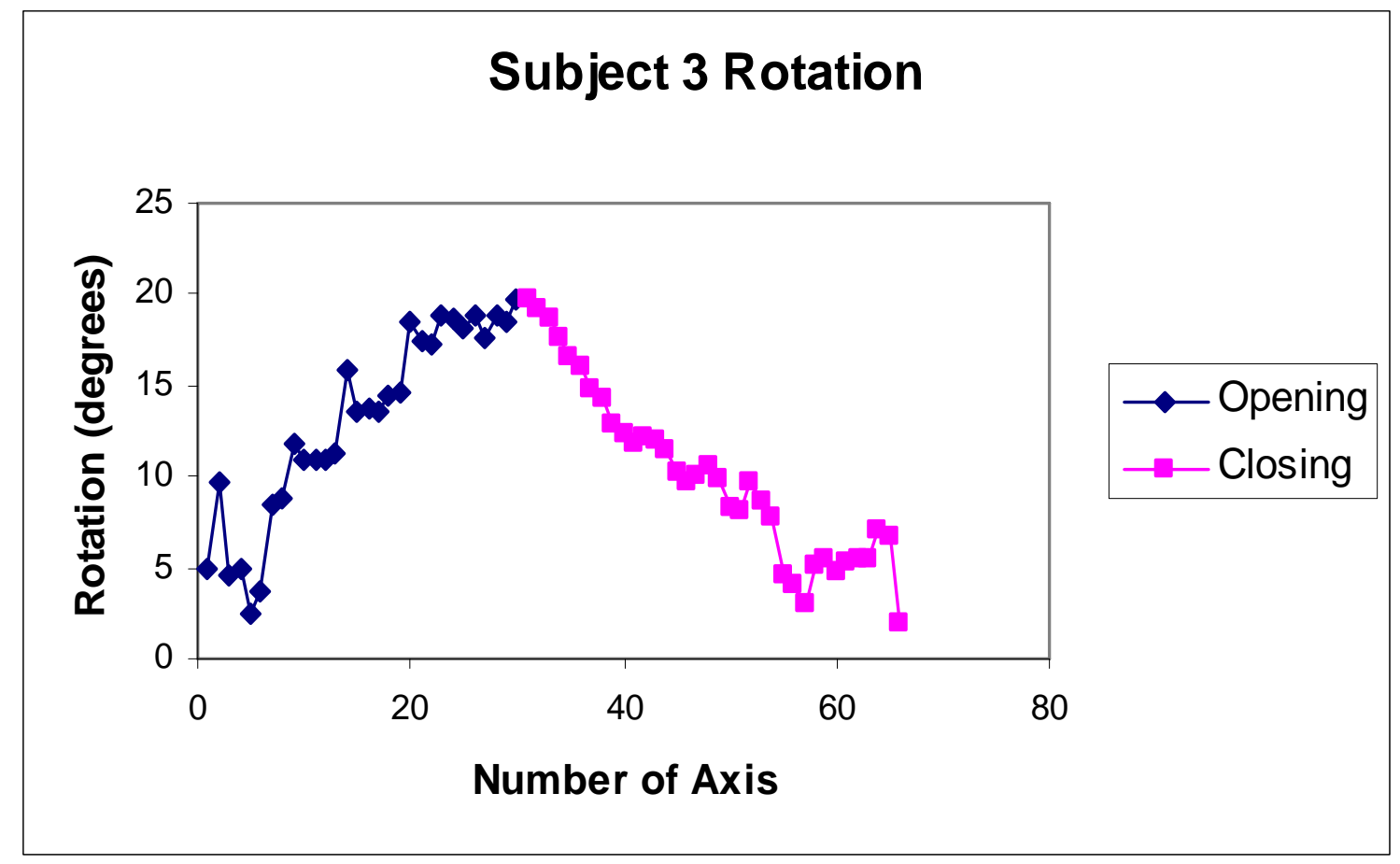

Figure D.3: Rotation about the SDAs for subject three.

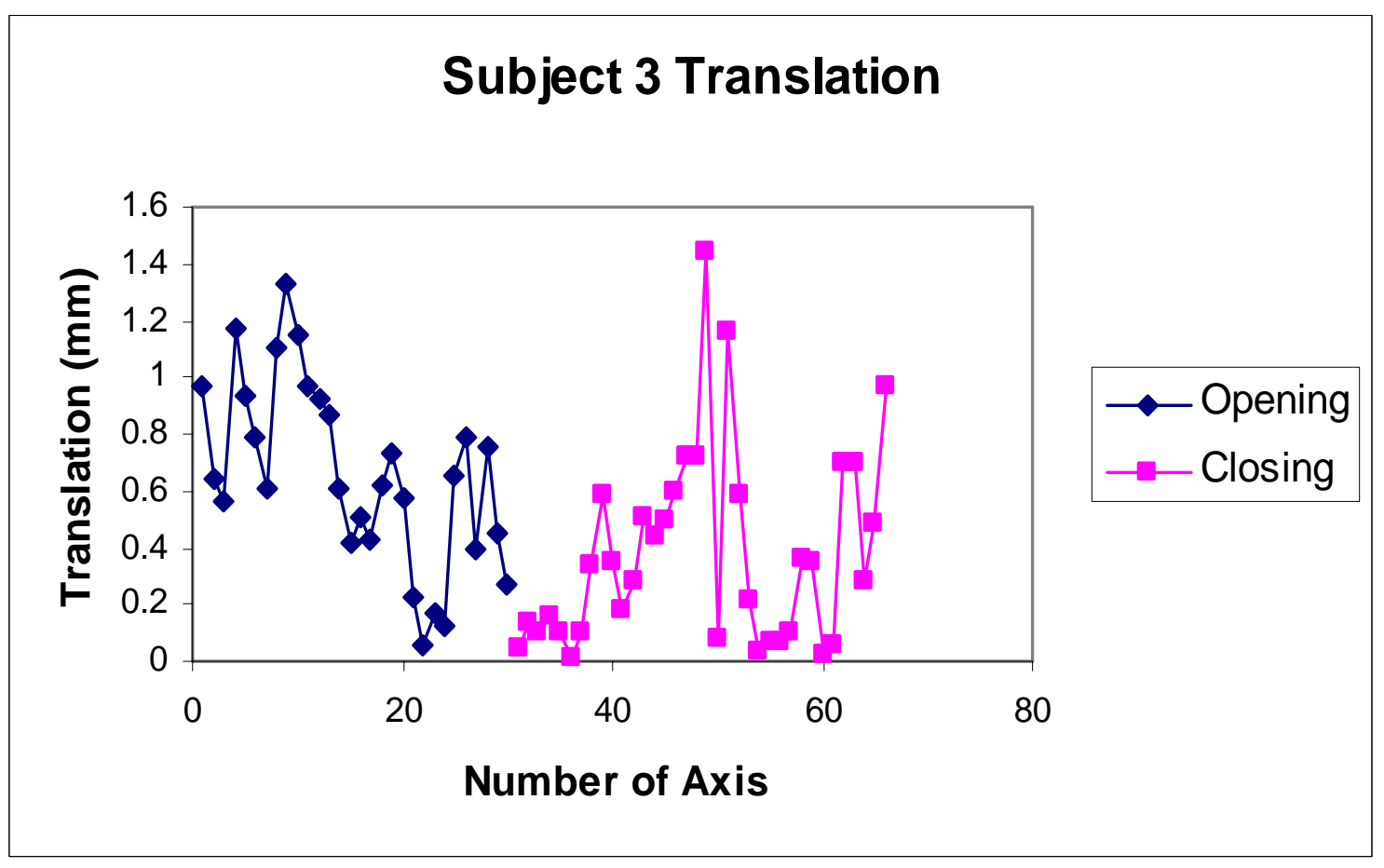

Figure D.4: Translation along the SDAs for subject three. 


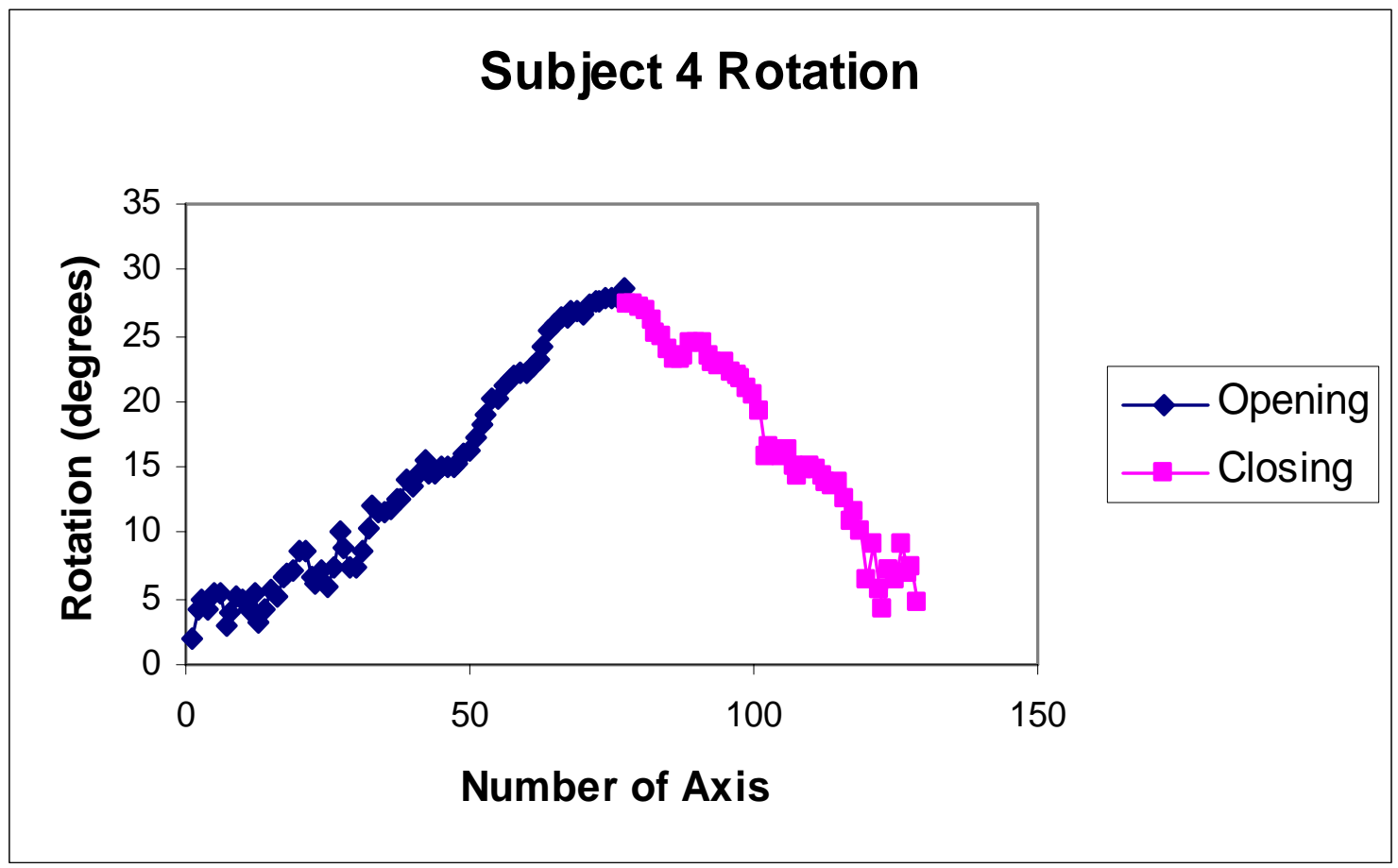

Figure D.5: Rotation about the SDAs for subject four.

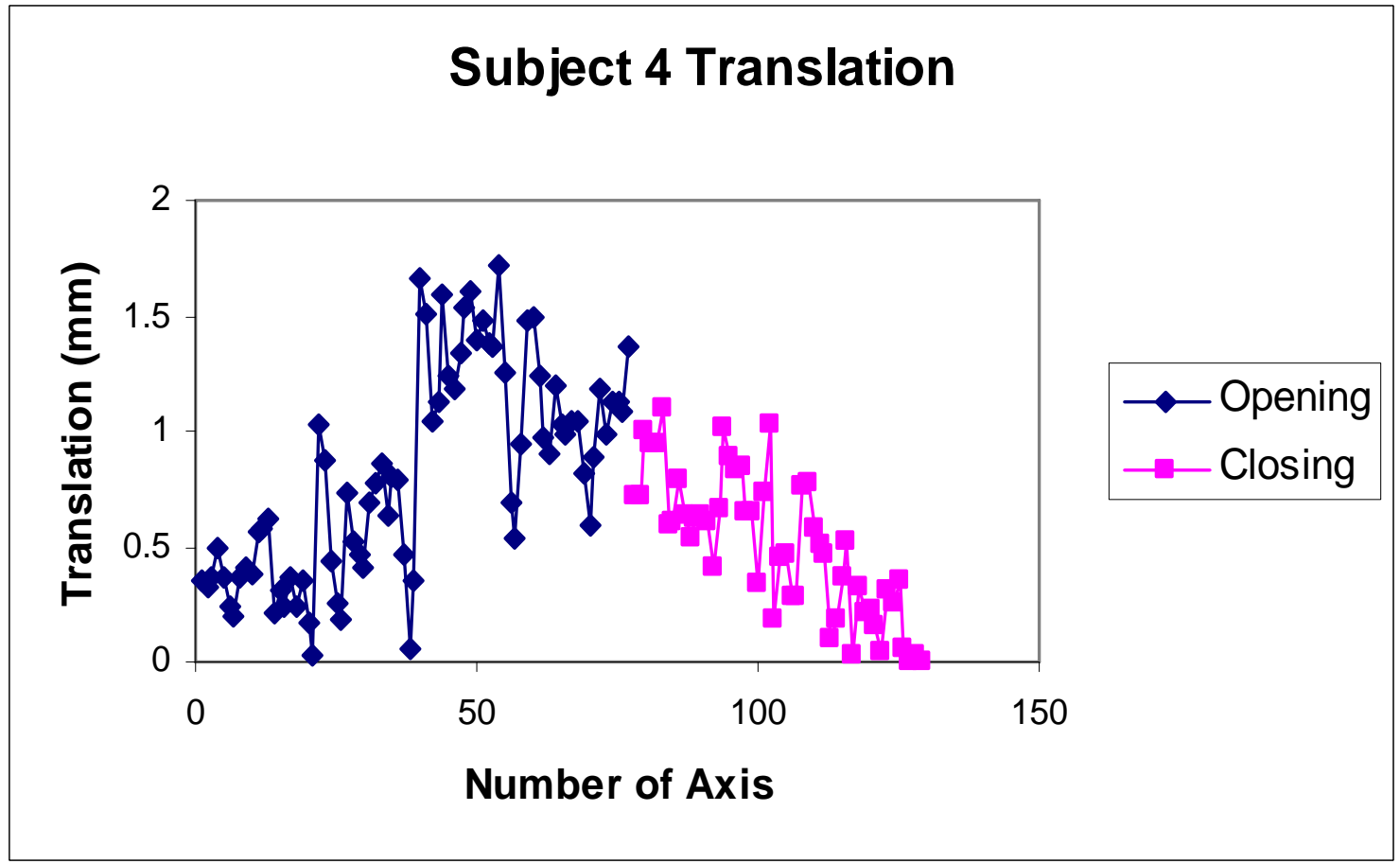

Figure D.6: Translation along the SDAs for subject four. 


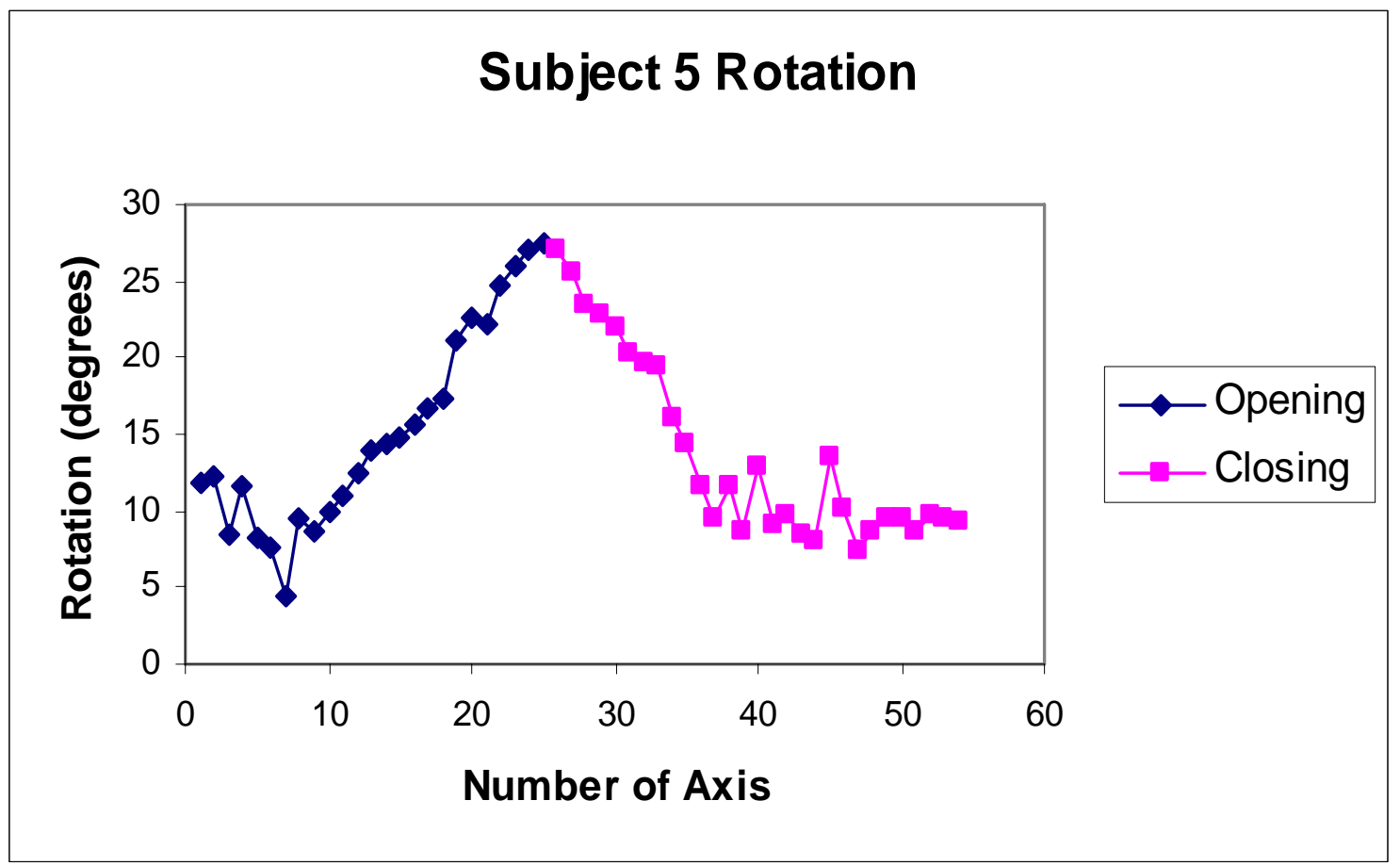

Figure D.7: Rotation about the SDAs for subject five.

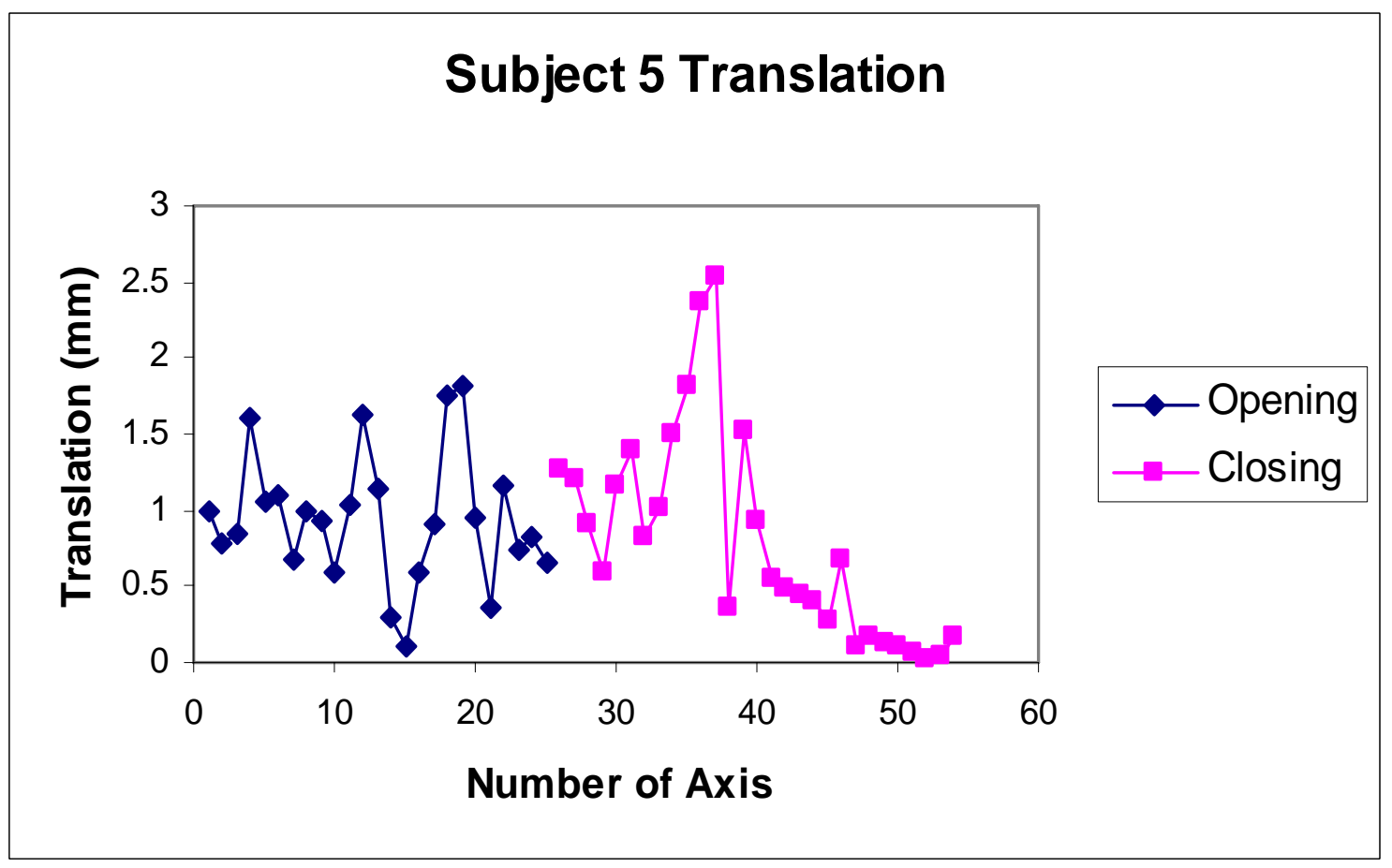

Figure D.8: Translation along the SDAs for subject five. 
Appendix E:

Two and Three-Dimensional Representation of the SDA 

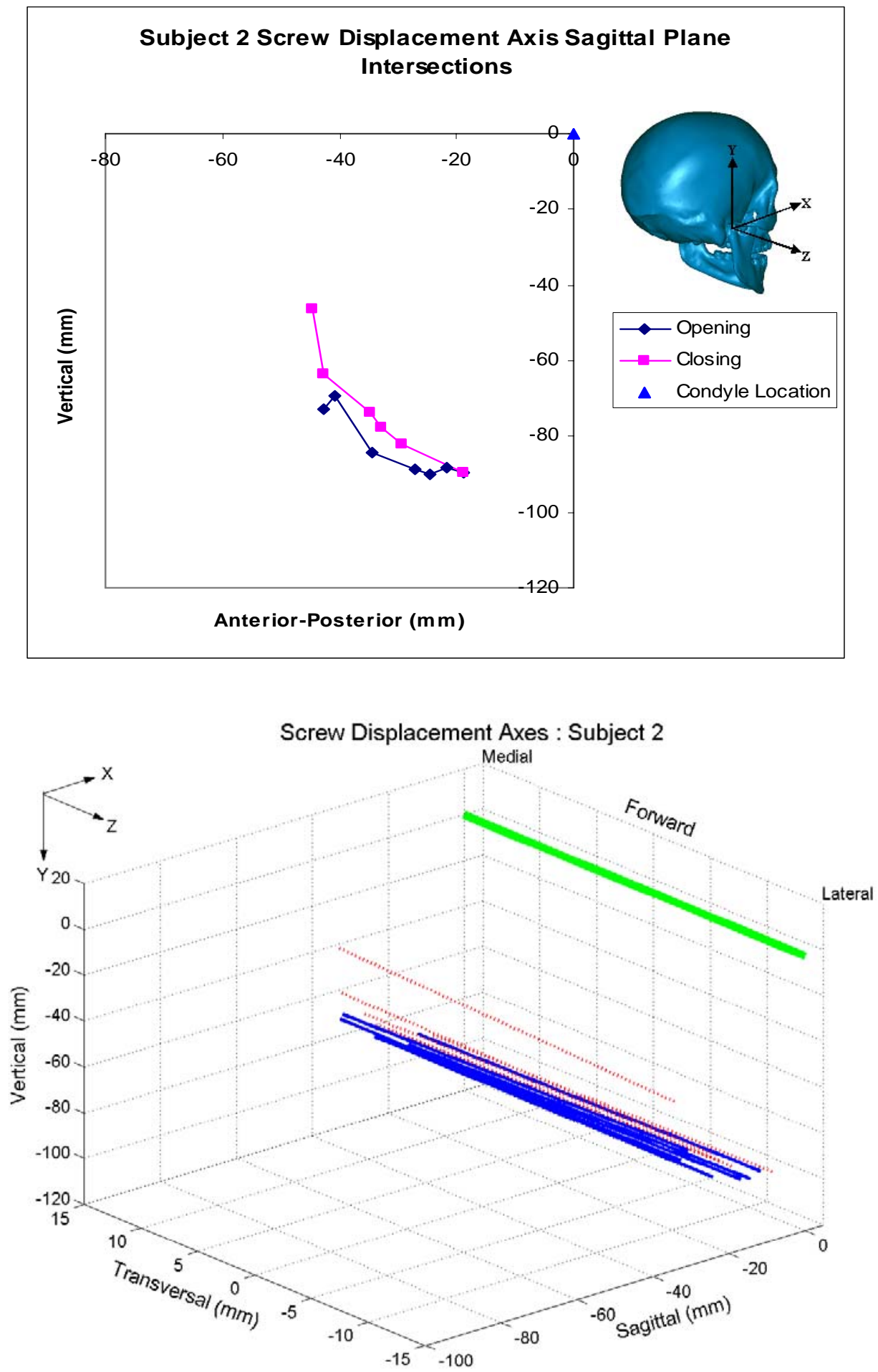

Figure E.1: Two (top) and three (bottom) dimensional representation of the SDA for subject two. In the three dimensional plot the solid blue axes denote opening motion and the dashed red axes denote closing motion. The thick green line is the axis of the condyles. 

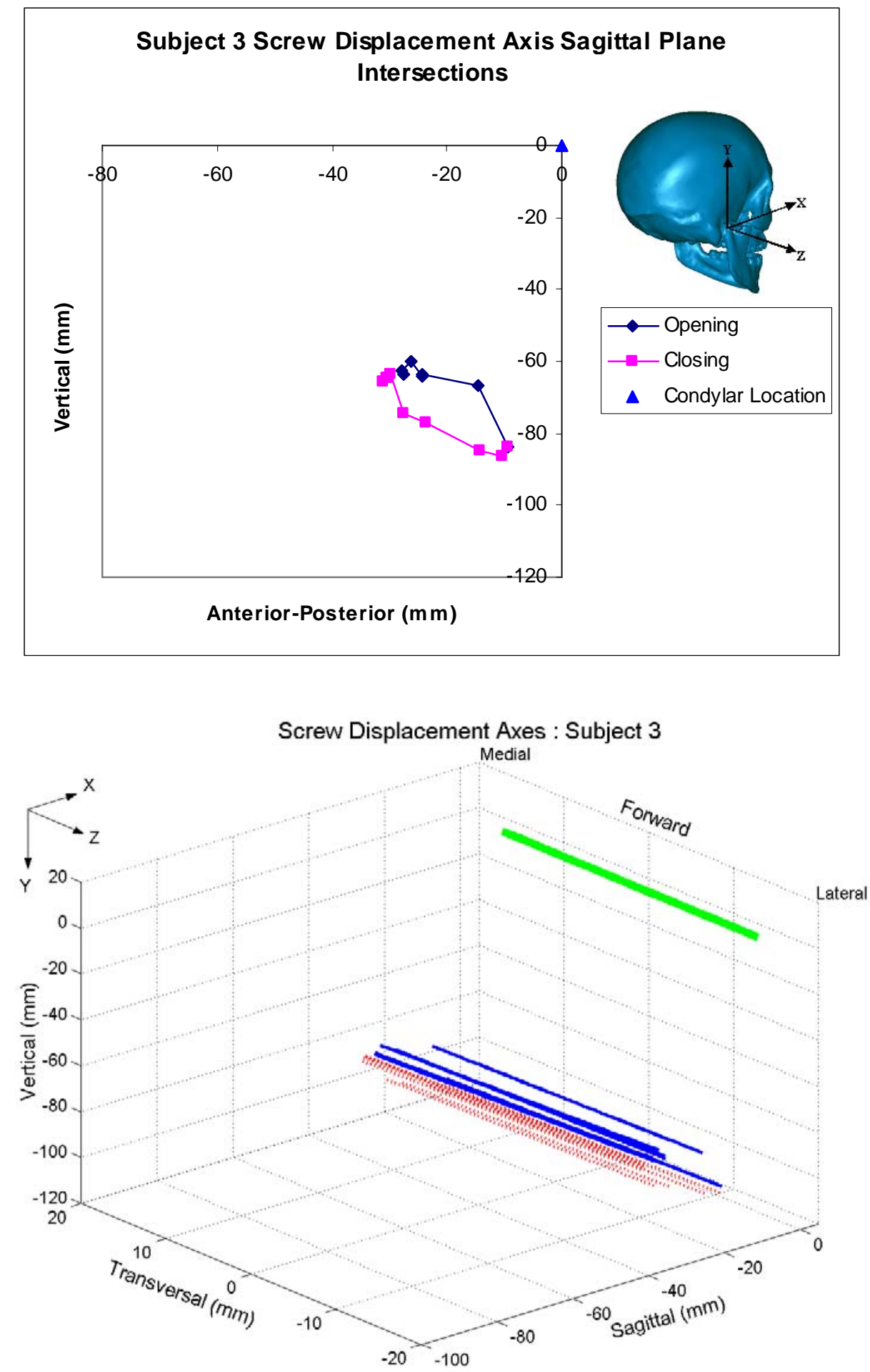

Figure E.2: Two (top) and three (bottom) dimensional representation of the SDA for subject three. In the three dimensional plot the solid blue axes denote opening motion and the dashed red axes denote closing motion. The thick green line is the axis of the condyles. 

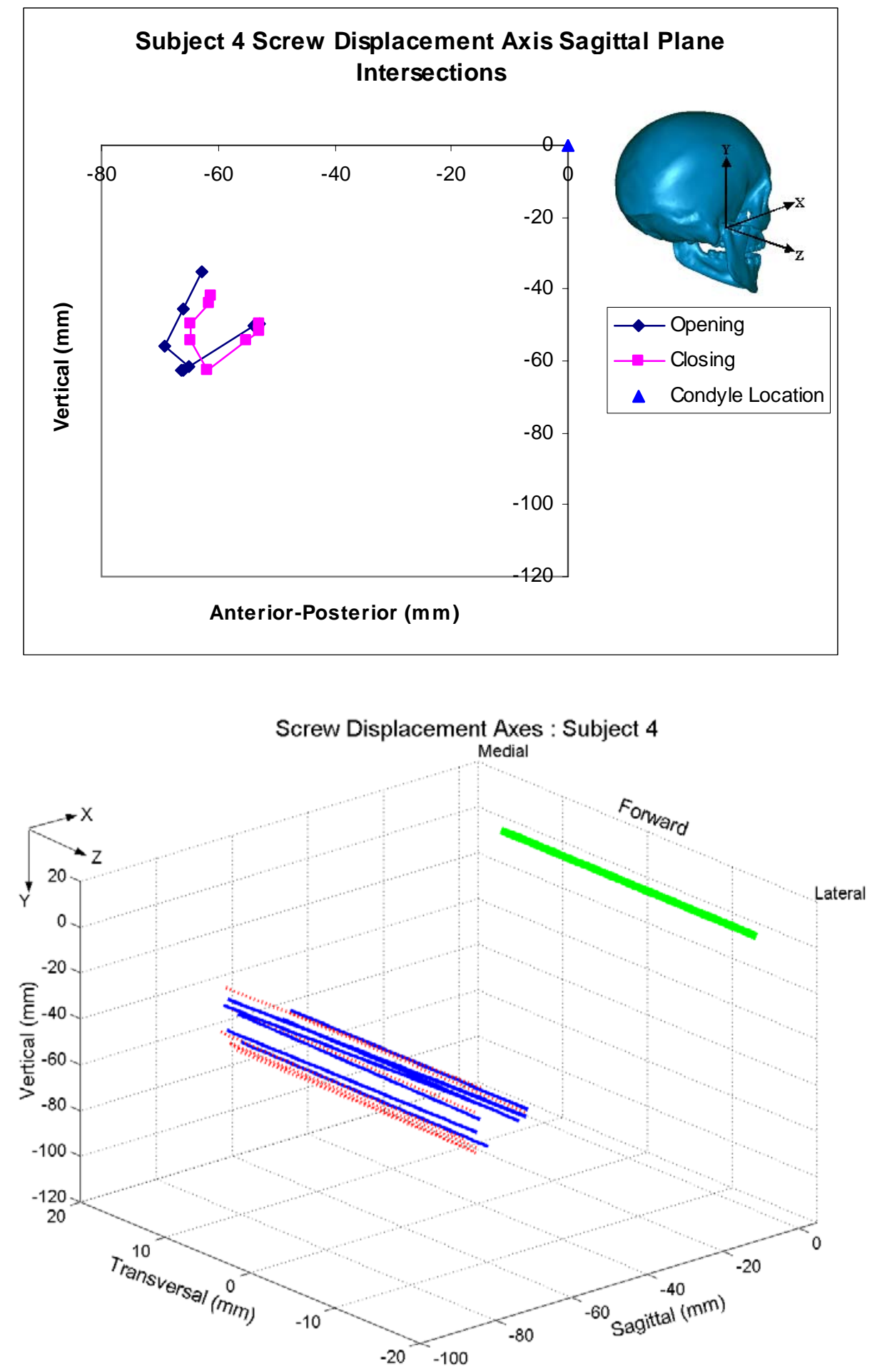

Figure E.3: Two (top) and three (bottom) dimensional representation of the SDA for subject four. In the three dimensional plot the solid blue axes denote opening motion and the dashed red axes denote closing motion. The thick green line is the axis of the condyles. 

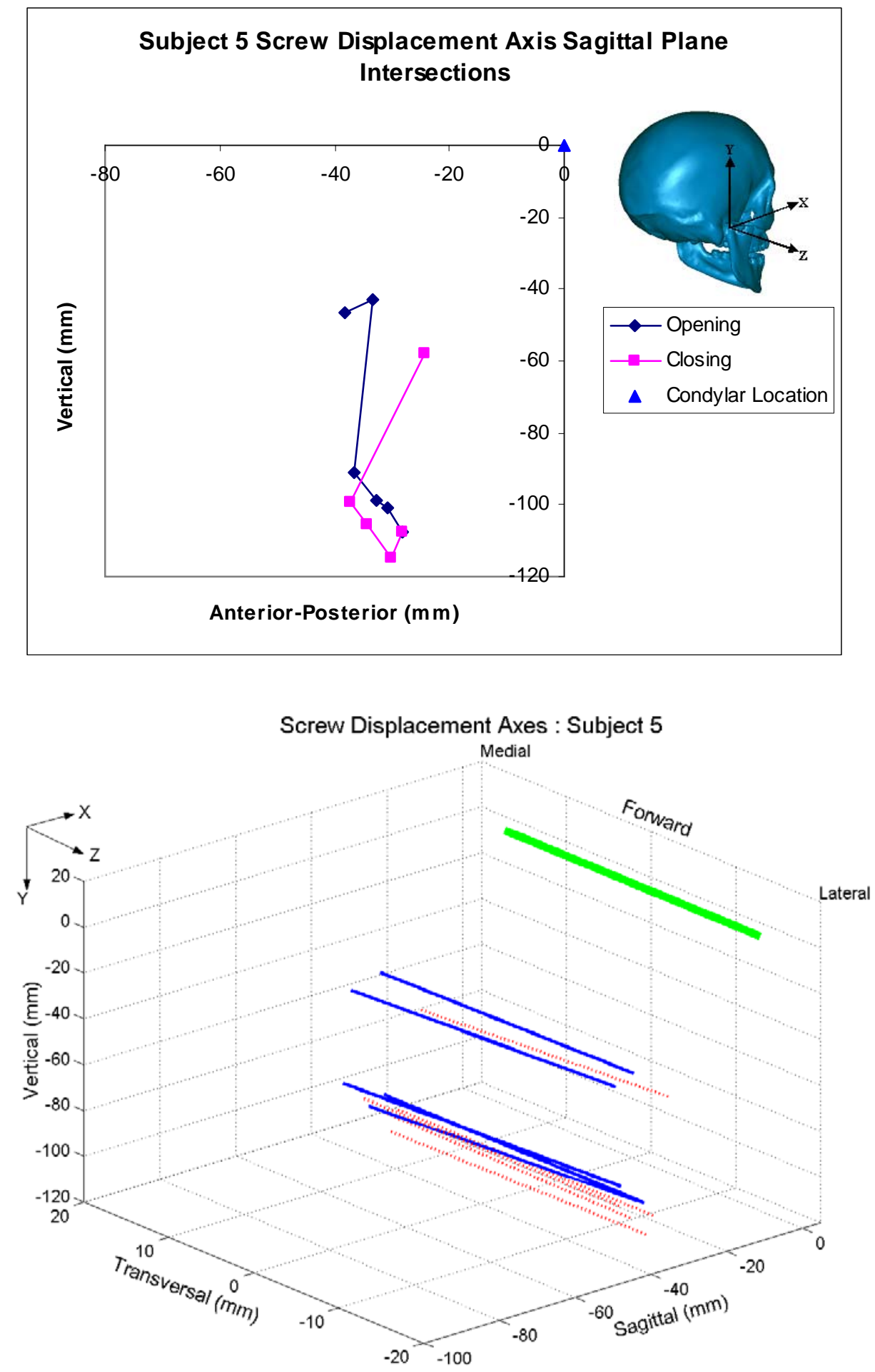

Figure E.4: Two (top) and three (bottom) dimensional representation of the SDA for subject five. In the three dimensional plot the solid blue axes denote opening motion and the dashed red axes denote closing motion. The thick green line is the axis of the condyles. 


\section{Vita}

Shawn Patrick Lehman-Grimes was born in Clarksville, Tennessee, on January 25, 1976. He attended elementary schools in the Nashville area and graduated from Montgomery Bell Academy in June, 1994. The following September he entered Emory University in Atlanta, Georgia, and in June, 1998 received the degree of Bachelor of Arts in Art History. He entered the University of Tennessee Health Science Center Dental College in August, 1998, and in June, 2002, received a Doctorate of Dental Surgery. In August, 2002 he entered the University of Tennessee Health Science Center Graduate Program and in May, 2005, was awarded an orthodontic certificate and a Master of Dental Science degree.

He presently is in private practice in Springfield, Tennessee. 